University of Louisville

ThinkIR: The University of Louisville's Institutional Repository

8-2006

\title{
Positioning Guglielmo Marconi's wireless : a rhetorical analysis of an early twentieth-century technology.
}

Aaron Antonio Toscano 1976-

University of Louisville

Follow this and additional works at: https://ir.library.louisville.edu/etd

\section{Recommended Citation}

Toscano, Aaron Antonio 1976-, "Positioning Guglielmo Marconi's wireless : a rhetorical analysis of an early twentieth-century technology." (2006). Electronic Theses and Dissertations. Paper 1450.

https://doi.org/10.18297/etd/1450

This Doctoral Dissertation is brought to you for free and open access by ThinkIR: The University of Louisville's Institutional Repository. It has been accepted for inclusion in Electronic Theses and Dissertations by an authorized administrator of ThinkIR: The University of Louisville's Institutional Repository. This title appears here courtesy of the author, who has retained all other copyrights. For more information, please contact thinkir@louisville.edu. 
POSITIONING GUGLIELMO MARCONI'S WIRELESS: A RHETORICAL ANALYSIS OF AN EARLY TWENTIETH-CENTURY TECHNOLOGY

\author{
By \\ Aaron Antonio Toscano \\ B.A., Virginia Tech, 1998 \\ M.S., Towson University, 2000
}

\begin{abstract}
A Dissertation
Submitted to the Faculty of the

Graduate School of the University of Louisville

in Partial Fulfillment of the Requirements

for the Degree of
\end{abstract}

Doctor of Philosophy

Department of English

University of Louisville

Louisville, Kentucky

August 2006 

Copyright 2006 by Aaron A. Toscano

All rights reserved 
POSITIONING GUGLIELMO MARCONI'S WIRELESS: A RHETORICAL ANALYSIS OF AN EARLY TWENTIETH-CENTURY TECHNOLOGY

\section{By}

Aaron Antonio Toscano

B.A., Virginia Tech, 1998

M.S., Towson University, 2000

A Dissertation Approved on

July 7, 2006

by the following Dissertation Committee:

Dissertation Director 


\section{DEDICATION}

This dissertation is dedicated to my parents. 


\section{ACKNOWLEDGEMENTS}

I would like to thank my entire dissertation committee and several faculty members at UofL for their guidance and encouragement. In particular, I cannot thank my director, Dr. Debra Journet, enough for the countless drafts she read and her extraordinary insight on how to shape my project. Dr. Journet has seen this project from its very beginning when I was a student in her Research Methods seminar in spring 2003. Her support and mentorship have been integral to my next position in academic life at the University of North Carolina at Charlotte. My dissertation was extremely ambitious when I began, and Dr. Journet worked with me every step of the way to produce a manageable and interesting final product. I must also thank Dr. Mary Rosner for her support and expertise (especially in STS), which was an enormous asset to my dissertation overall. Dr. Rosner, who was also my Classical Rhetoric professor, introduced me to Bruno Latour's work (and, therefore, the field of STS) and also helped me approach this dissertation from a smart and interesting rhetorical framework and "frame of mind." Her comments always encouraged me to "think of my readers" and strive to find an appropriate voice in which to write. I will continue to work on this for years to come and promise always to remember that “efficiency” isn’t just a modernist trope of progress. And my understanding of modernism would not have been as rich had it not been for Dr. Aaron Jaffe. Dr. Jaffe directed my SLA on modernism and has provided me with excellent feedback on my dissertation's goal of incorporating a body of literature I knew very little about before coming to UofL. His advice on Marconi and 
(critically) thinking about technology's role in literature and society went beyond the pages of this dissertation to discussions of critical theory in our IRG meetings. I benefited greatly from my time in those meetings. I also appreciate Dr. Dennis Hall’s commitment to my dissertation and scholarly development through his supportive feedback on my drafts and his insightful comments at the 2005 KPA conference. Dr. Hall has been a very generous reader, and I thank him very much for his interest in my project. I also wish to thank Dr. Avery Kolers from the Philosophy Department at UofL for being an outside reader and taking the time in the summer to help me out. I am grateful to have been able to work with all my committee members, and I appreciate the time everyone has given me.

In addition to my committee, others have contributed directly and indirectly to my work. I would like to thank Dr. Alan Golding and Dr. Suzette Henke for their guidance on Modernism. Dr. Golding was very committed to my having as good an understanding of modernism as possible in the few months he served on my SLA committee, and he continued to be encouraging after my exam was over. I began my interest in Modernism during Dr. Henke's $20^{\text {th }}$-century literature seminar in spring 2003. The seminar was rigorous but extremely rewarding. I have nothing but the best things to say about UofL's English faculty. Although not a professor of mine here at UofL, I must thank my former high school debate coach, Mr. J. Timothy Kane, for his support and guidance while I was at T. A. Edison High School in Franconia, VA. Mr. Kane truly sparked my early interest in rhetoric, which set me on a path to pursue an academic career.

Finally, I want to thank my Alter-EGO/Granville friends for maintaining a rather interesting environment outside of grad school. 


\begin{abstract}
POSITIONING GUGLIELMO MARCONI'S WIRELESS: A RHETORICAL ANALYSIS OF AN EARLY TWENTIETH-CENTURY TECHNOLOGY
\end{abstract}

\author{
Aaron Antonio Toscano
}

July 7, 2006

This dissertation is a rhetorical analysis of Guglielmo Marconi’s wireless. Texts surrounding the invention reveal intersections between technology and society and communicate information about the wireless through tropes of progress. The wireless was seen as a monumental early twentieth-century technology that would change the world by extending communication potential. This dissertation demonstrates that the wireless was created rhetorically before it existed as a black-box technology. Marconi’s technical texts, popular press articles, and F. T. Marinetti's reinscriptions are discourses where the wireless existed rhetorically. To borrow Charles Bazerman's definition, the rhetoric of technology deals with the ideology surrounding "objects of the built environment”; a culture's attitudes and values help shape the technologies produced by a society. Technologies do not become realized without adhering to a society's values, attitudes, and practices. A system of mass communication existed in the early twentieth century (telegraph and telephone wires), but, almost more importantly, the public was conditioned to embrace new technologies for the sake of human advancement. Texts surrounding the wireless's creation show that certain conditions of modernity—speed, 
efficiency, evolution, and ahistoricity—appear as tropes of progress in wireless rhetoric. The non-mechanical factors that create or allow a technology to become realized are found in (re)presentations that show the wireless as a product in according with prevailing cultural values.

This dissertation is divided into four chapters. Chapter I reviews literature on Science, Technology, and Society studies that offers a theoretical framework for analyzing the wireless as a product of modernity. Chapter II examines three important presentations (reprinted in technical journals) Marconi gave to the technical community that demonstrate four topoi in Marconi’s rhetoric of the wireless—cultural pride associated with advancement/evolution, expectations and current successes, economic viability, and patents showing Marconi’s ownership. Chapter III analyzes the rhetoric used by pro-Marconi journalists in American periodicals that construct the wireless in the popular press. Chapter IV explains how “progress” was embedded into Western industrial cultures. Specifically, the chapter demonstrates how the wireless and other technologies fit F.T. Marinetti’s love of "progressive” technologies, which was an exaggeration of industrial cultures' fascination with new advancements. 


\section{TABLE OF CONTENTS}

\section{PAGE}

ACKNOWLEDGMENTS...................................................................................... iv

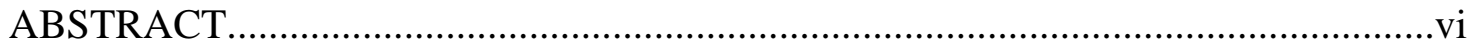

INTRODUCTION

CHAPTER

I. SOCIAL VALUES, ATTITUDES, PRACTICES, AND TECHNOLOGY ...................................................11

II. MARCONI'S REPRESENTATIONS OF THE WIRELESS TO THE SCIENTIFIC COMMUNITY......................................................54

III. POPULAR PRESS REPRESENTATIONS OF MARCONI'S

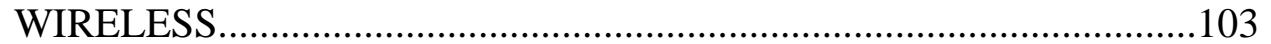

IV. TROPES OF PROGRESS IN F. T. MARINETTI'S EARLY FUTURIST TEXTS.

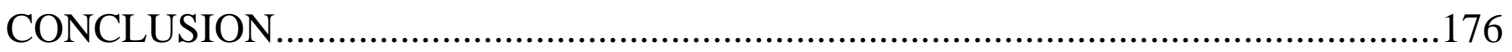

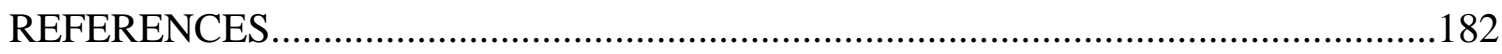

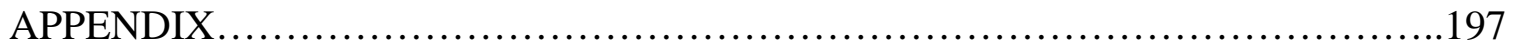

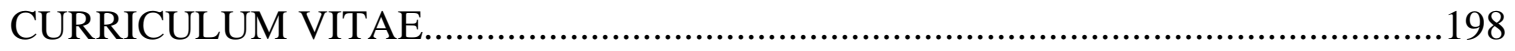




\section{INTRODUCTION}

\section{CROSSING THE ATLANTIC SENZA FILI}

As Sir Oliver Lodge has stated, [using wireless signals to cross the Atlantic] was an epoch in history. I now felt for the first time absolutely certain that the day would come when mankind would be able to send messages without wires not across the Atlantic but between the farthermost ends of the earth. Guglielmo Marconi, "Messages Without Wires” (32)

Guglielmo Marconi first made international headlines when he successfully sent and received wireless signals across the English Channel on March 27, 1899. This significant event marked the first international wireless communication. Many important English and French journalists observed the event and promoted Marconi as an international celebrity much like Thomas A. Edison and Alexander Graham Bell. Less than three years after crossing the English Channel, Marconi solidified his celebrity status by transmitting wireless signals across the Atlantic Ocean on December 12, 1901. Newspapers around the world reported what had happened between Poldhu in Cornwall, England and Signal Hill in St. John's, Newfoundland—-the Atlantic Ocean had been crossed without using wires. Marconi was awarded the Nobel Prize for Physics in 1909 for his work in wireless communication.

Marconi was a technologist with a shrewd business sense and enough electrical engineering skill to represent the wireless as an important advancement in science and technology (Bucci, Pelosi, and Selleri; Corazza; Crowther; Garratt; Jensen; Kraeuter; D. Marconi and M. Marconi; Sungook; Tarrant). Marconi used towers, balloons, and other 
related wireless components he compiled or improved in order to physically construct his invention. However, Marconi represented the wireless through charts and scientific and engineering discourse to the electrical engineering community. Through this discourse, Marconi proposed the wireless as a possible new technology. He had to appeal to the audience's values—rigorous scientific practice, need for detail, potential impact—in order to show that the wireless was a viable technology.

Marconi's invention demonstrates that technological advances are not merely created out of thin air. Technologies are inventions and innovations created by physical, rhetorical, and mechanical actions. Also, a technology is both a product and distinguishing characteristic of any historical context: Social conditions help create new technologies, and society itself is shaped by these contexts (Feenburg; Giddens; Lomask; Nye). To understand how technologies become realities, we must examine how they are promoted, negotiated, and constructed. While technological blueprints show how a technology is schematically represented, they do little to reference the historical and cultural context in which the technology was created. Also, understanding the social situations present during a technology's creation allows us to discover the relations between science, technology, and society.

For the past four decades, many scholars have critically analyzed the rhetoric, philosophy, history, and sociology of technology and science in order to demonstrate the social construction of scientific knowledge and technical artifacts. This work falls under the broad category of Science, Technology, and Society (STS) studies. STS seeks to understand technology and science from a cultural perspective by investigating both discursive and physical situations that surround engineers or scientists making 
"discoveries." The field also recognizes that technologies and sciences do not come from laboratories isolated from society; instead, for technologies or sciences to be realized, they must fit or be made to fit within established cultural values and practices. STS attempts to demonstrate how ideological and individual values negotiate which discoveries become realities.

Although STS can be separated into special emphases such as historical, sociological, or philosophical analyses of technology and science, it generally shares the belief that technology and science are constructed based on social values and through social interaction. Rhetoric is important for the field because new "discoveries" are presented to various audiences not just as physical apparatus but also as discourse. Regardless of specific focus, rhetorical analyses of technology or science aim to uncover the methods and tactics used to construct the reality or image of a new discovery. Because social values appear within technological contexts, we can "read" the semiotics of technology as we can read other semiotic systems. As Charles Bazerman argues, "[t]he invention is legally not a physical entity. It is a symbolic representation—a text representing an idea” (The Languages of Edison's Light 91). Bazerman does not just mean patent documents are the texts symbolically representing an invention; any discourse—for instance, Marconi’s presentations—is a "symbolic representation" that also acts as an "ideologically saturated" medium.

Beyond the ideologically saturated words an inventor/author uses to describe any technology is the technology itself, which is often simply an idea swirling in a dialectical frenzy of social, rhetorical, and physical negotiations. Texts and speech acts enable audiences to interpret, reinterpret, and question the need for the technologies that enter 
their culture. People learn about technologies not only by actually working with them but by interacting with their representations. Bazerman points out that "technology has always been fundamentally designed to meet human ends," but adhering to those ends requires "technology, as a human-made object," to be "articulated in language and at the very heart of rhetoric” (“The Production of Technology” 383). The wireless was a technology conceived by an audience through discourse before users encountered the physical "black box." A realized technology is a "black box"—a technology about which debate has ceased—which is Latour's metaphor, developed from the term cyberneticians use to signal whenever a piece of machinery or set of commands is too complex, that describes scientists and engineers' approaches to "established" facts (Science in Action 23). Any science that is a black box is assumed to be unalterable. Scientists and engineers risk devoting too many laboratory resources if they attempt to debunk or simply reexamine black boxes. Once a black box is established, new science can be constructed based on the premises held by a black box.

This rhetorical analysis examines how Guglielmo Marconi’s wireless became realized as a product of modernity. The wireless eventually became the black-boxed radio, a fully realized technology, but, before it did, Marconi presented this monumental technology to technical and scientific audiences, journalists re-presented the wireless in favorable popular press articles, and F. T. Marinetti reinscribed the wireless into early Futurist aesthetics along with other "progressive” technologies. In this dissertation, I limit my examination to favorable representations of the wireless in order to concentrate on how authors attempt to excite their readers or convince them that Marconi's wireless was an important reality. 
My research into Marconi’s contemporary discourse and rhetoric provides examples of how "progress" and related attributes accompanied most descriptions of the wireless. In fact, being labeled "progressive" in industrial cultures meant that a technology, individual, or nation was advanced economically, evolutionarily, and even militarily. New products had progress labels affixed by inventors, writers, marketers, and users. The discovery I find most interesting from my research is that the discursive images of technologies create the sense that the technologies physically exist. Often times, though, the representations are merely projections of a technology's possibilities. When these images become believed and reported, the technology seems to exist before a viable product makes it to the marketplace. Investors, consumers, or readers must believe in a technology's viability before it can be said to exist. Marconi’s wireless existed as an idea prior to his major commercial success. It was a compilation of gadgets from other inventors working on similar wireless systems. Much of Marconi's positioning of the wireless is marketing, but the wireless' rhetoric holds cultural values as well.

Currently, there are no rhetorical analyses of Marconi’s wireless invention. Most research on Marconi has been in the form of biographical sketches of his life (Corazza; Garrat; D. Marconi; M. Marconi; Sungook; Tarrant) or historical accounts of the wireless as the precursor to radios and related communication technologies (Bucci, Pelosi, and Selleri; Crowther; Jensen; Kraeuter; Tarrant). The historical and biographical scholarship on Marconi's wireless describes the wireless in a detailed time-line fashion and portrays Marconi as a genius inventor. While such studies are important for narrating the wireless's physical construction and Marconi’s life (I rely on both in my study), they perpetuate the "lone inventor" myth. While I acknowledge the fallacy, I choose to 
concentrate on the positive representations of his particular commercial invention as a way to uncover the time period's attitudes and values. He was not the sole inventor, but he was, arguably, the most important historically. The existing research credits Marconi with bringing a monumental technology to life, and this work is useful for understanding the historical significance of Marconi's wireless. Research has been done on the effects of radio on particular communities after the wireless became entrenched in national (and world) infrastructure (Squier; Patnode; Rutland). But no rhetorical analysis has been done on the wireless and only recently has anyone examined the relationship between the wireless and modernist aesthetics (c.f. Campbell). Finally, no scholarship considers what cultural work the wireless did based on contemporary descriptions. Therefore, my project focuses on the wireless’s rhetoric and adherence to cultural values.

In order to have a sound theoretical framework from which to argue the wireless's social, rhetorical, and aesthetic values, Chapter I reviews important STS theories and case studies that show technology and science to be products of social interaction. I first discuss theorists such as Charles Bazerman, Bruno Latour, and Wiebe E. Bijker who argue that groups affix values to new technological advancements. Next, I explain how rhetoric contributes to the non-physical ways in which technologies are constructed for audiences. After all, a technology’s rhetoric helps establish a technology as a product congruent to social values, attitudes, and practices. Because Marconi’s wireless fit the early twentieth century’s progressive ideology, I discuss how new technological advancements in the twentieth century often conformed to modernist ideals of industrialized nations. These arguments help me demonstrate the importance of 
rhetorical analyses of technology in general and the rhetoric behind Guglielmo Marconi’s wireless specifically.

Chapter II analyzes the topoi Marconi uses when presenting the wireless to a technical audience. Marconi's rhetoric promotes the wireless's viability and necessity for members of the Royal Institution and the Royal Society of Arts, London. Before the wireless became the radio, Marconi prophesized its usefulness, linking it to cultural values. The wireless embodies certain industrial traits—speed, efficiency, profitability, evolution/advancement—and these technical presentations employ such images. Even in the most technical forum, Marconi promotes cultural pride and includes the wireless's social and economic characteristics alongside discussions of its technical viability. At the time of Marconi’s presentations, the wireless was not yet a major commercial product; instead, it was an idea for linking ships at sea, ships to land stations, and even nations with one another. In order to have a successful product, the wireless had to be portrayed as possible and progressive. The need for instant communication had been around for nearly 40 years as evidenced by telegraph and telephone technology. The wireless did not replace those technologies, but it did expand the reach of communication and, therefore, mass communication. As an important mouthpiece for the wireless, Marconi offered his audiences not the physical product but the idea of a potential product to mark human advancement and bolster economic progress.

Chapter III demonstrates how Marconi’s wireless was re-presented to audiences through favorable popular press articles in American periodicals. Many journalists reconstructed the wireless rhetorically by emphasizing the technology's exciting attributes, industrial value, and profitable potential. The rhetoric the authors employed 
closely follows the topoi Marconi used in his presentations to technical and scientific audiences. The articles promote the wireless's efficiency, profitability, usefulness, and other progress markers. The popular press also portrayed the wireless as a technology marking human evolution. Although the texts I use do not represent all early twentiethcentury audiences, the descriptions are at least suggestive of positive discourse concerning the wireless. After all, the wireless became a successful black box-the radio—-so the re-presentations suggest how positive accounts of the wireless fit the cultural values and attitudes concerning technology in the early twentieth century. Progressive ideology of the early twentieth century is entwined with these favorable descriptions. Although these positive popular press accounts were not the only types of descriptions about the wireless, they illustrate what Marconi's contemporaries had to say about an ultimately successful technology, an invention heralded as a monumental invention from the turn of the last century.

Chapter IV demonstrates F. T. Marinetti's glorification of early twentieth-century technologies such as the wireless. Marinetti saw the wireless as an important tool and marker of human advancement. More than any other modernist artist, Marinetti shows the "virtues" of new technologies. Machines appear as muses to Marinetti who fantasizes about becoming one. Such a transformation would make Marinetti the most efficient being possible: By casting aside his human qualities and "softness," he would be free. Marinetti's art makes use of parole in liberta—words in freedom—-to accentuate the aesthetic goals of minimalism and telegraphic prose. He advocates an aesthetic based on reducing expressions to the fewest number of words. Within this minimalist aesthetic, Marinetti promotes the speed and efficiency of wireless communication by using words 
not attached to traditional syntax. Similarly, Marinetti claims the wireless is an inspiration for such a telegraphic style. Marinetti's art reconstructs the cultural values of industrialization by promoting textual efficiency. Also, Marinetti glorifies technologies for their war potential. Along with the wireless, Marinetti groups together the following technologies he felt defined modernity: tanks, airplanes, machine guns, and automobiles. Unlike other high modernist authors, such as D. H. Lawrence and Virginia Woolf, Marinetti values the destructive nature of new modern technologies. His manifestos exaggerate tropes of progress by advocating a love of mechanization.

In the conclusion, I reiterate how the rhetoric of technology helps establish a technology as an artifact in accordance with cultural values. Even though an inventor or team of inventors may actually create a technology, societal forces fuel the technology's development. Technological descriptions must also follow the discourse community's conventions of rhetoric: Writers' descriptions of technologies form and are formed by the community’s values and practices (Bazerman; Journet; Latour; Longo; Mercer; Myers). For example, the wireless did not stand alone as a tool with a purely functional role; instead, the wireless's texts show that descriptions demonstrate how the technology fit into the culture. The wireless changed mass communication for the early twentieth century (Attwood and Ryecart; Jensen; Tarrant), but first the wireless had to "fit" into and define the historical context of a technologically saturated world. We can locate society's values by examining how others reinterpret the technology through the various discourses on the wireless. This emphasis is not only a concern for STS, but also for technical writing scholarship. 
This dissertation does not attempt to show the physical construction of the wireless but to demonstrate how rhetoric created an image of the wireless that related to social, economic, scientific, and literary influences. My focus on the wireless's rhetorical construction demonstrates how early twentieth-century ideology can be read into the discourse that promoted the invention as a product of modernity based on a century of science. Technologies do not simply spring from the earth and change society; instead, human societies create an environment that allows certain technologies to be developed. What follows is part of the wireless's story. 


\section{CHAPTER I}

\section{SOCIAL VALUES, ATTITUDES, PRACTICES, AND TECHNOLOGY}

What is called Western or modern civilization by way of contrast with the civilization of the Orient or medieval times is at bottom a civilization that rests upon machinery and science as distinguished from one founded on agricultural or handicraft commerce. It is in reality a technological civilization ... If the records of patent offices, the statistics of production, and the reports of laboratories furnish evidence worthy of credence, technological civilization, instead of showing signs of contraction, threatens to overcome and transform the whole globe. Charles A. Beard, “The Inevitability of the Machine” (97)

The great nineteenth-century positivists ... imagined that the statements of science were going to replace opinions and beliefs about all things ... Our century has been the graveyard of positivist ideas of progress. Alain Badiou, Ethics (84)

This chapter reviews literature drawn primarily from Science, Technology, and Society studies (STS) that supports rhetorical analyses of technology. Based on these STS studies, I plan to make three arguments. First, using the work of theorists such as Charles Bazerman, Bruno Latour, and Wiebe E. Bijker, I argue that technologies are created through a complex system of social interactions where groups affix values to new technological advancements. Second, I argue that rhetorical analyses identify the nonphysical ways in which technologies are realized or understood. Third, I demonstrate that social values related to progress have often been affixed to new technological advancements in the twentieth century. In the case of my study of Marconi's wireless, the relevant social groups of the early twentieth century saw the invention as progress, modernity’s most powerful “god term” according to Richard Weaver (212), and 
considered the invention an important human advancement. Progress or any other value is not physically built into an invention; instead, value is rhetorically constructed. These STS arguments enable me to demonstrate the importance of rhetorical analyses of technology in general and Guglielmo Marconi’s wireless specifically.

The field of STS includes the philosophy of technology, the history of technology, and the sociology of technology, as well as the rhetoric of technology, which I consider in a later section of this chapter. Obviously, these theoretical frameworks overlap, but I hope to make clear that all are based on examining the socio-political shaping of technology. This work supports my own analysis of Marconi's wireless as a product that held meaning for an audience in an historical moment and was shaped by social interactions. The following descriptions on the frameworks are not meant to be hermetic categories but general ideas.

The philosophy of technology derives from research analyzing the meaning of technology for a culture. Philosophers of technology argue that technology itself appears to be a major context for industrial cultures (Feenburg; Fuller and Collier; Heath and Luff; Melzer; Nye; Rescher; Winner). Arthur M. Melzer argues that humans are defined by their tool use: Homo sapiens are the "the tool-making animal[s]" with "stages of civilization differentiated in terms of the tools men have actually made” (111). Whether one examines the Bronze Age or our contemporary Information Age, human societies appear to be defined by the major technologies they have at their disposal. Therefore, although technology cannot be said to have caused a prevailing cultural attitude, it exists as a defining principle for individuals. No social structure is "free” of technology's influence; thus, society is governed in some ways by a techno-socio politic. Basically, 
the philosophy of technology attempts to answer why humans organize themselves, at least in industrial cultures, around technology and the meanings associated with technology.

The history of technology aims to define an historical moment by its technology (determinism) or to discover how an historical moment shaped technology (constructivism). Some histories of technology provide lists and brief descriptions of technologies from certain historical periods (Bunch; Burns; Cardwell; Glick, Livesey, and Wallis; Mitcham; Restivo; Rhodes). Other studies focus on a technology in an historical moment or a type of technology from a time period (Cowan; Cross and Szostak; Downey; Lewis; Löfgren and Willim; Misa; Reynolds and Cutcliffe; Willmore; Yeang). As with any analysis of technology, defining a time period by a technology can be reductive. Not only do historians risk arguing for technological determinism when claiming technology alone shaped an aspect of society, but they also risk creating a "whig" history if their work "presents history as uninterrupted progress, implying that the present state of affairs follows necessarily from the previous” (Bijker 45). Instead of aiming for a grand narrative of technology's influence on history, other scholars look at smaller "revolutions” involving technological change (Cowan; Esper; Fallows; Hoddeson; Walker; Van Slyck). My dissertation also studies a single technology. The wireless's overall success, the fact that it became the "radio," means it fit well with the social framework of the early twentieth century. Just as the historical context of the early twentieth century is shaped by society, the society accepting a new tool shapes the technology’s meaning through cultural attitudes, practices, and values. 
The sociology of technology demonstrates how societies—relevant social groups and wider cultural forces—shape and are shaped by technologies. As mentioned above, placing too much emphasis on the effects of technology on society can risk technological determinism. However, a dialectical relationship between society and technology exists, and this relationship is socially constructed. Many scholars analyze specific groups or specific technologies to demonstrate how society shapes what technologies become created based on wider cultural beliefs and attitudes (Arthur; Das and Kolack; DeLaet; Dobres and Hoffman; Kline and Pinch; Kranakis; Noble; Strum and Latour).

Additionally, scholars demonstrate how technologies are created socially but on a smaller scale; for instance, many scholars examine the work of a single invention or inventor to demonstrate the social construction of technology (Bazerman; Bijker; Ceruzzi; Johnsom; ${ }^{1}$ Latour; Oudshorn; Weber). Inventors and relevant social groups must interact within the social framework in order for a technology to be realized. "The social framework," of course, is a product of the culture's attitudes and values that fits or is made to fit social practice.

\section{Technology is/as Social Construction}

In Bruno Latour's work on the sociology of technology and science, he describes how one can view an engineer or scientist's work in situ in order to understand the forces behind technological and scientific "discovery.” By visiting laboratories and examining engineering and scientific discourse, Latour and other scholars have uncovered the nonmaterial forces and attitudes that shape what technologies and sciences become realized. ${ }^{2}$ Latour's theory of the sociology of technology stems from Michel Foucault's critiques of 
power in society. ${ }^{3}$ Latour argues that one must consider more than the technological object when analyzing why a technology succeeds or fails; instead, a researcher has to "grab the actors" (Aramis 89). He wishes "to show technicians that they cannot even conceive of a technological object without taking into account the mass of human beings with all their passions and politics and pitiful calculations"; by doing so "they can become better engineers and better-informed decisionmakers” (Aramis viii). By applying such a perspective, Latour's methodology lets the individuals' interactions with the technology supply meaning(s) to why a technology fails or succeeds: His "sociology prefers a local history whose framework is defined by the actors and not the investigator" or by grand narratives such as capitalism or transportation theories (Aramis 19).

Similarly, Bijker’s analysis uses a "snowballing” technique to follow actors or “relevant social groups,” as he defines them, who interact with a technology in its early stages before it becomes realized (46). Because “[t]echnological development should be viewed as a social process [and] not an autonomous occurrence,” Bijker believes “relevant social groups will be carriers of that process” (48). Latour and Bijker’s arguments that technologies and scientific discoveries ${ }^{4}$ are products of social interactions are shared by many other scholars in STS (Bazerman; Feenburg; Gilbert and Mulkay; Hikes and Hikes; Latour and Woolgar; MacKenzie and Wajcman; Rouse; Rosalind Williams; Yeang). This approach assumes technology is not created in a vacuum but constructed through contemporary values and practices. Because the actors themselves are products of their culture, Marconi would act in ways congruent to the values of industrialized cultures in the early twentieth century. The assumption that socially constructed attitudes may shape technology allows me to view the wireless historically as 
a product of modernity and larger prevailing attitudes. As Anne L. Hiskes and Richard P. Hiskes also argue, "social forces and practical goals always determine the current state and direction of technological research" (16). ${ }^{5}$ In the case of the wireless, social forces desiring progressive technology and practical goals pushing for communication at sea and to places not accessible by wires drove the wireless's construction. To make the wireless fit larger social values, Marconi and other wireless supporters reconstructed the images of electromagnetic science and technology in relation to the new invention for various audiences.

Such reconstructions are "public statements" that have been carefully crafted and do not immediately count as "the pure world of truth" without an audience's validation (Bazerman, Shaping Written Knowledge 23). Furthermore, as Bazerman argues, “[t]o recognize the rhetorical character of visually transmitted symbolic activity is only to recognize that we live and use our texts in a human world” (Shaping Written Knowledge 23). The rhetoric of the wireless and the actual physical invention are nothing without social interaction. The ideas Marconi and others affixed to the wireless exist within the context of socially maintained ideology. As Lynn Åkesson argues, realizing technologies is more than just being able to produce a working model because technological realization "go[es] beyond the product and depend[s] on relations, feelings, emotions and culturally constructed beliefs about whether something is worth investing in or not” (44). Åkesson's overall argument is that all technologies must be marketed well before they become recognized. Because technologies must fit within a culture's values and attitudes, the "marketing” or PR involved will most likely adhere to or be made to seem to adhere to prevailing cultural beliefs. 
The wireless of the early twentieth century, I will suggest, was more of a rhetorical reality than a physical one: Pro-wireless discourse portrayed the wireless as "real,” but a viable commercial product was not immediately available. Before any technology becomes a black box, the relevant social groups must use, communicate, evaluate, and, ultimately, produce a viable technology. I do not claim technologies solely shape themselves or the practices of relevant social groups; to say that would risk technological determinism. Instead, my study focuses on the wireless's rhetoric as "created" by favorable discourse, rather than on how users physically interacted with the invention. However, I do include the perceptions and, subsequently, the reinterpretations of Marconi and journalists who recount their own experiences witnessing the early wireless’s capabilities. The "social interaction” I refer to throughout the dissertation is discourse.

Because society ultimately accepts or rejects a technology, how a technology fits or is made to fit into social life depends partly on audience perception. Although I will not analyze early twentieth century audiences’ specific responses to technological discourse, I focus on favorable discourse about the wireless because I assume that an ultimately successful technology’s positive discourse reveals attributes that help an audience realize its significance. I believe my study helps demonstrate the common rhetorical aspects that "build" a technology so audiences will accept it. But before I discuss features of rhetorical analyses, I want to briefly describe the dialectical relationship between society and technology from the point of view of relevant social groups. Technologies might not alter the ways people perceive the world or usher in new social conditions, but technologies have altered human practices on small and large 
scales. For example, the introduction of the automobile helped create a market for American suburban life because workers no longer had to live on a "mass transit" line or within walking distance of work. However, would Americans have wanted to live in single-family homes if they were not an individualistic culture with a tendency to expand their living spaces? Likewise, the introduction of mobile phones changed the practice of calling: Now people can talk almost anywhere. Therefore, because suburban life and mobile phones were perceived as valuable, important relevant social groups within the culture approved the new technologies and changed living and telephoning practices to some degree.

\section{Relevant Social Groups Affix Meaning to Technologies}

As socially constructed artifacts, technologies represent the values of the culture from which they came. For instance, a culture that advocates the "free sharing of ideas" and technical collaboration among its universities and other publicly funded research institutions would most likely pursue technologies to help facilitate such communication. ${ }^{6}$ Likewise, a culture at war or simply a military-industrial complex perpetually preparing for war will create technologies to improve its defensive or "preemptive” capabilities. A culture’s needs are often based on the values its people or, more importantly, its institutions hold (Noble; Nye; Rhodes; MacKenzie and Wacjman). Such groups ultimately determine what technologies are created and how they are modified for particular tasks. As Bijker argues,

Technology is created by engineers working alone or in groups, marketing people who make the world aware of new products and processes, and consumers who decide to buy or not to buy and who modify what they have bought in directions no engineer has imagined. (3-4). 
No technologies would ever be realized if they were not perceived as conforming to social values and practices.

After Marconi’s wireless became a black box—a commercially viable productthe electrical engineering community no longer debated the reality of radio waves, and the radio became a solution to communication problems. Being able to transmit and receive signals, a "fact" allowed by radio, became the basis for research into radar and navigational technologies (Tarrant 233), not to mention technologies related to broadcasting. But, no matter how well an invention works, a black box technology must also adhere to larger cultural values. Relevant social groups immersed in a particular culture affix meaning to inventions building technological frames. Bijker explains that “[a] technological frame is built up when interaction 'around' an artifact begins”; if a frame is not built up in order to "move members of an emerging relevant social group in the same direction,” a technology will fail (123). Before users will accept a technology, they must believe the product adheres to social values. These values give meaning to a technological frame. Bijker argues that "[a] technological frame comprises all elements that influence the interactions within relevant social groups and lead to the attribution of meanings to technical artifacts—and thus to constituting technology” (123). Therefore, these frames can be understood as sets of meaning(s) groups affix to technology. From a cultural studies point of view, a frame is a deterministic screen or cultural lens that defines a technology for an individual or a group. In other words, people define a technology's values and uses by the socially constructed heuristic or frame between themselves and the technology that, in turn, helps define a technology. 
While that argument may appear circular—a technology is defined by a frame that defines the technology—it actually suggests the dialectical relationships between technology and society. Other scholars define these relationships as "technological regimes” (Nelson and Winter; Rip and Kemp) or "paradigms” (Dosi). According to Rip and Kemp, “[a] technological regime is the technology-specific context of a technology which prestructures the kind of problem-solving activities that engineers are likely to do, a structure that both enables and constrains certain changes" (340, italics mine). Although Rip and Kemp focus on engineers, the argument easily transfers to other relevant social groups who are constrained by their own cultural/personal lenses based on how they perceive a technology should be used. Therefore, participatory actions both constrain and construct technological meanings.

Engineers and scientists work under larger social frameworks for producing knowledge. Bruno Latour and Steve Woolgar's study of biologists at the Salk Institute shows the interconnectedness of ideology, science, technology, and history, allowing us the chance to understand broad patterns of cultural beliefs. Jonas Salk, in his introduction to Latour and Woolgar's Laboratory Life, claimed that “[Latour's] own style of thought was transformed by our [biologists'] concepts and ways of thinking” (13). Salk further comments on the centrifugal and centripetal knowledge diffusion between science and sociology, noting that "[sociologists at the Salk Institute] are coming to recognize that their work is only a subset of our [biologists'] own kind of scientific activity, which in turn is only a subset of life in the process of organization” (13). Latour and Woolgar's goal at the Salk Institute was to uncover "the social construction of scientific knowledge in so far as this draws attention to the process by which scientists make sense of their 
observations" (32). Such a process is important to Latour and Woolgar because they argue that sociological studies often examine the scientist without examining the scientific aspects (23-4). They go on to argue that researchers ought to pay attention to “'technical' and 'intellectual' terminology,” which "is clearly an important feature of [scientists'] activity" (27). This activity comes with a warning against "the uncritical acceptance of the concepts and terminology used by some scientists" because that "has had the effect of enhancing rather than reducing the mystery which surrounds the doing of science” (Latour and Woolgar 29). This process often comes in the form of discourse, such as technical papers or presentations.

No science stands solely on its own merits or the merit of one or a few scientists; instead, science is peer reviewed. Latour and Woolgar use Harris’s terms “emic validation" and "etic validation" to describe which types of audiences have the final say on scientific representations. According to Harris, etic validation derives from “a community of fellow observers"; this group is "the audience who will ultimately assess the validity of a description" (qtd. in Latour and Woolgar 38); emic validation holds that "the ultimate decision about the adequacy of description rests with participants themselves" - the scientists (qtd. in Latour and Woolgar 38). The two types of validation help define when but not why a science or technology exists. ${ }^{7}$

Once validated, a science or technology can be said to exist. However, the existence may only be among a select relevant social group before the "facts" diffuse to other groups. In order to diffuse the facts adequately, a group must persuade others about the value of the science or technology. Such persuasion is rhetorical as Latour and Woolgar point out. When the scientists at the Salk Institute attempted to make order out 
of (relative) chaos, they aimed for "the successful persuasion of readers" by stabilizing facts through discourse; the readers, however, "are only convinced when all sources of persuasion seem to have disappeared” (76). According to Latour and Woolgar, observers believe "a systematic, ordered account is attainable" from any observation "no matter how confused or absurd the circumstances and activities of his tribe might appear” (43). Once a fact is stabilized, it appears to have always been there waiting to be discovered (Latour and Woolgar 177). The science seems inevitable in hindsight:

Once the controversy has settled, reality is taken to be the cause of this settlement; but while controversy is still raging, reality is the consequence of debate, following each twist and turn in the controversy as if it were the shadow of scientific endeavour. (Latour and Woolgar 182)

Audiences accept the science as a reality because "[f]acts are constructed in such a way that, once the controversy settles, they are taken for granted” (Latour and Woolgar 183).

The various mechanisms that bring science and technology to life are not salient features of technical or scientific discourse. One mechanism is granting credit, and scientific credit often goes to the individual who is perceived to have "gotten there first." According to Bruno Latour, "[w]hen we are dealing with scientists, we still admire the great genius and virtue of one man and too rarely suspect the importance of forces that made him great" (Pasteurization of France 14). These "forces” of which Latour speaks are many: economics, philosophy, epistemology, ideology, society, etc. They can also be the groups or teams supporting the "lone" scientist or inventor. The ingenuity and perseverance of a successful scientist cannot be overlooked, but we cannot lose sight of the fact that science and technology are built upon past “discoveries” that engage multiple actors. Also, if one believes a "fact" was just waiting to be found, he or she ignores the construction of scientific ideas. Latour claims "[a]n idea ... never moves of 
its own accord. It requires a force to fetch it, seize upon it for its own motives, move it, and often transform it” (Pasteurization of France 16). Scientists often make discoveries based on their fields' histories: "The social context of a science is rarely made up of a context; it is most of the time made up of a previous science" (Latour, Pasteurization of France 19). Pasteur and others discovered new science by building on past science, which appeared as part of the social context of a science. While in popular imagination, lone scientists are seen as revolutionaries, Latour argues that science has to be communicated before the "revolution" can take place (Pasteurization of France 72). Science and engineering need rhetoric to help communicate new discoveries or inventions. Relevant groups use rhetoric to create an image of a technology that reifies the invention through discourse. Relevant groups not only use rhetoric but are persuaded by rhetoric to create meaning for a technology. These groups work to define meaning under the social forces that allow products to take shape within a culture.

\section{The Rhetoric of Technology}

The study of how technologies are described and realized discursively is known as the rhetoric of technology. Charles Bazerman defines the rhetoric of technology in a rather useful way: "The rhetoric of technology shows how the objects of the built environment become part of our systems of goals, values, and meanings, part of our articulated interests, struggles, and activities” (“The Production of Technology” 386). When new technologies become accepted by a population—an acceptance that does not need to be universal—society may change certain behaviors; however, the social forces that propel technologies to be created or simply accepted exist a priori to those 
technologies. Claiming that a direct causal link exists between technology and social change may be reductive, but we cannot dismiss the power new technologies have on behavior (Feenburg; L. White; Raymond Williams). After all, some people might be persuaded to weave technology into their social practices because they perceive the technology as useful. How a technology is made to seem useful can be understood through a rhetorical analysis of a particular technology's discourse.

Defining the "rhetoric of technology" requires defining technology. What makes something a technology? Popularly, technology is associated with computers and other "hi-tech" consumer items. While those items are technologies, they are not the only types of technologies that exist. Donald MacKenzie and Judy Wajcman claim ““[t]echnology’ is derived from the Greek techne, meaning art, craft, or skill, and logos, meaning word or knowledge. The modern usage of 'technology' to include artifacts as well as knowledge of those artifacts is thus etymologically incorrect but so entrenched that we have chosen not to resist it” (26). Technologies are thus closely related to new knowledge based on science, techniques, and industry. This knowledge is socially constructed through discourse based on relevant social groups' values and practices. The groups accept and consequently stabilize technologies based in part on the value they perceive in particular tools.

Whether a technology be a physical tool (i.e., a wrench, hammer, or keyboard) or a mental tool (democracy, management science, or the scientific method), it is often defined as the available knowledge of a civilization closely connected in contemporary times to industry and commerce. The industrialized world's economy depends on creating new technologies for growth and "prosperity." These technologies can be 
managerial or engineering ideas to increase or make production more efficient (management science from Fordism/Taylorism), or they can be actually mass produced products (cars, mobile phones, Big Macs ${ }^{\circledR}$ ) from highly rationalized, efficient systems. ${ }^{8}$ Regardless of the type of technology, the idea that technology is some kind of tool related to work or profit predominates. After all, the term “modernization” suggests an entity (such as a nation) acquires or develops technologies that will theoretically improve its economic position. ${ }^{9}$ As an important profitable technology for industrial nations of the early twentieth century, the wireless fits the above "scientific/industrial" definition. In fact, many contemporaries claimed the wireless was an important scientific discovery, and Marconi’s application furthered national and international industrial goals.

Because society shapes technology, we can locate some social values implicit in representations of the wireless or any technology. Even though values may be affixed to technologies, the rhetoric of a technology often adheres to a prevailing cultural value. For instance, many contemporary analyses of technologies often examine how “democracy,” a major framework for Western industrial cultures, is affixed to technologies or threatened by new technologies (Feenberg; Montagu and Matson; Selfe; Sikorski; Winner). However, rarely can a technology be said to embody democratic principles of egalitarianism or equal representation. Because the "democracy" label is important to Western industrial culture, technologies are often discussed as furthering or not furthering democratic values. Those values are affixed through rhetoric.

The next four subsections discuss how rhetoric helps realize or (re)construct a technology. Specifically, I discuss how Charles Bazerman’s study of Edison’s light offers a theoretical framework for rhetorically analyzing technology, how technologies 
are products of systemic forces (i. e., the desire for technologies to be seen as democratic), how technologies become stabilized through rhetoric, and how technologies do not become stabilized.

\section{Bazerman's Example of Edison's Incandescent Light bulb}

Charles Bazerman’s analysis of inventor Thomas A. Edison’s incandescent light bulb (The Languages of Edison's Light) studies patents, laboratory notebooks, personal letters, specifications, scientific reports, and popular press articles in order to explain how the light bulb and the Edison System (power stations) were both physically and rhetorically created. Bazerman analyzes discourses surrounding the invention in order to demonstrate the rhetorical acts that led to the technology's creation and acceptance. Edison was a technologist in search of profit and fame, and he, as would Marconi, succeeded in garnering an international celebrity status. Because Edison was a successful (and prolific) inventor, we can assume he invented products that appealed to audiencespotential users. Although all of Edison's inventions were not successful, many were accepted through careful marketing/PR strategies. In other words, Edison and his supporters made his inventions fit the attitudes and values of consumers, causing them to desire his inventions.

Bazerman traces Edison's growth as a young telegrapher ${ }^{10}$ turned industrialist whose legacy continues to this day in the company General Electric. Edison physically and rhetorically "invented" the light bulb, and he kept the public anticipating his invention for economic not technical reasons (Bazerman 181). ${ }^{11}$ This marketing strategy suggests that a technology needs more than a physical nature to be realized; a 
technology’s viability is tied closely to its profitability. In fact, Edison had to argue for his invention’s future value in order to secure investment (Bazerman 200). He had to show this value through fairs, advertisements, demonstrations, letters to stockholders, and interviews with popular press writers, or else the light bulb could have failed commercially as his phonograph did in the 1880s (Bazerman 198). Edison marketed his electric system in places like New York City and Louisville before the light bulb was ready, and the public accepted the "reality" of the technology when the light bulb was mainly a rhetorical construction (Bazerman 234). That is, the public accepted the light bulb before incandescent lighting actually illuminated cityscapes.

Potential users may thus accept the existence of new technical and scientific “discoveries” based on rhetoric. An important rhetorical strategy for technological acceptance is proving value. In fact, most of Bazerman's work covers the economic strategies Edison used to have the public and investors realize that the light bulb existed. Bazerman quotes Adam Smith to show how the market and, therefore, society perceive technological value: “[A]ll economic transactions are rhetorical . . . they are exchanges of value and value is a human discursive construct” (141). New technology does not spring from the earth or from a lab without being conditioned or molded by social forces, and economics is one major force. New technology must work within the current technological system and carve out a niche for itself; it must also "create a dissatisfaction with a current technology" to induce consumers rhetorically to buy new products (Bazerman 142). After all, marketing is "the rhetorical economic work of locating unmet desire and matching potential products to desire” (Bazerman 143). In our postmodern 
world, desire can be manufactured in order to make consumers want certain products (c.f. Chomsky, especially Manufacturing Consent).

Before consumers demand new tools, technology needs to succeed materially and "symbolically (that is adopt significant and stable meanings within germane discourse systems)" (Bazerman 335). Bazerman goes on to borrow the concept of "heterogeneous engineering" from Bijker to show that technologies are products of "the coordination and application of many kinds of knowledge and practice, all of which are united and instantiated in the final product" (335). The concept of "heterogeneous symbolic engineering" is imperative for inventors who wish to "[build] enduring meaning and values for the technology they wish to implant in our daily lives” (Bazerman 335, italics mine). Bazerman argues that incandescent light had to "take a place within the discourse and the representational meaning systems of [Edison's] time before it could transform them"; therefore, "the new technology ... had first to be built on historical continuities of meaning and value” (350). In the absence of historical continuity and cultural values, technologies do not become realized simply for their own sake. Instead, technologies are often products of systemic forces and rhetorically constructed to be in accordance with prevailing cultural values.

\section{Technology as a Product of Systemic Forces}

Although "technology for the sake of technology" may seem to be the goal of industrial societies, changes in technology "will always be only one factor among others:

political, economic, cultural, and so on” (MacKenzie and Wajcman 4). STS scholars and other technology critics attempt broader analyses of technologies by examining how 
socio-political systems in particular produce new technologies. Technology is a product of systemic forces within and across societies. In our capitalist economic system, we often associate technologies with highly profitable companies (i. e., Microsoft, Oracle, Dell), but profit is only one of several factors that cause users to embrace a particular technology. After all, companies and not users profit. This “market” force helps fuel technological development. Consumers are offered many products, and they often have to replace products as new ones come out. Consumers or "the public" are not the only relevant social groups, but technologies do not become realized without them. Often consumers are the recipients to whom more powerful, more invested relevant social groups direct their rhetoric. As with any economic system, the means of production and the means of marketing products are controlled by an oligarchy of "invested" agents working within the techno-structure.

This techno-structure values certain technologies over others. Although large organizations have more influence over technological creation, consumers are not helpless in the face of technological creation; see, for example, human input into such technical designs as “ergonomic” keyboards or "value sensitive design” (c.f. Radetsky). However, perception of a technology's value also “conditions” the technologies produced. Langdon Winner argues that, specifically in the United States (but across much of the industrialized world), "[a] fascination with efficiency is a venerable tradition in American life" (46). Americans, Winner argues, have "[a]n eagerness to define important public issues as questions of efficiency” (46). This, in turn, creates a condition where "[d]emonstrating the efficiency of a course of action conveys an aura of scientific truth, social consensus, and compelling moral urgency” (Winner 46-7). That condition 
informs Winner’s ‘Technical Constitution of Society,' which has five “distinctive institutional patterns" excerpted below:

1. "[T]echnologies of transportation and communication ... [that] facilitate control over events from a single center ....”;

2. "[A] tendency for new devices and techniques to increase the most efficient or effective size of organized human associations ....”;

3. "[R]ational arrangement of sociotechnical systems [that] has tended to produce its own distinctive forms of hierarchal authority ....”;

4. "[T]he tendency of large, centralized, hierarchically arranged sociotechnical entities to crowd out and eliminate other varieties of human activity ....”;

5. "[T]he various ways that large sociotechnical organizations exercise power to control the social and political influences that ostensibly control them” (47-8).

The above five areas constitute some of the systemic forces that perpetuate technological creation. These forces also control users' preferences and organizational behavior.

Because of technology's socially constructed nature and larger institutional control over "hierarchally arranged sociotechnical entities," a dialectical relationship exists between technology and society. Anthony Giddens explains this phenomenon as the dialectic of control: "[A]ll forms of dependence offer some resources whereby those who are subordinate can influence the activities of their superiors” (16). Although Giddens was not specifically describing technology as a "superior," his theory applies because technology must be validated by users or potential users. Unfortunately, this relationship can be skewed in favor of dominant "invested" parties because an illusion of power to influence actions also exists. According to Giddens, those within the social 
system are confronted with two "faces" of power: "the capability of actors to enact decisions which they favour" and "the 'mobilization of bias' that is built into institutions" (15). An example of this power situation is bias towards the dominant two-party system in American politics. Citizens can effect change within the government by voting, ${ }^{12}$ but the two-party system maintains its dominance, making third parties simply nuisances because they often can only take enough votes away from one of the dominant partiesassuming they are even that powerful. Third parties cannot really expect to win a majority or plurality in presidential elections. Independents have won seats in state and local politics in America as well as seats in Congress. Third parties have tried to win Presidential elections, but no modern ones have come close because the two-party dominance of Democrats and Republicans is overwhelming; therefore, voters are mobilized in accordance to this political bias.

The above analogy of America's two-party system can also be extended to the illusion of "real" democratic choices. Just as voting for Candidate A or B (or sometimes C) constitutes limited choice in American politics, ${ }^{13}$ relevant social groups may also position technologies to feign democratic ideals or potentials if not viewed critically enough. Democracy, a major value for Western industrial cultures, is often affixed to new technologies. However, "democracy" in the next section is often used synonymously to mean egalitarian participation, a reality to which the technologies discussed often do not adhere. Capitalist forces or, simply, the marketplace often decide what technologies become realized because users have already "bought into" the technological system that has conditioned them to continue to buy the latest and greatest products—built-in obsolescence. 
What I hope to make clear is that scholars often want new technologies to adhere to democratic principles. They validate a technology’s potential by claiming a technology, such as the Internet, supports democratic principles. My purpose is not to debunk the scholars I discuss in the next section but to demonstrate how important the notion of democracy and participation are to rhetorical constructions of technology regardless of whether these terms are accurate. Although I could discuss the many popular commercials that advertise the "freedom" of high-speed Internet, I focus on the attitudes of technology critics who promote the Internet as a democratic tool or a potential democratic tool because that analysis relates to rhetoric and the values affixed to hopes for technologies; commercials relate more to consumerist rhetoric.

\section{Rhetorically Constructing Technology through Democracy}

Scholars claim that technologies are products of “social interaction” (Bazerman; Bijker; Feenburg; Latour; Winner), but that term is misleading if one assumes technocreation follows an egalitarian inventor-consumer relationship. Although scholars argue for techno-liberation as a political goal, our current late capitalist, post-industrial information age influences the technologies created. Understanding why "democracy" may help stabilize technologies requires understanding how scholars argue that certain technologies have the potential for increasing democracy. For instance, Andrew Feenburg assumes that the Internet is representative of democratization across all technologies. He claims "computer users in France and the US who introduced human communication on networks originally designed for the distribution of data accomplished

a liberating technical innovation” (xv). ${ }^{14}$ He goes on to argue that "[i]n all such 
democratic interventions, experts end up collaborating with a lay public in transforming technology" (xv). Therefore, the onus placed on the "lay public" requires them to converse with the established experts to create a democratic technology. Feenburg's use of "collaborating" is misleading because Internet users are not conversing with those who maintain and promote Internet use.

The Internet's liberation is not congruent to the technological liberation of computer users. Feenburg's argument that the Internet is a liberating technology does not account for the ways consumers are conditioned to access the Internet through a cycle of dependence on large computer manufacturers. Consumers are conditioned to take part in built-in-obsolescence, and the increasing "user friendliness" of computers further removes users from understanding the structure and programming of complex twentyfirst-century networking technology. ${ }^{15}$ Users are continually at the mercy of help desks and IT departments when things go wrong or when "important" upgrades must be made. Also, with the exception of virus updates, upgrades done by manufacturers are hardly in the interest of the consumer; for instance, eventually programs bought for one operating system will no longer be supported by future upgrades of the operating system. In the early 1990s and before, when most home computer users had non-networked systems, having an operating system for five or more years was not a serious problem for compatibility. But our current highly networked infrastructure now burdens the consumer to buy new expensive software to harness the capabilities of new hardware. The new software requires new hardware to get online, which further complicates the idea that the Internet is a "democratizing” technology. If true collaboration existed, users 
would be able to have older systems be more compatible with newer technologies in order to extend a product's usage. ${ }^{16}$

Within the field of computers and composition, scholars (most notably, Gail Hawisher and Cynthia Selfe) have embraced a call to techno-democratization.

Technology as a democratizing force is reified in "computer lab apparatus": the tools and networks that comprise the totality of computer-assisted instruction-the Internet being the most important tool within the last decade. Selfe warns of the "perils of not paying attention” to the increasing knowledge gap between skilled and unskilled students entering college-a gap affecting individuals’ future prosperity (4). Selfe’s work largely focuses on economic class, but she also covers aspects of the digital divide (the gulf between whites and African Americans online) and the educational backsliding caused by political rhetoric espousing the need to improve children's technical-scientific skills without the necessary public finding. Because these new computer technologies enable students to gain important literacy skills, Selfe argues that the very futures of our students are at stake if they are denied access. Similarly, Henry Louis Gates, Jr. argues that African Americans “are failing to gain access to the new tools of literacy," meaning the Internet, and that the Internet is "the most diverse and decentralized electronic medium yet invented” (15). Both Selfe and Gates underscore the idea that access to contemporary literacy tools is a democratic imperative. ${ }^{17}$

On a broader democratic level, Langdon Winner argues that technology, if created in accordance with democratic goals, will support democracy. Winner analyzes undemocratic and horrendously authoritarian technological systems. The often cited example from Winner is that of the architect Robert Moses and his technological Jim 
Crowism: As "the master builder of roads, parks, bridges, and other public works of the 1920s to the 1970s in New York," Moses "built his overpasses according to specifications that would discourage the presence of buses on his parkways” (Winner 23). Such an undemocratic system "limit[ed] access of racial minorities and low-income groups to Jones Beach, Moses’ widely acclaimed public park” (Winner 23). Winner argues that Moses' architecture reifies the systemic effects of a racist, classist society; certain groups' access to public areas is denied by physical barriers, which "embody a systematic social inequality, a way of engineering relationships among people that, after a time, became just another part of the landscape” (23, italics mine). A similar situation exists in low-income, inner-city dwellings where property values dropped as a result of “urban planning” that sent highways, railways, and other eye sores through predominantly African-American communities. ${ }^{18}$

Racism, a systemic force, helped bring about the technological segregation of Moses's “architecture.” Such a situation is representative of how white America treated African Americans throughout history. Moses's setup was simply a microcosm of larger cultural oppression—legally upheld until $1954 .{ }^{19}$ As American history proves, "all men are created equal" is relative to who's in charge. Therefore, "democratic" societies stabilize technology from non-egalitarian social values, attitudes, and practices. Ironically, these undemocratic practices are still in accordance with social values as Winner's example of Robert Moses shows. Also, some technologies "make it” through illegal back channels; for instance, Edison had to deal heavily in the graft of the Gilded Age to see his New York system to fruition; after all, Tammany Hall had to be “convinced” (Bazerman 227). The electric works Edison proposed had to fit certain 
political agendas. Because electricity is a public works issue, politicians had to support the endeavor, which, in turn, boosts their prestige. Therefore, a working technology is simply one aspect of technological realization. To be successful Edison had "to speak the language of politics ... involving patronage, jobs, political support, factional infighting, and perhaps payoffs" (Bazerman 228, italics mine). Such a practice of paying off civil servants is hardly a tenet of democracy.

Besides civilian projects being political in nature, military projects require governmental support, and, as was the case with the U.S. Navy's long-range wireless experiments around 1910, some projects are only possible with state funding. Chen-Pang Yeang analyzes how the U.S. Navy "decided to build the world's most powerful radio transmitter in Arlington, Virginia, one that would exemplify American’s [sic] military and economic potential” (1). Here is politics of a different sort. Instead of dealing in bribes to carry out radio experiments, the military, which was "in a better position than scientists in university laboratories to conduct long-range radio experiments, for only the state could afford such large-scale projects," had a de facto monopoly on large-scale technological creations (Yeang 3). By 1910, the navy had financial resources because of an internal push towards modernization. ${ }^{20}$ They needed a company to outfit ships with wireless technology and construct land-based stations, which meant awarding a contract to the company with the "proper" equipment and contract bid. Politics had a hand in the award. Despite the fact that the National Electric Signaling Company’s (NESCO) wireless device "was not in fact able to match the contract's long-distance specification," the navy seems to have wanted "an American over a British or German company"-the British company bidding on the contract was Marconi’s (Yeang 9). Because the foreign 
companies were upset, the navy provided an opportunity for other companies to carry out some experiments (Yeang 9). After all, upsetting possible future companies from helping carry out scientific or technical research would be disadvantageous. The navy was planning more fleet improvements and may have needed commercial support.

The navy did not just decide to outfit ships with wireless because the technology was available; the desire to modernize the navy — a political attitudinal change — occurred because "a number of top-rank officers” believed “[the wireless] could be incorporated into the 'New Navy'” (Yeang 5). ${ }^{21}$ The U.S. Navy dealt in favoritism on a micro level but did so because of the appeal to modernization on a macro level. Radios were the high-tech items in the early 1910s, and they fit the government's idea of what progress meant—modernizing by acquiring new technologies. Having wireless technology onboard meant the navy was being progressive about selecting one of the time period's most successful products. What the Navy's favoritism and Edison's graft dealings show is that "behind the scenes" forces in which relevant social groups engage also stabilize technologies. Values such as democracy, progress, and modernization are affixed to technologies by relevant social groups, but the reality of such labels does not have to exist. The meanings simply help a technology’s favorable perception within a culture.

But sometimes technologies do not become realized: Many unsuccessful technologies were feasible, but they were not represented to appear practical. Technology studies often focus on the successful products that make it to the market, so we rarely hear about failed technologies According to Staudenmaier, who studied the STS journal Technology and Culture, STS scholarship mainly studies successful technologies (Bijker 7). Relevant social groups affix meaning to technologies that help 
stabilize them and not stabilize them. Labeling technologies with positive meanings such as progress, democracy, and freedom help technologies; negative meanings such as dangerous, expensive, and inefficient do not help. Two important cases where relevant social groups were not able to affix positive meaning(s) to technologies are Rosalind Williams’ study of MIT's reengineering (1994-1999) and Bruno Latour's widely popular account of ARAMIS, the failed Parisian rail car system.

\section{Not Stabilizing Technologies}

In one of the few studies on a failed technology, Williams examines how MIT's reengineering was not accepted by enough relevant social groups. These relevant social groups were faculty, staff, administrators, students, and various consultants. The concept of "reengineering was defined as 'the fundamental rethinking and radical redesign of support processes to bring about dramatic improvements in performance” (Rosalind Williams 643). In order to implement these changes, "a core team analyzed key administrative processes and eventually recommended that eight of them be redesigned" (Rosalind Williams 643). The biggest, most expensive change "went into installing a new financial system, SAP R/3, which replaced MIT's” accounting system (Rosalind Williams 634). Williams argues that it was the business side of MIT that forced these changes, and not enough users were happy with the proposed changes. Williams notes that one colleague "describe[d] staff resistance to reengineering” by stating ““[n]othing is more real than feelings"” (667). Faculty and staff feelings were not "factored in" by the administrators or consultants implementing the changes. 
Reengineering failed because relevant social groups did not affix positive meaning to the new technology. ${ }^{22}$ MIT's administration apparently was convinced that the new business model of "reengineering," which was popular in the 1990s for increasing productivity (Rosalind Williams 643), would be embraced by all parties. Unfortunately, the technology, or rather technologies comprising reengineering, did not fit within the values and practices of important relevant social groups. Williams explains reengineering's failure as follows:

While the MIT administration was heavily invested in reengineering, the rank-and-file staff had mixed reactions ... Others resented the intrusion of consultants and teams that they considered inexperienced or even incompetent, while feeling that underneath it all reengineering was just about eliminating jobs. The view of the MIT faculty was even more negative ... they regarded the whole effort with considerable skepticism and often with outright disdain. (644)

The faculty did not consider reengineering a valuable technology in theory or practice; instead, they "considered reengineering at best a distraction from, and at worst an assault upon, 'real' engineering” (Rosalind Williams 644).

Williams delves deeper into the issue of reengineering's failure by linking it to a greater "problem" of modern technology not being "true" technology. According to Williams, over "the last two centuries ... 'technology' has become strongly identified with engineering” (644). However, past engineering was devoted to constructing physical products “cover[ing] a wide range of endeavors" such as "sailing, hunting, weaving, plowing, fighting, cooking, traveling, mining” and so on (Rosalind Williams 644). Williams argues that "The Massachusetts Institute of Technology trains engineers," and "[f]or conventionally defined engineers at MIT . . . reengineering is not ‘technology’ at all but a 'business’ or management’ application of technology” (644). 
Because reengineering fit neither the idea of "technology" nor "engineering," it failed to be realized as a technology by enough potential users—most importantly, the MIT faculty. Williams makes it quite clear that as a business decision reengineering insulted the "feelings" of those who were supposed to embrace it as a solution for greater productivity. Reengineering simply did not fit the values and practices of the community.

Another technology that did not fit the values and practices of relevant social groups was the almost-completed Parisian commuter rail project, Aramis. The project began in the early 1970s and came to an end in late 1987. Millions of francs were spent on the project, but Matra Transport could not get the system successfully in place. Latour creates situations for a young engineer and a veteran sociologist to investigate what "killed” Aramis. Latour analyzes this failed technology by researching history, economics, behaviors, attitudes, and politics surrounding Aramis. Prototypes were developed, budgets were calculated, and the public was informed, but Aramis failed to become realized. To determine why Aramis did not "work," Latour has the two fictional characters interview Matra employees and members of the Parisian transportation authority and examine press releases, correspondences, specifications, and newspaper articles to construct Aramis rhetorically. These fictional characters "grab actors" in order to produce a sociological account superior to an historical narrative (Latour, Aramis 89). Latour argues that " $[t]$ he time frame for innovations depends on the geometry of the actors, not on the calendar” (Aramis 88). Engineers worked on Aramis; time did not. Also, other actors—managers, politicians, accountants—had a part in creating Aramis or, more accurately, not having it realized in Paris. Latour believes we ought to look to the 
actors for a more fruitful understanding of the time in which a technology was created: "Grab the actors, and you'll get periodization and temporalization as a bonus" (Aramis 89). Looking to the actors (or relevant social groups) allows researchers to understand when a technology exists. An inventor securing a patent has no more created a "working” technology than a group of engineers with a finished prototype that is not feasible (Latour, Aramis 66-67). The fictional characters in Aramis travel and interview the key actors in constructing the railcar, asking what factors contributed to any successes or failures at a given moment in Aramis's history.

What Aramis failed to do was become a black box. Aramis did not have an effective support system, and it could not mold human behavior through successful marketing or adapt to behavior through engineers' efforts. One crucial engineering fault was the design that allowed too many individuals the opportunity to choose the direction in which they wanted the cars to go; as M. Gueguen, the Parisian transportation authority director of infrastructures, pointed out to Latour's fictional sociologist: "People all go in one direction, then the other. If you let people direct their own cars to their destinations, at the end of the day all the cars would be at the end of the line; how would they get back?” (Aramis 90). Gueguen also adds that if you tried to fix the above issue “you'd have so many cars, the system would have to be so enormous, that it would cost a fortune” (Latour, Aramis 90). Also, Aramis’s small-car design went against the values of equal access to public transportation: One psychological study on Aramis noted that with the system as proposed "[t]here's no access for the handicapped, or for the blind, or for very tall people, or for luggage” (Latour, Aramis 187). Additionally, users “expressed fear of being closed in" or "trapped" in a railcar whereas the Metro allowed for greater 
mobility (185-6). Again, the potential users' value of security was not a technical but social/personal meaning affixed to what they saw as "confining” transportation technology.

Aramis had a few engineering problems, but not conforming to social values and practices meant it was not realized by the relevant social groups. The Aramis system was a local issue. Although one can say rush hours are similar in many industrial areas, Aramis was specific to Paris. The safety concerns, political "games," and culture cannot be said to be universal. However, industrial cultures do share an almost universal value associating progress with technological advancement (Feenburg; Stent; Weaver; Winner). The wireless's stabilization meant progress, and tropes of progress were part of a broader modernist consciousness that encapsulated the "cult of efficiency" promoted not only in technical and scientific discourse but also in avant-garde art.

\section{Modernism and Technology}

Modernist audiences in the early twentieth century were more likely to be persuaded to accept a technology promoted as a marker of progress. Technologies marked human progress(ion) from the past to the assumed more efficient present and future. Speed, efficiency, profitability, and movement were all attributes of progress and of modernism. Audiences held the idea of progress in such a high esteem that Richard Weaver argued the term was the industrialized world’s quintessential "god term” (212). Weaver defines a god term as "that expression about which all other expressions are ranked as subordinate and serving dominations and powers” (212). Although Weaver analyzes attitudes surrounding progress from a predominantly American point of view, 
his analysis is not limited to one industrialized nation: Any nation in the twentieth century wanting to increase its industrial power would fetishize progress and the values associated with it. Any rhetorical construction of a technology would be aided by being seen as progressive. The value of progress is not in its etymological meaning but in the meaning the modern audience associates with it.

Why would a word that basically means "to move forward" be rhetorically charged to be the god term of the day? That question is easily answered when we see that the era and the mindset of the era affect which words will be god terms. Weaver argues that a collective stance particular to a time period constructs the god term. Humans define themselves by “[revolving] around some concept of value” or else they "[suffer] an almost intolerable sense of being lost” (Weaver 213). "Progress" was such an entrenched and universal Western goal that anything associated with it made people "socially impelled to accept and even to sacrifice for" the values given to the object (Weaver 214). One would sacrifice “for the 'progress' of the community,” and “progress” was “the coordinator of all socially respectable effort” (Weaver 214). Therefore, technologies that espoused progress could arouse nationalist sentiments because the society could point to an object embodying human advancement. New technologies marked a civilization’s perceived greatness.

Attitudes towards progress support the “efficiency” practices of Frederick Taylor and Henry Ford, which revolutionized management science and factory production. Although Henry Ford claims not to have had "any Taylor influence over the assembly line,” it is impossible not to see Taylor’s influence (Beatty 207). John Dos Passos claims Taylor, who was consumed by efficiency, had "[p]roduction [go] to his head and thrilled 
his sleepless nerves like liquor or women on a Saturday night” (qtd. in Beatty 207).

Passos, writing in the 1930s, may be foisting an unwarranted fetishization of Taylor's, but such an attitude would be in accordance with the technophile and contemporary F. T. Marinetti. However, Henry Ford recognized Taylor's ideas or, at least, the importance of efficiency for production. ${ }^{23}$ Ford applied Taylor's scientific management to his assembly line and created a new technology indicative of hyper-industrialization at the beginning of the twentieth century.

Although Richard S. Tedlow claims Ford alone was responsible for the assembly line (227), industrial culture already valued efficiency as a goal for technologies. Tedlow ignores the social context by arguing that Ford's investment and not "the market" or “[p]ublic opinion” was solely responsible for the assembly line (227); however, this argument relies too heavily on "a vacuum theory" of technological creation. Social forces must have been "ready" to accept such a streamlined, dehumanizing workplace environment. Tedlow believes Ford “along with Einstein, Freud, Lenin, and a very few others" were "in that class of people who exercised a decisive impact on the history of the twentieth century" (227). What he does not recognize is that these men were the product of industrial cultures. Their genius or impact was congruent to cultural values.

As for Western societies, promoting industrial applications of science was very important. Savvy industrialists and other interested parties founded the Royal Society of Arts and the Royal Institution to advance commercial applications of science. David F. Noble briefly traces the Royal Society's impact on scientific and industrial promotion, explaining that "[t]here was also a strong connection between the scientific pioneers and early capitalist enterprise” (58). Although Noble's main argument is that these societies' 
religious convictions extended medieval millenarian beliefs into modernity, he also shows the early work of the Royal Society to be "researches focused upon the practical problems of " mechanical and commercial industries (59). These societies promoted technology as man’s conquest over nature—advancement through techno-evolution. Therefore, technology became a force to be worshipped. It had dominion over the natural world.

Henry Adams explores the power of machines to become the new spiritual force for humanity in "The Dynamo and the Virgin”:

[T]o Adams the dynamo became a symbol of infinity. As he grew accustomed to the great gallery of machines, he began to feel the fortyfoot dynamos as a moral force, much as the early Christians felt the Cross. The planet itself seemed less impressive, in its old-fashioned, deliberate, annual or daily revolution, than this huge wheel, revolving within arm'slength at some vertiginous speed, and barely murmuring — scarcely humming an audible warning to stand a hair's breadth further for respect of power ... Before the end, one began to pray to it; inherited instinct taught the natural expression of man before silent infinite force. Among the thousand symbols of ultimate energy, the dynamo was not so human as some, but it was the most expressive. (380)

Interestingly, Adams goes on to show his reverence not just for technology, but also for the inventors of new, impressive machines when he says, "[h]e wrapped himself in vibrations and rays which were new, and he would have hugged Marconi and Branly had he met them, as he hugged the dynamo" (381). Adams was in complete awe of these new machines, and his account is an apotheosis of their creators. Other modernists glorified technologies as "vehicles" of progress. F. T. Marinetti, the founder and leader of Italian Futurism, established speed, efficiency, and ahistoricity as goals for human advancement. Marinetti’s manifestos advocate that humans should emulate mechanical characteristics. 
Although an exaggeration of a social love of progress, Marinetti's works embody the cultural value of progress supported by industrial society.

Because technology was a factor in rapidly changing cultural practices and values, artists echoed or reinterpreted the meaning of technology in society. As a contemporary technology, the wireless inspired Marinetti’s artistic work. Specifically, he claimed that the wireless influenced his telegraphic style for poetry. ${ }^{24}$ However, many artists at the time were experimenting with telegraphic styles; John White suggests "that 'telegraphic' writing was generally 'in the air' in European avant-garde circles” (160). Regardless of how Marinetti was inspired, he reconstructed the wireless through language influenced by this historical modernist moment. Marinetti and the popular press, therefore, reconstructed the wireless for audiences using tropes of progress. Of course, Marinetti’s work exaggerates the wireless's possibilities, but those exaggerations show how progress shapes his artistic experiments and theories of modernism in general. Part of the Futurist aesthetic was to make bombastic claims about the value of technology and promote its presence as a force of human advancement: According to Marinetti and the popular press, humans advanced or "evolved" through new technologies.

Technology as a marker of human evolution relates to Social Darwinian misreadings of evolution. Evolution is commonly thought to be a progression toward a better species, a higher life form. But Charles Darwin's theory on evolution does not imply that humans or other creatures become better; instead, they become better adapted to their environments. Natural selection is the theory that adaptations enhancing survival cause certain traits to become prominent in a species. ${ }^{25}$ Evolution became an important 
narrative for late nineteenth and early twentieth century Western societies that often feared the opposite-degeneration. As Peter Childs points out,

The theory of degeneration threatened Europe with the possibility of a reversion to a less complex and more barbaric form of society. Notions of 'evolution', 'progress,' and 'reform' led to an urgent fascination for their apparent opposites: 'regression', 'atavism', and 'decline'. (39, italics mine)

Industrial societies had to be seen as advancing through technology, Childs goes on to argue: "If a country had not independently achieved an advanced stage of industrialization, it signified a social and cultural backwardness, and inferiority on behalf of the country’s people” (40). Marconi’s texts do not speak as narratives against degeneracy, but they do fit the techno-evolutionary narrative that Childs argues came from Darwinian science (36). Marconi and other inventors use evolution to mark civilization's progress when they introduce new inventions. The idea that technology signals or is affixed with values of evolution relates to how "democracy” is often affixed to or perceived in the Internet: Relevant social groups promote evolution and democracy in spite of the reality of such labels. Regardless of the accuracy of certain affixed values, technology still appears to fascinate audiences.

During the Industrial Revolution, new inventions were showcased for popular audiences in World’s Fairs. As David Nye points out, the World's Fairs embodied the cultural need to move forward because they "served as a site within the transitory present from which the visitor could glimpse the future” (205). World's Fairs showcased progress by showing the public the marvels of civilization; the displays were statements about the importance of technology in society: “They marketed the idea of progress itself, providing an overall impression of coherent historical development” (Nye 205). 
These popular venues also showcased a nation's technological power- - they were expressions of industrial might. And in the political sphere, new movements of the early twentieth century, such as Italian and German fascism, readily embraced hyperindustrialization and the militarization expressed in new technologies. Such inventions as the machine gun, torpedo, dirigible, and even the wireless (which Marconi and the popular press promoted as a necessary wartime tool), as Marinetti shows in his manifestos, would lead Italy into becoming an industrial powerhouse and world military leader. Nationalist sentiments ran high in Europe at the time, and technophiles like Marinetti argued a nation's technology established a nation's status.

The desire for modernization led Marinetti to his artistic project: "The liberation of the human body, the liberation of Italian democracy, and the efficient re-working of the machine are one project for Marinetti” (Hewitt 144). Andrew Hewitt argues the systemic reason for Marinetti’s technophilia "reflects nothing more than the economic underdevelopment of Italy and an understandable fascination with industrialization on the part of the Italian modernists” (146). Marinetti’s early Futurist work embodies this fascination and violent patriarchal characteristics of the machine-man. ${ }^{26}$ Hewitt reads Marinetti's works as proto-fascist or indicative of fascist aesthetics, identifying "the figure of the machine" in Futurist art as "the symbol of a specific social and political organization” (146). However, machine- or efficiency-inspired political/social organization is not limited to twentieth century fascism. The needs of industrialized nations appear to require societies to embrace technological advancement. After all, democratic and socialist nations promoted technology as advancement throughout the twentieth century and through today. From Henry Adams' glorification of dynamos to 
the contemporary drive in the U. S. for more math and science skills to secure a world leadership role, technologies are progress reified.

And the wireless's rhetorical reconstructions show that it embodied the value of progress in the early twentieth century. In order to demonstrate tropes of progress surrounding the wireless, this dissertation shows how Marconi’s wireless fit societal values and attitudes supportive of technology by examining a select body of texts espousing progress rhetoric. These reconstructions of the wireless through discourse are the first places the wireless exists. Before it becomes a black box, Marconi and others present the wireless as a viable technology in accordance with prevailing culture attitudes. 
Notes

1. Jim Johnsom is Bruno Latour's pseudonym in the article "Mixing Humans and Nonhumans Together."

2. Similarly, Bijker analyzes the social relations and historical discourse related to three technologies - bicycles, bakelites, and light bulbs - to demonstrate how those inventions were shaped by social attitudes as much as they were shaped by the inventors.

3. For an analysis on Foucault's contribution to philosophy of science, see Joseph Rouse's Knowledge and Power. Rouse argues from the Foucauldian perspective that group interaction influences the products created: "The various ways people are enclosed, grouped, distributed, separated, and partitioned mark a related spatial organization of power/knowledge. These distinctions constrain our patterns of activity and interaction, and in doing so they shape both our activities and us as agents” (217).

4. Because science also needs actors working together or, at least, interacting with experiments and research, both technology and science should be seen as comparable. After all, technology is often an application of science: In the case of the wireless, actors such as Marconi and others worked to harness the power of hertzian waves for commercial enterprise.

5. Hiskes and Hiskes divide historical approaches of technology into "four historical periods: (1) ancient Greece through the fifteenth century, (2) the Scientific Revolution from 1540 through 1750, and (3) 1750 to 1940"; the "somewhat speculative" fourth period starts in 1940 and goes to the present, which was 1986 (21). In each "period" science and technology vary in their relationship to each other. For instance, in ancient times science and technology were distinct but "very intimate" disciplines during the Scientific Revolution (21-2). Hikes and Hikes do mention, however, that "[a]lthough the scientific and technological communities were isolated from each other during the 17501940 periods . . . occasional transfers of knowledge between them did occur” (24).

6. This situation allowed the Internet to flourish. Also, a culture that values consumerism would use this technology to facilitate consumer purchasing.

7. However, a science such as evolution has much more to do with the public. Currently, major challenges to studying evolution in public schools show the politics of a socially constructed science. Many school districts have to contend with the possibility of indoctrinating students in "intelligent design" alongside the science of evolution. The major participants are not only scientists but parents, politicians, and judges.

Consequently, publishers will have to adjust their textbooks to include "scientific" discussions of creationism, currently under the guise of "intelligent design," if school districts demand such content; therefore, we see the market as a force in establishing science. The wireless had to be a market-oriented technology in order to be accepted as well. 
8. George Ritzer argues contemporary cultural systems such as McDonald's ultraefficient business model promote the "rationality of irrationality": "[R]ational systems are unreasonable systems that deny the humanity, the human reason, of the people who work within them or are served by them. In other words, rational systems are dehumanizing” (123-4).

9. For example, Chinese and Indian modernization relates to the two countries' acquisition of industrial tools that have allowed their economies to grow.

10. Bazerman claims that Edison is rumored to have been fired from his Louisville telegraphy post for unauthorized experimentation.

11. Unless specified otherwise, all Bazerman citations come from The Languages of Edison's Light.

12. This assumes, of course, that votes cast are actually counted.

13. This analogy works best for presidential elections and not state and local elections. In order to run successfully for president in modern times, candidates must be able to secure millions of dollars in campaign funds. That process is much easier with support from either the Democratic or Republican parties. Occasionally, third party candidates can receive enough votes to hurt other candidates if their political beliefs are closely aligned (i.e., Ross Perot taking votes from George H. W. Bush in 1992), but the outcome is the still the same-either A or B wins.

14. Feenburg also ignores the fact that the Internet was one of many post-Sputnik influenced technologies created to establish America's scientific, militaristic, and economic dominance through sharing scientific information with allies, bases, and universities.

15. The phrase "user friendly" is extremely important to understanding how computers shape social practice. Before graphical user interfaces (GUIs), such as Microsoft Windows, computer users had to understand the language of computers through textbased commands. To learn these commands, one had to learn a new language. Currently, this language has been converted to graphical object-oriented commands that can be done by dragging and dropping. For instance, copying the file "dissertation.doc" from the Desktop to the My Documents file folder can be done by simply dragging "dissertation.doc" from the Desktop to the My Documents folder. The text-based command would look like this:

COPY C:\Documents and Settings \Username $\backslash$ Desktop $\backslash$ dissertation.doc

$\mathrm{C}: \mid$ Documents and Settings \Username $\backslash$ My Documents $\backslash$

Although the above command is a relatively easy one, a user in a text-based computer environment had to enter commands similar to the one above in order to set preferences, run programs, scan for viruses, and do other "everyday" tasks. Those text-based commands are now done automatically or with the (double) click of the mouse. Each new computer "advancement," whether it be hardware or software, is marketed as more 
user friendly; therefore, to "fix" one's computer, users need only buy the next release and not understand the complex programming behind it.

16. An exception to this is the growing open source software available to users. Open source means that software is usually free or inexpensive. Operating systems such as LINUX are examples. However, users normally use open source in conjunction with proprietary software, such as Windows or Macintosh. For example, I have SUSE LINUX, but I use Microsoft products because my university uses these products and regularly upgrades the proprietary software. I would be worried if something as important as this very dissertation could not be opened on the campus computers if my laptop or desktop crashed. If I were to send a non-Windows file to my advisor that she could not open ... I would have a problem. Therefore, open source is not a viable alternative for users who must have compatible files and software in a closely networked environment (such as an office, a university, or a group of gamers).

17. Deborah Brandt, although not specifically addressing computer literacy but literacies, argues that literacy is a basic civil right (206).

18. The fact that we could identify predominantly African-American communities (as opposed to "human” communities) attests to systemic and historic racism.

19. Although Brown v. the Board of Education of Topeka Kansas overruled Plessey v. Ferguson, institutionalized racism still exists. Democracy is often associated with freedom and egalitarianism, but larger cultural values influence how citizens vote; historically, voting in America has been to the detriment of African Americans from slavery to Jim Crow.

20. Theodore Roosevelt had been trying to build up the navy since he was the Assistant Secretary of the Navy under William McKinley; he "observ[ed] the success of Great Britain, the growth of Germany, and the increasing dominance of Japan as a Pacific power, "and he believed the U. S. "must also have a great navy" (Nelson 3). In the historical moment of the Spanish-American War and the decade beyond, modernizing the navy fit with expansionist goals. From the point of view of a certain relevant social group for wireless technology being important for the navy, Roosevelt and senior officials helped shape the new navy through new technology.

21. Even though Marconi's company did not win the bid, Marconi was the first to outfit U.S. Navy ships. Marconi was "invited to install wireless telegraphy sets on two warships for onboard testing [in 1899]" (Yeang 2). By Marconi's own admission, he chose not to use his most up-to-date device during the U.S. Navy tests because he had not yet secured an American patent ("Wireless Telegraphy" 294), an obvious political and economic concern.

22. Rosalind Williams does not consider financial systems or other abstract computer systems as technologies (661). Her article expresses nostalgia for past "true" engineering, which according to her was "as much about creating a moral world as it was 
about creating a world of knowledge or of things" (658). She also "muses” about whether or not "technological development can continue to flourish indefinitely in a market environment” (664). She briefly discusses open source as a potential departure from capitalism and (possibly) to more democratic control because "[o]pen-source advocates believe that truly robust software can be built only when it is treated as a form of scientific knowledge, so that incremental contributions accumulate indefinitely through a system of peer review" (664). However, she feels that "technology that profits from change for the sake of change" is hardly a "proper" situation (664).

23. In Aldus Huxley's Brave New World, the characters use "My Ford" instead of "My God" to show disbelief. This apotheosis of Ford is Huxley's interpretation that society has embraced industrialization as a religious or spiritual value.

24. John White suggests that Marinetti's claim that his prose style was influenced by reporting his stories using Morse code while he was a war correspondent during Italy's bombing of Tripoli was a fabrication (162).

25. Although humans (or, hominids, more specifically) have a common ancestor with modern apes, humans did not evolve from apes. Such a view assumes that modern apes never evolved but, instead, stayed in the same form as they are today - not undergoing natural selection or adaptation. In other words, evolution is not a progressive change as popular definitions would have us believe.

26. And "machine-man" is more appropriate for Marinetti than "machine-human" because of his disdain for women. Although Hewitt argues that phallocentrism is indicative of fascist ideology (153), I argue industrial ideology is more relevant to Marinetti's early Futurist work. 


\section{CHAPTER II}

\section{MARCONI'S REPRESENTATIONS OF THE WIRELESS TO THE SCIENTIFIC COMMUNITY}

Think of ... all the calling which goes on every day from room to room of a house, and then think of that calling extending from pole to pole, not a noisy babble, but a call audible to him who wants to hear, and absolutely silent to all others. It would be like dreamland and ghostland, not the ghostland cultivated by heated imagination, but a real communication from a distance based on true physical laws. P. T. McGrath, "A Very Loud Electromagnetic Voice” (32)

Ultimately, Marconi’s wireless became a successful technology. The relevant social groups in the early twentieth century recognized it as viable and valuable through their negotiations and interactions. Prior to any technology's black-box status, though, is a period in which inventors, business people, potential users, governments, and similar groups "receive" information about a technology. Although one could argue that users learn about technology by interacting with a technology, discourse is also interaction. Normally, we associate technology with hi-tech items, specifically, computers. Before computers became "everywhere," they had to fit into social practices. The computer's success rests partially upon our Information Age's gravitation towards the potentials of databases, search engines, and related hardware and software. For society, computers are not only tools but symbols: Educators and parents believe they allow students greater opportunities to learn; businesses believe they represent efficiency and professionalism, therefore, profit; and everyday users, regardless of whether they are frustrated, believe computers are necessities in a world inundated with hi-tech networking. Technologies 
such as computers do not exist just because they are feasible or operational; they exist because they "caught on." Somehow the culture in which they exist accepted them or was made to accept them. Discourse adhering to social values, practices, and attitudes may cause acceptance.

This chapter demonstrates how Marconi rhetorically constructed his early wireless invention using strategies that show the wireless to be a product of the "built environment” of the early twentieth century. The environment is immediately the British scientific and technical community, but his extended audience stretches to other industrialized countries and across the Atlantic Ocean. Representations of the wireless go beyond merely mechanical or physical descriptions. The wireless was a new technology being presented in a scientific forum before it became the radio. Marconi's representations constructed an image of what the wireless might have become. These presentations were reprinted in technical periodicals and the annals of scientific societies such as the Royal Society of Arts, London, the Royal Institution of Great Britain, and the Smithsonian Institution. These texts that contain Marconi's presentations show the wireless as a new product signaling human evolution, creating an economic enterprise, supporting the military, and increasing the efficiency and scope of (mass) communication. The wireless "fit" the social framework of the early twentieth century because it was an advancement presented as a new communication device that would allow humans another form of control over nature. Marconi promoted the wireless as a tool to make the seas safer for travel, insure cargo better, and connect ocean goers with "land news." 
Marconi’s representations of the wireless demonstrate how rhetoric can position a technology to be viable both commercially and culturally. Selecting technical presentations, which later became technical documents and archived texts, is an appropriate way to discover a rhetoric of technology. Marconi presents his wireless in these texts as an ideal product for society and an invention indicative of modern progress. The texts, however, are but one of several types of rhetorics for the wireless. In the next chapter, I will examine how the popular press uses another rhetoric to (re)present the wireless for a popular audience. Additionally, patent documents and lab notes are rhetorics because they represent the wireless symbolically—-through text and images. My study notes those symbolic rhetorics but focuses on discourse for a wider audience. Although much can be said about the forums in which Marconi presented his findings, this chapter concentrates on the texts reprinted from his presentations. However, I do briefly show how the history of such scientific societies as the Royal Society of Arts, London and the Royal Institution of Great Britain support my claim that the wireless fits the prevailing attitudes and values of progress during the early twentieth century.

In order to demonstrate how the wireless fit within an industrial culture that favored "progress," I have selected three of Marconi’s early presentations to examine how he discusses or represents the wireless as a viable early twentieth-century technology through discourse in the following texts:

1. to the Royal Institute of Great Britain on February 2, 1900 ("Wireless Telegraphy”)

2. to the Royal Society of Arts, London on May 15, 1901 ("Syntonic Wireless Telegraphy") ${ }^{1}$ and 
3. to the Royal Institute of Great Britain on March 3, 1905 ("Recent Advances in Wireless Telegraphy”)

The three presentations are instances where Marconi rhetorically represents the significance of the wireless. He delivered them to an important community and spoke to concerns outside of science and engineering prior to the wireless becoming a literal and figurative black box —-the radio. Marconi delivered the presentations before highly technical/scientific audiences, and his discourse conveyed more than technical information during the wireless's early stages. Marconi presented much of the potential of his new system along with current successes: He discussed how ships communicated with other ships and land-based stations; he mentioned how people and cargo were saved by distress calls; and he prophesized that the wireless would change how information was disseminated. The forums where he delivered his presentations were important—-the Royal Institution and the Royal Society of Arts, London were products of the Industrial Revolution, clearinghouses and think tanks for "mechanical arts.” Their goal was to promote the practical application of science to human endeavors. These groups and groups similar to them—Birmingham's Lunar Society, the French Societe d' Encouragement pour l'Industrie Nationale, and the American Society for the Promotion of the Useful Arts—-were technical venues where scientists and engineers displayed their work and promoted ingenuity, and they were also founded by inventors, industrialists, and businessmen with entrepreneurial-industrial pursuits (Noble 77-9).

These three presentations are not meant to be definitive examples of Marconi’s rhetoric; instead, they represent Marconi's engagement in the rhetorical construction of a technology prior to its becoming a black box. Although Marconi was a widely known 
and respected inventor in Europe and America, between 1900 and 1905, he did not have a widely successful commercial product. He did have ships outfitted with the wireless, but he was still in the pitching stage-attempting to prove the wireless was beneficial (and real). Also, his presentations supported his ownership of the wireless, which I will demonstrate later in this chapter as important to establishing himself as the future "father of the radio.” Marconi did not just speak about the technical make up of his invention; instead, his presentations show the wireless as a technology embedded in the values of a culture. Specifically, the texts reveal four topoi related to Marconi’s rhetoric, which are representative of other rhetorical constructions of technologies: the cultural pride associated with technological advancement/evolution, expectations and current successes of the wireless, the economic viability of the wireless, and patents to show Marconi's ownership of the wireless.

The rest of this chapter demonstrates how Marconi fit his wireless into the technical discussion and how the four topoi above, combined with other rhetorical strategies beyond physical representations, define the wireless's rhetoric. First, I show how the wireless fit into the early twentieth century's scientific-technical framework and the importance of Marconi's texts and presentations for the wireless's rhetorical construction. Second, I examine how Marconi builds a scientific ethos in order to bolster his "wireless rhetoric." Finally, I demonstrate how the above topoi create an image of the wireless. 


\section{The Wireless's Place in Early Twentieth-Century Science and Technology}

Marconi's presentations to the technical and scientific community represent the wireless as human advancement. The West seemed ready to welcome technology for the sake of newness, and Marconi’s audiences gathered in these technical/scientific forums to learn about what was new in electromagnetic arts. His using wireless signals to cross the Atlantic Ocean made him a celebrity, but he had rivals and critics who did not feel he had a good working technology (c.f. Weightman). The forums, therefore, were necessary for gathering support for the wireless's existence. Readers may be quick to assume that Marconi wanted increased investment in his company to help the wireless’s R\&D; after all, seeking capital investment seems necessary for anyone (or any company) trying to produce a new product. However, Marconi’s investors were “locked” according to the company prospectus of June 18, 1900, which states "[s]hares are only offered at present to the shareholders of Marconi’s Wireless Telegraph Company, Limited” (qtd. in Hancock 25). New investors or directors may have become board members between Marconi’s February 1900 presentation and the April 1900 founding of Marconi's Wireless Telegraph Company, Ltd., but the share rules show that only current investors would be allowed to invest in the company. The presentations were most likely conversations solidifying the wireless's scientific merit. However, the scientific merit of the wireless and its economic practicality were not mutually exclusive.

Although the technical community ${ }^{2}$ could not have jumped onto the company's board of directors, Marconi's mentioning of the economic possibilities of the wireless in his presentations shows that the application of science to practical endeavors reflects how his rhetorical choices adhere to certain values of industrialized society. Marconi might 
not have been consciously constructing his presentations to "fit" traditional scientific discourse, but his presentations do support modernist, industrial, Western values for technology. Furthermore, the texts convey the wireless's rhetoric because they discuss the wireless's potential nature. Ultimately, the wireless was successful because it became a black box - the radio. Marconi, the technologist, does quite a bit of marketing in these texts, which reinforces the fact that his words were not simply to discuss the physical makeup of his wireless, but also its economic potential.

Marconi demonstrated the wireless's value as a viable product to enhance contemporary communication, positioning the wireless as a better communication tool than cables. Such positioning is really a PR campaign, and Marconi staged some important wireless transmissions to intrigue the public: He had Queen Victoria send a message to her son, and, a few years later, he had Theodore Roosevelt and the King of England send messages to each other; both events were covered in the popular press. He commented on his successes at sea reporting on yacht races during the presentations; of course, this has no scientific merit but is certainly exciting. As Edison did before him with electrical works (Bazerman), Marconi was looking to create a market for his system before his system became a reality. Marconi’s early system (circa 1900) needs to be distinguished from the future radio: The radio is an artifact and, as I mentioned earlier, a black box technology; the wireless, is an idea comprised of a transmitter, receiver, and various other parts that connects people and stations without wires. The early wireless is a scientific-technical-business product: "Marconi’s work-network nods respectfully to the scholarly achievements of scientific discovery, conceived as properly applicationless, but simultaneously pirates its apparatus, adapting it to a precedent technology 
pregnant with extant applications, telegraphy with wires” (Jaffe forthcoming). Therefore, Marconi's application becomes positioned to be the next advancement over cables and wires. The texts where the wireless "exists" in the early twentieth century are artifacts on wireless negotiations between Marconi and the technical community. They reveal more than the invention's mechanics; they reveal potential economic viability.

Part of the wireless's negotiation was to discuss its economic viability; after all, as Charles Bazerman notes, "technology must always overtly adhere to the marketplace, political ambitions, and personal desire” (“The Production of Technology” 383). Those who credit Marconi with inventing the wireless attach significance to his economic vision for the wireless. Thus, Judge William K. Townsend—supporting Marconi from a necessary legal position—agreed that Marconi was a proprietor of wireless knowledge because he "appreciate[ed] that this new current was destined to carry onward the freight and traffic of world commerce” (qtd. in Hancock 6). The court granted Marconi the patent because he took the science of hertzian waves (also called "wireless signals" and, later, “radio waves”) and created a commercially viable system for harnessing their power. Even though Marconi had great success in courts and in the wireless market, his discussions show ownership. Also, his discussions show that he is worthy of making scientific claims and constructing a reliable product.

\section{Building a Scientific/Technical Ethos}

Marconi presented the wireless as a new incarnation of electromagnetic science, a field dating back nearly a century from his early work. He shows that his work is built upon an old field in his introduction to his 1900 presentation "Wireless Telegraphy," 
where he brings up six major scientists: Andre-Marie Ampere, Joseph Henry, Michael Faraday, James Clerk Maxwell, Heinrich Hertz, and Sir John Ambrose Fleming (287). Two of the six are familiar to most audiences, but all are familiar to technical audiences. Ampere was a French physicist of the early nineteenth century for whom the ampere (amp) was named. Heinrich Hertz was a German physicist who first discovered radio waves. His name today is mainly associated with measuring cycles per second $(\mathrm{Hz})$. Marconi's references to past inventors show him "standing on the shoulders of greatness.” In part, he is borrowing a scientific ethos by showing he understands the field's rich history, but he is also situating himself in this history. This strategy helps solidify his credibility while promoting the wireless as an important new technology.

Of course, Marconi's accolades to past scientists could just be out of respect, but they also introduce the audience to a technology with an important history. The introduction to Marconi's 1900 presentation offers the following descriptions about three important scientists in the field: James Clerk Maxwell's "splendid dynamical theory of the electro-magnetic field”; Heinrich Hertz to whom “[w]e can not pay too high a tribute to [his] genius"; and Professor Hughes "the eminent electrician” ("Wireless Telegraphy” 287). Marconi also uses Professor Fleming's words to praise Hertz when he claims Hertz's discovery is the "greatest insight into the hidden mechanisms of nature which has yet been made by the intellect of man” (“Wireless Telegraphy” 287). Not only does he simultaneously praise Hertz and invoke Fleming, but Marconi adds a mystical element to his own work: The "hidden mechanisms of nature"—sending wireless signals—-were now achieved. Marconi's language seems to suggest a way of comprehending these invisible waves, which are part of the built environment, part of technological 
advancement. Later in the popular press Marconi will be shown as a wizard (like Edison and Baekeland) whose efforts are seen as magical because he can conjure up the forces of nature. In his presentation here, it is nature that he is controlling: “A century of progress such as this has made wireless telegraphy possible. Its basic principles are established in the very nature of electricity itself. Its evolution has placed another great force of nature at our disposal” (“Wireless Telegraphy” 287). Marconi’s words "a century of progress” obviously refer to the science of electromagnetism, but, rhetorically, those words connect the wireless to human evolution. After all, nature is at the disposal of humanity.

The scientists Marconi invokes are the "geniuses” who harness nature’s power, and Marconi implicates himself in this important work. In another presentation, Marconi shows that he is continuing in the rich tradition of eminent scientists when he mentions "the memorable researches and discoveries of Faraday carried out in the Royal Institution” (“Recent Advances in Wireless Telegraphy” 131). Since Michael Faraday was the founder of these weekly meetings at the Royal Institution, Marconi's invocation works in two ways:

1) He implicitly links himself with Faraday—-the man who first worked in electromagnetism, and

2) He positions his and Faraday's work in electric communication as an important field—a foundational field—for the Royal Institution.

He finishes his brief historical prelude by mentioning Maxwell’s “wonderful mathematical theory of electricity and magnetism," which was "inspired by Faraday’s work," and explains in the text how, in turn, Maxwell's work influenced Hertz, who "in 1887 furnished his great practical proof of the existence of these true electro-magnetic 
waves” (“Recent Advances in Wireless Telegraphy” 131-2, italics mine). Marconi describes each of the above scientists’ works as “memorable,” “wonderful,” and "great," respectively. In the context of scientific progress these memorable, wonderful, and great accomplishments are gifts to humanity.

Marconi’s brief histories set him up as the next important figure in wireless research: "Building on the foundations prepared by these great men, [I] carried out in 1895 and 1896 [my] first tests, with apparatus which embodied the principle on which long-distance wireless telegraphy is successfully worked at the present day" ("Recent Advances in Wireless Telegraphy” 132). By adding his name to this rich history, Marconi positions himself as an important figure for technological progress. Marconi builds himself into the history of the wireless again by claiming that "a new method adopted by the author in 1898 . . . was a step in the right direction” for improving syntonic wireless telegraphy. Had Marconi not been able to have stations in close proximity without interference, meaning without syntonic wireless telegraphy, “a very important and effectual limit to the practical utilization of wireless telegraphy would be imposed” (“Recent Advances in Wireless Telegraphy” 133). He then explains in technical terms how he was able to correct his system so that transmitters and receivers could be tuned correctly, thus allowing messages to be sent to the correct place without being lost, jumbled, or re-routed ("Recent Advances in Wireless Telegraphy” 133).

Marconi builds his scientific ethos in order to have credibility with the scientific and technical communities. His audience is more inclined to accept his invention's value and practicality (and even existence) if he adheres to the discourse community's "rules" for presenting new knowledge. And presenting a new invention as a viable technology, 
one not (seemingly) as ubiquitous as the radio is today, requires Marconi to present himself as scientifically credible. Wireless signals or, as they were called, "hertzian waves,” were not fully understood in the early twentieth century. Part of Marconi’s discourse is to dispel myths about the limits of hertzian waves by countering with scientific "facts." Building upon the work of those before him helps establish his scientific persona and allows him to be seen as an authority who will accurately portray the wireless; he must become the wireless's mouthpiece, and a believable mouthpiece would have to be scientifically knowledgeable. This necessary part of his rhetoric further constructs the wireless for his audience: It is not a trivial, dubious gadget; instead, the result is a practical apparatus fulfilling a perceived social need ending a century of scientific progress.

His audience is also hearing (or reading) his scientific ethos when he adheres to a few “standard” scientific-paper practices. While Marconi attempts to create a consensus about the science of wireless signals, he does not downplay his involvement in his research except through his use of passive voice and third person speech (which may only be an editorial stance for the journal in which it is reproduced). Still, his narrative borrows the scientific ethos Gilbert and Mulkay describe in scientific papers where conclusions (or accomplishments for Marconi) seem to follow "unproblematically from empirical evidence” (46). Nowhere in the texts does Marconi present the problems or failures he encountered when constructing the wireless. Instead, he offers readers the successes as if they were simply waiting to be discovered. This rhetorical strategy is a necessary component of persuading an audience:

[There is persuasion] through character whenever the speech is spoken in such a way as to make the speaker worthy of credence; for we believe fair- 
minded people to a greater extent and more quickly [than we do others] on all subjects in general and completely so in cases where there is not exact knowledge but room for doubt. (Aristotle 1.2.4)

Marconi's strategy is to portray both him and the wireless as credible. The technology had not yet been universally recognized by the technical community, so Marconi built a scientific ethos while rhetorically constructing the wireless, an emerging technology without “exact knowledge” but much doubt.

The scientific aspects of his presentations are necessary because he is convincing an audience-an interested but skeptical one - that wireless signals do, in fact, exist. Once the technology becomes a regular feature of an established system or tool, the technology does not need to justify its existence scientifically. For instance, the internal combustion engine "runs" on the idea that gasoline can explode in a controlled way in order to drive pistons and other mechanisms to make an automobile move. The science of such a tool had to be hypothesized before the practical application-such as a diesel engine-could be created. The wireless followed a similar timeline. Marconi hypothesized that he could send wireless signals, and his experiments enabled him to see the wireless through to fruition. But before the final application existed, Marconi promoted his "flawless" hertzian wave experiments through scientific rhetoric.

All of Marconi's tests were not successful, but that fact is nearly impossible to extrapolate from his presentations. Even the historical accounts seem to gloss over his failures and present events as if they happened more or less flawlessly (Tarrant; Corrazza; Hancock). Marconi, as would any inventor, had to "try out" different ways to transmit and receive wireless signals. Although some accounts mention Marconi having trouble with a test or tests, the accounts normally claim factors other than the technology 
are to blame (c.f. Hancock; Tarrant). In the 1900 presentation, for instance, Marconi blames human error when explaining why his system was defective during the Boer War in South Africa. Some assistants went to help, "[b]ut when they arrived at De Aar, they found that no arrangements had been made to supply poles, kites, or balloons” "“Wireless Telegraphy” 295). The crew had to use inferior makeshift kites; therefore, "[t]he results which [Marconi's assistant] obtained were not at first altogether satisfactory, but this is accounted for by the fact that the working was attempted without poles or proper kites” (“Wireless Telegraphy” 295). Additionally, Marconi makes it clear that the wireless is still a good system: "It is therefore manifest that [the wireless operators'] partial failure was due to the lack of proper preparation on the part of the local military authorities, and has no bearing on the practicability and utility of the system when carried out under normal conditions” (“Wireless Telegraphy” 295).

The problems above could have been harmful to Marconi's reputation (ethos) and, therefore, harmful to the wireless system. Imagine the public hearing that Marconi's assistants using any apparatus failed to establish communication. Regardless of inferior equipment, observers will perceive the results as a system failure, and that perception would be hard to overcome. Marconi himself states "that if I had been on the spot myself I should have refused to open any station until the officers had provided the means for elevating the wire, which, as you know, is essential to success" ("Wireless Telegraphy" 296). Marconi creates the idea of a flawless invention to convince his audience of its potential existence. Of course, having a viable military application would bolster Marconi's economic potential, so he offers with confidence "that before the campaign is ended wireless telegraphy will have proved its utility in actual warfare” ("Wireless 
Telegraphy” 296). Marconi even foreshadows the wireless’s military usefulness when he invites the audience to "agree with me that it is much to be regretted that the system could not be got into these towns prior to the commencement of hostilities" ("Wireless Telegraphy” 296).

Marconi is positioning the wireless and himself favorably. The scientific ethos he builds is an enhancement to his rhetorical construction of the wireless. But being credible is not enough to have the wireless realized. Marconi must also show how the wireless fit with the social attitudes of his audience. Marconi spoke to the audience's desire for advancement, another cultural trait of Western society.

\section{Cultural Pride through Technological Advancement}

Technological progress is a major trope for modernity. Inventions were seen as progress, and progress was an important cultural variable throughout modernity. Marconi himself presented his invention as a monumental technology, one that would define the future of communication. By claiming that his work with the wireless has enormous, even unthinkable, potential, Marconi adheres to the belief that technological capabilities are beyond comprehension. He also reaffirms the popular belief that technological advancement marks human progress. Contemporarily, one could find a “science fiction” quality in technology being beyond comprehension in the works of $\mathrm{H}$. G. Wells. But what had not yet become part of the mass consciousness was Wells' techno-dystopia or high modernist authors’ concern with mechanization and technological atrocity in war (such as the views of D. H. Lawrence and Virginia Woolf). 
Human evolution appears to be implicit in positive representations of technologies. The wireless's feats became human feats. Marconi portrays the wireless as a "record breaker" to show where his work fit in the history of electromagnetic science and where the wireless would take humanity in the future. Technological progress had virtually no limits, and that realization meant celebration for a culture. David E. Nye mentions how Americans celebrated technological feats, viewing them as sublime. The opening of the Erie Canal and the start of construction on the Baltimore and Ohio Railroad were both firsts that Americans celebrated, and they did so on the Fourth of July (Nye 47). Nye goes on to say "the canal was understood as a product of democracy," meaning the culture shared in the glory of having contributed to its creation (36). Technologies were a part of the national consciousness and new displays were a chance to celebrate human endeavors. Being the first to accomplish or create something is significant; for instance, a person could cross the English Channel by swimming, a pilot could cross the Atlantic Ocean by flying an airplane, or a newspaper could be published in a place where it never before existed. Marconi accomplished all three of the above events using wireless signals, and all were major technological feats.

Marconi's texts also speak to the wireless's place in human advancement when he discusses the firsts in wireless communication. Technological firsts are important to a culture because they are instances of cultural pride. The "first" Marconi mentions in his 1900 presentation is a relatively small one compared to walking on the moon or even sending the first wireless transmission across the Atlantic, but being able to print "a small paper called the Transatlantic Times" was a major commercial step forward for his system (“Wireless Telegraphy” 294, italics mine). This event revolutionized 
communication during travel, and Marconi took pride in announcing that "the first instance of the passengers of a steamer receiving news while several miles from land ... seems to point to a not far distant prospect of passengers maintaining direct and regular communication with the land” ("Wireless Telegraphy” 294, italics mine). Again, Marconi is looking ahead or, more accurately, positioning the audience to look ahead, which is an important rhetorical move for a culture inundated with new technological advancements.

Although firsts can bolster cultural pride, they may also ignite intercultural dispute: When invited to celebrate the wireless's fiftieth anniversary, the Russian ambassador to Rome declined because the Soviet Union had already celebrated the wireless's creation two years earlier by honoring the man they believed to be the true inventor of the wireless-the Russian Alexander Stepanovitch Popoff (Hancock 2). H. E. Hancock refutes that Popoff was the "father of the wireless," claiming "Russian psychology" is to blame for the ambassador rejecting Marconi’s historical significance as the wireless's inventor; but the culture capital of being the first is quite apparent (2). Popoff had technically been the first to send wireless signals, but Marconi is credited with being the first to put the wireless into commercial use, which seems to give him his stature among many biographers (Bucci, Pelosi, and Selleri; Corazza; Crowther; Garratt; Hancock; Jensen; Kraeuter; D. Marconi; M. Marconi; Sungook; Tarrant). The commercial first of Marconi’s wireless allows him “a communicative application for credit-taking” (Jaffe forthcoming). Here is where the technologist "wins” over the scientist according to Aaron Jaffe: “To say that Marconi—or, for that matter, Hertz, Tesla, Popov, Branly, Bose, Lodge, Fleming, Fessenden, DeForest, or Armstrong- 
invented radio is not to say he did so ex nihilo but instead that his name became 'blackboxed' with a certain modification of the application's component configuration” (forthcoming). Additionally, Marconi’s black-box status or "brand” has support from audiences that associate the wireless with him.

Being the first to envision the economic potential of the wireless, or, at least, being the first recognized by history, bolstered Marconi’s credibility. When he discusses his "firsts," he furthers his scientific ethos, allowing his rhetorical construction of the wireless — as a monumental technology — to have more credibility. Here the distinction between the wireless and the radio is most crucial: The radio is a technology that has not been in question in nearly a century; the wireless in its pre-black-box stage needed to be accepted by the technical and scientific communities. Showing his expertise to the electromagnetic community is part of his rhetoric, and Marconi struggles not only with showing his new invention in a positive light, but also with debunking established scientific "truth.” In fact, even Edison, an established techno-celebrity, did not believe Marconi crossed the Atlantic because such a crossing was contrary to the accepted scientific belief that radio waves could not pass through the curvature of the earth (Tarrant 63). Eventually, Edison and the rest of the scientific community revised their earlier doubts and accepted Marconi’s triumph. Therefore, building his scientific ethos was a necessary aspect of his rhetorical maneuvering — speaking as an expert who had to convince audiences that he had a new product that (first) worked and could be used for profitable, practical applications. Later in this chapter I will show how Marconi directly dispels this myth, but it is important to emphasize that his accomplishments, which I have 
no doubt he made, did not stand by themselves. Marconi had to convince the audience he accomplished this transatlantic feat.

Another way Marconi builds a scientific ethos is by detailing his new improvements to emphasize his expertise and success. Marconi describes a "magnetic receiver" that increases the distance of wireless transmissions, thus reducing doubt about his wireless claims. In his 1905 presentation he told the audience about this improvement now being "used on the ships of the Royal Navy and on all trans-Atlantic liners which are carrying on a long-distance news service," and "[i]t has also been used to a large extent in the tests across the Atlantic Ocean" ("Recent Advances in Wireless Telegraphy” 137-38). In other words, Marconi's improvement is already in practical use. He also reaffirms his status within the scientific community by again mentioning that "[I] had the honor to deliver [my] last lecture at the Royal Institution,” when he spoke about the possibility of a magnetic receiver being able to "work a recording instrument" ("Recent Advances in Wireless Telegraphy” 138). Doing so greatly increases the value of his system. Fortunately, "[Marconi] is glad to be able to announce that he has recently been able to construct a magnetic receiver that will work a relay and a recorder" ("Recent Advances in Wireless Telegraphy” 138). Besides having a more commercially viable system, Marconi can also reinforce that his past hypothesis from a previous presentation was correct, thus bolstering any new claims or hypotheses he makes for the future of his wireless telegraphy system. Marconi’s ethos, therefore, is a necessary bridge for showing credibility in order to make convincing future predictions about the wireless's viability. 


\section{Expectations and Current Successes of the Wireless}

The fact that the wireless was an advancement was not enough-Marconi had to show its practical necessity. Was the wireless simply a gadget that amateurs and engineers would tinker with in basements and sheds? Or would the wireless have a commercial value that could be realized by a large portion of the culture? One mission of the Royal Institution and Royal Society of Arts was to promote applications of science. Marconi thus shows the wireless's economic value by illustrating instances where the wireless seems crucial to social practices, often portraying the wireless as a useful humanitarian device. Marconi's wireless did not transform society; instead, it fit into social practice. Because telegraph and telephone wires were already in place, the wireless did not change communication needs—one need being the ability to communicate across vast distances. But Marconi argues for the value of the wireless in three ways:

1. He creates dissatisfaction with current technology, which speaks to the technology’s perceived need.

2. He discusses the current successes and places where the wireless exists even if they are on a small scale.

3. He dispels myths about the technology.

Marconi had to show dissatisfaction with current technology in order to make his new system seem necessary. New technology must work within the current system and fulfill a niche or demand, which is done rhetorically by a "relevant social group." Wiebe E. Bijker’s argument that "relevant social groups” help rhetorically (and physically) construct technologies is important to creating dissatisfaction. Although Marconi, the 
wireless's mouthpiece, spoke to a small audience, his words helped condition relevant social groups such as other scientists, engineers, business people, and the public. These groups had to believe that the wireless was important and then demand it or its services (telegrams, communication, rescue dispatching, and entertainment). Similarly, as Bazerman argues, Edison's marketing had to “create a dissatisfaction with a current technology" in order to induce consumers to purchase it (142). Edison had to create dissatisfaction when he was developing his incandescent light bulb: He showed that gas lighting was inferior to his new electric lighting. In remote parts of the country the new technology meant the difference between light and darkness, but, because Edison was mainly marketing to urban areas using gas or candle lighting, he had to make other rhetorical claims. Many advertisements in newspapers showed that "gas technology had a number of drawbacks": Besides the fear of fires and poisoning, the ads pointed out that electric lighting was more flattering to female beauty (Bazerman 150).

As Edison competed with gas, Marconi had to compete with the technology of cable by showing the wireless as better and more versatile. Cables can only be used to communicate with the two countries between which they are laid,

but if a wireless connection is established between two such countries the stations may be instantly used in time of war, or in any other emergency, to communicate with other stations, situated say, at Gibraltar, the West Indies, or some inland point in North America, and also, if necessary, with war ships carrying apparatus tuned to the waves such stations radiate. (“Recent Advances in Wireless Telegraphy” 143-4, italics mine)

Marconi tries to convince the relevant social group of scientists and engineers that cable has a limited use; also, he subtly warns that the wireless would be necessary if war were to break out. Juxtaposing international wireless communication and war can create an aura of insecurity, and his boast that the wireless is currently used "from Cornwall to the 
Scilly Islands, on the not infrequent occasions of the breaking down of the cables” further constructs cable technology as an unpredictable, unacceptable technology ("Recent Advances in Wireless Telegraphy” 144, italics mine).

In addition to showing cable technology as less secure and less reliable than the wireless, Marconi seems confident “in [the wireless's] ability to furnish a more economical means for the transmission of telegrams from England to America and from England to the colonies than the present service carried on by cables" ("Recent Advances in Wireless Telegraphy” 144). Therefore, Marconi quantifies a "real” value in adopting the future wireless system: It is cheaper than the alternative. Finally, Marconi does not just argue that the wireless is inexpensive; he also proclaims "that some day it would be possible to send messages to the other side of the globe," and that feat would allow "the possibility of carrying out tests of very great scientific interest" ("Recent Advances in Wireless Telegraphy” 145, italics mine). The wireless is not just a commercial instrument better than cable; it is a scientific development; it is progress understood as evolving the human capacity to communicate.

Unless a new technology, such as the wireless, can be shown as superior to current technology, it may fail. Marconi specifically creates dissatisfaction with another contemporary shipping technology/practice when, in his 1900 presentation, he discusses a test between the two vessels the Alexandra and the Juno. In order to create this dissatisfaction, he points out that wireless technology is superior to sight for signaling other ships. Apparently, the Juno transmitted signals from the flagship Alexandra to other ships with Marconi's wireless, which he calls "the system” in this description, and "[t]his enabled evolutions to be carried out even when the flagship was out of sight" 
(“Wireless Telegraphy” 291). Marconi goes on to argue wireless progress and superiority over the current system by claiming “[communication among the ships] would have been impossible by means of flags or semaphores" ("Wireless Telegraphy” 291). Semaphores are visual signals using flags, lights, or a person's arms to display an alphabetical code. His wireless system was superior to existing technologies, implying they are outdated and inefficient.

Besides creating dissatisfaction with current technologies, Marconi also shows that the wireless continues to be improved. Because technological narratives are ones of progress, pointing to "the old way of doing things" creates dissatisfaction. But instead of creating dissatisfaction about another technology, Marconi implicitly creates dissatisfaction with older versions of the wireless. He does this effectively when he describes tests done on commercial vessels. Because these tests show improvement, they are inherently "progressive.” Marconi provides the audience with examples of progress in order to construct a working image of the wireless. Throughout the wireless's invention and even after the radio became a black box, inventors and observers (for instance, assistants and reporters) stressed the range of communication applications. Marconi often refers to increased distances (for transmissions) in his presentation when discussing his wireless's range. Obviously, each development that increases range and quality can be accurately measured and easily reported. Induction coils, for example, used in Marconi's tests allowed signals to travel farther than previous wireless apparatus. In March 1899, Marconi sent signals from "the South Foreland light-house and Wimereux, near Boulogne, over a distance of 30 miles" and “[t]he maximum distance obtained at that time ... was 42 miles” (“Wireless Telegraphy” 291). The July 1899 
"evolutions" between the Alexandra and Juno had "messages [that] were obtained at no less than 74 nautical miles (85 land miles)” (“Wireless Telegraphy” 292). This new induction coil or "tuned circuits" was the famous wireless patent number 7777 (Hancock 19). Marconi brings up some specific tests of the new system and improved distances in his 1905 presentation to reinforce his technology’s progress: While discussing yet another improvement he refers to a time in early 1900 when his system would only transmit 200 miles or less (“Recent Advances in Wireless Telegraphy” 139); by 1902, Marconi shows that the system has greatly improved and messages can be "up to a distance of 2,300 miles" ("Recent Advances in Wireless Telegraphy" 140). Even if the audience knew about other wireless inventors (for instance, Bose, Deforest, or Tesla), Marconi's new patents were improving wireless technology. In other words, he creates dissatisfaction with other wireless systems—even his own older devices.

Marconi expresses the benefits of the new improvements to his wireless in terms of modernist tropes like speed, efficiency, and even automation. This new receiver "is far more simple" and "requires far less attention ... [b]ut the chief advantage lies in the fact that with this receiver it is possible to attain a very high speed of working" ("Recent Advances in Wireless Telegraphy” 138). Marconi's improvement automates the reception of transmissions, "[s]o for as speed is concerned ... this new detector is not dependent upon the ability of the operator" ("Recent Advances in Wireless Telegraphy" 139). Thus, the audience has some dissatisfaction with the former wireless devices. By automating the system (to some extent) and increasing the speed at which the system transmits signals, Marconi illustrates a more efficient system over the previous coherer device: ${ }^{3}$ "In conjunction with Professor Fleming, [I have] recently introduced 
improvements which greatly increase the efficiency of the apparatus” ("Recent Advances in Wireless Telegraphy” 139). Because humans are shown as more inefficient than machines, automation creates dissatisfaction with human involvement. ${ }^{4}$ Efficiency meant the system was streamlined, reliable, and not wasteful; all of those qualities construct the wireless as a viable technology that fits with the time period's Fordist/Taylorist values, especially the perceived economic needs like shipping and, consequently, colonialism. The wireless brought the British Empire closer.

The overall result of creating dissatisfaction with current technologies such as cables and visual signaling and older wireless technology is to foster an ideal representation of the wireless, one that speaks to technology's values. Obviously, efficiency and reliability are important for the technology to "catch on" or become part of the time's reality. But Marconi’s rhetoric manufactures the belief in a potential technology as a real artifact. The wireless, as a potential device, had to be made to fit the culture’s value system. Simply being a "better alternative" to current technology was not enough to show that the wireless was valuable. Additionally, Marconi had to argue for its future potential. The next section demonstrates that the wireless's potential helped create its current value.

\section{The Wireless's Technical Progress and Future Potential}

Marconi often represents the wireless as a technology that has moved forward and continues to advance. Although Marconi briefly mentions in one presentation that “the early development of [wireless telegraphy's] practical application was slow," the contemporary "practical application ... is many times as great as the predictions of five 
years ago" ("Wireless Telegraphy” 288). The new improvements he discusses in this early presentation allow him to repeat that wireless telegraphy is beyond expectation: He could now "convey the intelligible alphabetical signals over distances far greater than had been believed to be possible a few years ago" ("Wireless Telegraphy” 288). Marconi also enhances his scientific ethos during a description of his wireless's progress: He breaks a law (a black box) that relates energy and wire height to the distance a signal may travel. Apparently, Marconi transmitted signals 85 miles, but “[a]ccording to a rigorous application of the law, 72 miles ought to have been obtained ... thus we obtain a greater distance than the application of the law would lead us to believe" ("Wireless Telegraphy" 289). ${ }^{5}$ As he would eventually dispel the myth of wireless signals not being able to travel over the earth's horizon, refuting the mathematical law of wire height to wireless signal distance positions the wireless as a technology not confined to conventional (or even scientific) wisdom.

Showing the wireless as "beyond expectations" gives it the special quality of always being seen as a scientific/technological breakthrough. Such a quality helps Marconi’s “damage control” when he recounts a problem with the Cape Breton station which had many accidents in 1903. Because of the accidents, "the [Marconi Wireless Signal Company, Inc.] decided not to attempt the transmission of any more public messages until such time as a reliable and continuous service could be maintained and guaranteed under all ordinary conditions" ("Recent Advances in Wireless Telegraphy” 141). Although this seems like a failure on face, success is now just around the corner because "[a] new station, supplied with more powerful and perfect apparatus" is being built, and Marconi assures the audience "that in a very short time the practicality and 
reliability of transatlantic wireless telegraphy will be fully demonstrated” ("Recent Advances in Wireless Telegraphy” 142). He argues further that “[p]ending the reconstruction of these long-distance stations, valuable tests have been carried out, and daily commercial work is carried on over distances of about 2,000 miles” ("Recent Advances in Wireless Telegraphy” 142). Because the wireless has such a long reach, "five trans-Atlantic steamships are thus publishing a daily newspaper containing telegraphic messages of the latest news" ("Recent Advances in Wireless Telegraphy” 142). The wireless allowed passengers onboard ships to receive news while traveling just as railroad passengers received news via telegraph wires at different railroad stations (Bazerman 24). This idea of instant news fits the cultural desire to be in constant contact.

Because the wireless is shown to be beyond expectations, Marconi can claim that his system will overcome current problems and improve. One issue he had to counter was the problem with "the daylight effect," a phenomenon that "may cut off [wireless] signals at great distances” just after day break (“Recent Advances in Wireless Telegraphy” 143). This effect is simply the fact that wireless signals do not need as much power to transmit in the night as they do in the day. Marconi allays concerns by claiming he "does not for a moment think that this daylight effect will prove to be a serious drawback to the practical application of long distance wireless telegraphy” ("Recent Advances in Wireless Telegraphy” 142). Marconi does not give the audience a technical or scientific reason as to why he is not worried about the daylight effect on commercial operations, but his assurance might be good enough because he is the expert with personal technical capital. After all, he has proven the wireless to be a scientific 
breakthrough; believing the wireless will overcome "the daylight effect," which may not even be understood by the audience, is completely within reason. ${ }^{6}$

Besides reiterating that the wireless does more than it was expected to do, Marconi has to convince the audience that he actually sent wireless signals using transmitters and receivers outside of view from each other—beyond the earth's horizon. Marconi accomplished this, but, since it was contrary to scientific belief, he had to change the community's belief; he had to establish a new fact and dispel two myths: the myth of the supposed interference of the curvature of the earth and the myth of iron deposits affecting wireless transmissions. Many scientists did not believe signals could be sent beyond the horizon until after his messages crossed the Atlantic. He dispels the idea that "iron in the hills" interferes with wireless communication by claiming such a belief is a "very unscientific opinion": He denies iron was a hindrance when conducting tests with "[a] fleet of 30 ironclads" or "transmit[ting] my messages with absolute success across the very high buildings of New York, the upper stories of which are iron” (“Wireless Telegraphy” 295). This refutation adds to Marconi’s proclamation that the wireless puts the "great force of nature at our disposal" because nature- the curvature of the earth and iron—do not interfere with wireless signals. Marconi also dispels myths by suggesting constant improvements mean that "the technology will work itself out.", Similarly, in this context, the "daylight effect" appears to be a short-term hindrance that will work itself out because he "does not for a moment think that this daylight effect will prove to be a serious drawback to the practical application of long distance wireless telegraphy” ("Recent Advances in Wireless Telegraphy” 142). And the future proved his hypothesis to be correct. 
The importance of dispelling myths about the wireless cannot be overlooked. As the wireless's mouthpiece, Marconi must defend it from others professing doubt: "One of the chief objections which is raised against wireless telegraphy is that it is possible only to work two or a very limited number of stations in the immediate vicinity" ("Recent Advances in Wireless Telegraphy” 132). Marconi counters this objection by explaining his improvement in technical terms and argues that "[t]his objection appears to be much more serious to that section of the public which knows little or nothing of telegraphy in general than to telegraph engineers" ("Recent Advances in Wireless Telegraphy" 132); in other words, Marconi sets boundaries for who may claim to have advanced wireless knowledge by saying "we in the scientific community know better," causing those who believe the myth to think twice. After all, who wants to be seen as unknowledgeable? Marconi singles out another inventor to dispel myths as well. When describing his new syntonic system in 1901, he refers to experiments carried out by a certain Professor Slaby—a lesser known wireless inventor. Marconi dissects Slaby’s supposed experiments by mentioning how he improved upon Slaby's work. Marconi even points to problems with Slaby's system by saying “[t]he reasons which demonstrate that a closed circuit, such as is employed by Slaby, must be a poor radiator, are obvious to those who have studied and read the classical works published since the time of Hertz's experiments” (“Syntonic Wireless Telegraphy” 786). Basically, Marconi portrays Slaby as ignorant with respect to wireless telegraphy fundamentals. Marconi, who was then the most prominent name in the field of wireless telegraphy, attempts to convince the audience that only non-engineers would believe the wireless could not be used with multiple stations in close proximity to each other. 
But what is seemingly more important than the technical explanation of "syntonic apparatus” is Marconi’s affirmation that "[i]t was possible nearly five years ago to send different messages simultaneously without interference” ("Recent Advances in Wireless Telegraphy” 136). Claims about that interference are thus historically inaccurate and at least five years out of date. Marconi shows a technical diagram of the "recent improvement introduced in method of tuning the receiver" ("Recent Advances in Wireless Telegraphy” 136), but, again, he refers to an unknowledgeable audience holding a mistaken belief. He says "[t]here exists at present among the large section of the public considerable misconception as to the feasibility of tuning or syntonizing wireless telegraphic installations” ("Recent Advances in Wireless Telegraphy” 136, italics mine). The issue he is about to address is that of intercepting messages. Although the reasons for Marconi addressing intercepted messages are not completely clear, we can infer that he may have been responding to a criticism of the wireless. "Syntonizing" refers to simultaneously sending and receiving wireless signals. Apparently, there was concern that wireless signals might not reach their intended destination if they happened to be picked up by unintended stations. Marconi corrects the audience-although his words are directed at "correcting” the public—about the "accepted understanding” of what constitutes a truly 'intercepted' message: An intercepted message is not one that is picked up by the wrong receiver; it is a message blocked from the "intended recipient" (“Recent Advances in Wireless Telegraphy” 136). Marconi assures the audience that any wireless signals "tapped or overheard at stations for which they are not intended . . . does not by any means prevent the messages from reaching their proper destination” ("Recent Advances in Wireless Telegraphy” 136). 
This argument may seem strange to those of us in the twenty-first century. His assurance to the audience is not about security or privacy violations (or, for that matter, about identity theft). He claims messages will be received regardless of whether another station "catches" them. His audience, presumably, was not worried about eavesdropping but about missing the message. Bringing up the issue of intercepted messages allows Marconi the chance to counter the concern that signals can be maliciously blocked from the intended station. Although Marconi mentions the possibility that "a powerful transmitter giving off strong waves ... may prevent the reception of messages[,] ... the so-called interfering station is at the same time unable to read the message" ("Recent Advances in Wireless Telegraphy" 136), his main concern is to show "that any telegraph or telephone wire can be tapped, or the conversation going through it overheard, or its operation interfered with” (“Recent Advances in Wireless Telegraphy” 137). He adds that "Sir William Preece has published results which go to show that it is possible to pick up ... the conversation ... passing through a telephone or telegraph wire" ("Recent Advances in Wireless Telegraphy” 137). There is no scientific reason for mentioning cables or telephone wires in this description, but, commercially, if the cable is susceptible to the same “tapping," Marconi’s system is not inherently worse.

Additionally, Marconi also addresses the concern that multiple stations interfere with wireless communications. He foreshadows the future of the wireless by stating that

[t]he ether about the English Channel has become, in consequence of great wireless activity, exceedingly lively, and a non-tuned receiver keeps picking up messages or parts of messages from various sources which very often render unreadable the message one is trying to receive. (“Syntonic Wireless Telegraphy” 786) 
By discussing the crowded "ether about the English Channel," Marconi plants the notion that the wireless is being used extensively. By itself such a statement could mean little, but, for a progressive technology such as the wireless, improvements are bound to develop. Marconi is creating dissatisfaction with his older system, which he has improved. He lets the audience know that he is "now prepared with syntonic apparatus suitable for commercial purposes” (“Syntonic Wireless Telegraphy” 786). Besides just being a useful device, the wireless must be shown to be a profitable one.

\section{Applications and Economics}

Marconi also constructed the wireless as an economically viable technology in his rhetoric. Any technology is necessarily influenced by economic factors: Technologies cost money to develop, make money through sales, and lose money by not fulfilling a niche. Marconi promoted the wireless as a technology useful for social practices and profitable for (current) investors. A profitable technology is an important technology. Marconi spoke to the audiences' desires concerning profitability in forums with a history of using science applications to improve industry (c.f. Noble). Marconi’s presentations speak to these industrial concerns and, thus, create an image of a current and future technology with practical applications. In purely economic terms, Marconi manufactures both supply and demand for the wireless: He creates it, and he fits it into current industries.

The wireless's early potential was evident in the description of its maritime applications and insurance savings. An important component to Marconi’s early success was the interdependency of the Atlantic shipping fleet. Marconi’s repeated sending of 
"S" across the Atlantic Ocean in 1901 worked, but only as a scientific event and not a commercial enterprise. It would be some time still before a reliable commercial transatlantic wireless service could be consistently maintained. No ship apparatus could transmit signals across the entire Atlantic Ocean in 1901 without a relay system. A wireless operator could transmit signals to any ship within range in order to have a message relayed. For instance, if a ship leaving Europe wanted to get a message to an American destination port (or any land station) shortly after leaving its port, the ship would have to contact another ship closer to the destination port; likewise, if a station in the United States wanted to contact a ship just leaving Europe, it would have to send signals to a closer ship that could then relay the message (Hancock 46). Hancock notes that "[p]rogress brought improved apparatus and the need for such charts lessened" as new technology allowed ships farther wireless range (47). The relay system shows how Marconi’s wireless fit into the current cargo shipping industry. Relaying was not new for communication and had been in use since the first telegraph wires. Early telegraph wires needed to have repeaters—stations set at certain distances that would repeat the message in order to send it farther along the wires—because the mechanisms to transmit signals were not powerful enough. Marconi's system was thus based on current communication practices for weak output.

Although this relay system eventually became obsolete, it established the Marconi system as a "standard” brand of wireless technology. By September 1901 "[t]he Marconi system was now in regular and continuous use on” forty-four ships from major shipping companies such as Cunard, Lloyd, and the Red Star Line (Hancock 44). These ships combined with the 54 land-based stations on both sides of the Atlantic Ocean (Hancock 
44) made the Marconi system a well-known tool in shipping. By 1906 about 11 "ships were equipped with Marconi long-distance receiving apparatus capable of receiving messages throughout the whole course of their voyage across the Atlantic” (Hancock 46). By 1907, when “139 ships, British and foreign, [were] fitted with Marconi’s wireless telegraphy apparatus” (Hancock 47), Marconi’s system was already black boxed. But before those commercial milestones, Marconi further constructed the wireless's importance for maritime usage by calling attention to its military (Navy) application.

Marconi concludes his 1901 presentation by highlighting his system’s benefits and future, specifically for the Royal Navy: "As I have already stated, communication over a distance of 300 kilometers is now being maintained with my system ... It may be said that long distances of transmission are not necessarily an advantage, but I notice that the navy wants long-distance apparatus supplied to it” (“Syntonic Wireless Telegraphy” 786, italics mine). Whoever may have said that transmitting over $100 \mathrm{~km}$ is not an advantage is unimportant; in fact, no one may have said it. By stating his system produces and receives long-distance communications and mentioning that the military wants this capability, Marconi excites more than just the technical community: He also increases interest in his company for military applications. Marconi goes on to argue that his improved "25-centermetre-spark induction coil . . . might have been of use to the besieged garrisons in South Africa and China” (“Syntonic Wireless Telegraphy” 784). As a side note, the radio became an important WWI technology and a precursor to RADAR and SONAR shortly before WWII. However, Marconi's early presentations spent little time on military applications (outside naval vessels) and focused more on commercial enterprise. Combat operations were not promoted as a good fit for the 
wireless although Marconi at times implied that the wireless had potential. In fact, early wireless tests by the US Navy (around 1910) were mainly communication tests that enhanced the scientific understanding of radio waves (c.f. Yeang). Although war applications surrounded the wireless's rhetoric, Marconi also represented the wireless as an important safety feature for ships.

Marconi promotes the wireless by arguing that the world needs the safety it affords: "[I]n the future ... humanity is likely to have before very long to recognize in telegraphy through space without wires the most potent safeguard that has yet been devised to reduce the peril of the world's sea-going population" ("Syntonic Wireless Telegraphy” 786). Goods were shipped between industrial nations, but raw materials were also shipped from colonies. High seas communication among different vessels for news and other correspondence made the wireless appear as a new modern convenience. Marconi concludes his 1900 presentation with the following prediction: "[T]he progress made this year will greatly surpass what has been accomplished during the last twelve months; and, speaking what I believe to be sober sense, I say that by means of the wireless telegraph, telegrams will be as common and as much in daily use on the sea as at present on land” (“Wireless Telegraphy” 296). That last speech not only states the future potential of the wireless in commercial terms, but it also reinforces the notion that the technology seems destined to "surpass" even the safety progress of the previous year. Therefore, because of the progressive nature of the wireless, the coming years will produce a technology for safety beyond expectations. This safety device seems to be "right around the corner." Much will be reported in the 1910s about the safety of having 
the wireless at sea (for instance, rescuing those from the Titanic) but Marconi at this point has to rhetorically construct the wireless as useful and life saving.

Marconi discusses commercial safety applications further by claiming the audience already understands the wireless's value and current use; for instance, Marconi highlights that "the system has been in practical daily operation between the East Goodwin light-ship and the South Foreland light-house since December 24, 1898” by stating first "[a]s is probably known to most of you" ("Wireless Telegraphy" 290). He goes on to say that "[i]t is difficult to believe that any person who knows that wireless telegraphy has been in use between” the above locations "without breaking down on any single occasion, can believe or be justified in saying that wireless telegraphy is untrustworthy or uncertain in operation” (“Wireless Telegraphy” 290-1, italics mine). After all, as Marconi points out, the system was installed "in a small damp ship" and "under conditions which try the system to the utmost” ("Wireless Telegraphy" 291, italics mine), which seems to suggest the question "Could you imagine how good the system would be under ideal conditions?” In case the question does not pop into the minds of the audience, Marconi hopes that the government will invest more money into his system so "millions of pounds' worth of property and thousands of lives may be saved" ("Wireless Telegraphy" 291). This call is related to the discussion about how important the wireless is for "avoid[ing] loss of life and property" ("Wireless Telegraphy” 290). In one particular instance, Marconi shows how cost effective his system is with "one short wireless message property to the amount of £52,588 was saved” (“Wireless Telegraphy” 290). 
For the rest of its history, safety and savings would always be wireless attributes. Writing 50 years after Marconi crossed the English Channel, Hancock claimed insurance underwriters as well as cargo transporters saved money because the wireless increased the safety and reliability of shipping (16). Hancock offers an anonymous quote from an "authority” who claimed insurance companies may decrease “"premiums for insurance on Marconi-fitted ships"” (31), which was what Marconi’s allusion to "millions of pounds' worth of property” suggested. All the talk about safety and saving money was embedded in the wireless's rhetoric as an efficient and important system. Marconi spoke to the importance of the system because he was the wireless's mouthpiece, but he was also a proprietor who wanted a profitable system.

Marketing the wireless as a safe, efficient tool has nothing to do with the science of radio waves, nor does it have anything to do with the engineering behind its physical construction. Also, without marketing the benefits and superiority of the wireless over cable, the wireless would not have existed. Safety, dissatisfaction, and profitability of the wireless are independent of the science and engineering upon which the wireless is based. Profitability, though, is vital for the wireless's development. The Marconi Wireless Signal Company was incorporated to profit from the wireless technology it created. In a technology's life cycle there comes a point when "no one is necessary any more to shape the black box” (Latour Science in Action 137). However, prior to becoming a black box the wireless needed Maroni and engineers (or some relevant social group) to "shape" it into a reality. Latour believes that inventors usually hand over the maintenance of a technology to others to allow the technology "to more easily spread" (Science in Action 137). Although Marconi "handed over” some control when he sold his patent rights to 
other companies, establishing himself as the rightful owner of the patents was key to continuing the wireless's profitability. In order to profit from the wireless, Marconi had to secure patent rights, and his discussion on those patents helped him instill himself as the future "father of the radio."

\section{Patents Showing Marconi’s Ownership}

Marconi’s presentations mention his patents by name in order to claim ownership for the wireless's improvements. He uses many diagrams that experts would understand. These schematic representations-written in the language of electrical engineersrepresent the various parts of the wireless system. When Marconi refers to the diagrams, the audience is supposed to understand the various functions they represent. During his presentations he mainly explains what has changed with the new apparatus and does not go into great detail about the function, which is something a lay audience might need. Even though the diagrams are the ultimate jargon of technical discourse-using symbols for coils, coherers, and other apparatus-Marconi’s presentations are accessible, so researchers outside of the electrical engineering profession can uncover social influences in his work.

The 1901 presentation for the Society of Arts, London allows Marconi to assert his ownership. For instance, Marconi describes how he “connect[s] the receiving aerial directly to the earth instead of to the coherer” by referring to a schematic description of “the new methods of connection which I adopted in 1898” (“Syntonic Wireless Telegraphy” 754) in order to do more than introduce the fact that he is about to describe the connection; he is also emphasizing his use and ownership of the improvement. 
Because he "adopted" this method three years earlier, he explicitly states that he is not discussing a theory but a fact. Immediately after he refers to the schematic, he establishes his history in the electrical engineering community by referring to "this improvement in the discourse delivered before the Royal Institution on February 2, 1900” (“Syntonic Wireless Telegraphy” 755), showing that he has addressed the community about his improvement prior to the current presentation. He attempts to secure the idea of his legal rights to the new connection method by specifically mentioning "my first British patent specification referring [to the connection method] was applied for on June 1, 1898, No. 12,326, and published in due course” (“Syntonic Wireless Telegraphy” 755). Marconi refers to this patent three more times in the presentation by always showing possession (i.e., "my patent,” “my British patent,” and “the description given by myself”). He also establishes that he has been working in the field considerably longer than most think: "It may probably surprise some of you when I mention how comparatively long ago some of the patents which I shall discuss to-night were applied for and perfected” (“Syntonic Wireless Telegraphy” 754). This rhetorical signal tells the audience to be surprised that Marconi might not have been given enough credit for being in the field longer. Also, his technical ethos can only be bolstered by showing that he started in the field “comparatively long ago.” These declarations may have little to do with the science behind transmitting wireless signals, but they definitely show ownership and status. Rhetorically, Marconi secures his property through patents and his status through invoking those patents.

In order to further his patent claims as real devices currently in use, Marconi offers the audience a practical success story of his system: 
If the system [of earthed wires] had not been used by me, I very much doubt whether we should have succeeded in maintaining communication with the East Goodwin lightship during 1899, in maintaining communication across the English Channel that same year ... and in supplying the Admiralty in the course of the year 1900 with 32 installations. ("Syntonic Wireless Telegraphy” 755)

Reminding the audience of his commercial successes shows ownership because he is not just showing the patent diagram; he is showing its practical use(s). Also, by implying (or being explicit) that he owns the means to transmit wireless signals, he boosts confidence in his potential commercial success. He legally, commercially, and rhetorically becomes the inventor of the wireless to the audience: Legally, he owns the patents; commercially, shipping fleets use his system; and rhetorically, the company, products, and stations have Marconi in their names.

Marconi cites his patent No. 12,326 as containing "improvements on my original system, which have been in use by myself and my assistants for several years” ("Syntonic Wireless Telegraphy” 755). Again, Marconi implies he is not new to wireless technology, but he also defends himself specifically against two others in the presentation-Professor Slaby, an inventor of a rival system, claims in an article that in Maconi’s system “[t]he receiving wire was suspended insulated and attached at the lower end to the coherer, the other pole of which was connected to earth,” and G. Kapp, who claims only in the "Slaby-d'Arco system ... the receiving wire is earthed" (qtd. in “Syntonic Wireless Telegraphy” 755). Marconi defends his claim that he used "earthed" receiving wires, a fact "openly discussed by the scientific press of this and other countries a long time previous to the date of Slaby’s paper” (“Syntonic Wireless Telegraphy” 755). He continues to prove he used earthed wires by citing other publications and a few diagrams, but his representation is not solely to show the makeup of the wireless; instead, 
he appears to position himself commercially as the true owner of the wireless system. Even though he legally owns the patent No. 12,326, he goes into considerable detail to prove the patent is part of his working system, a technology he has been using for a while.

Understandably, having a working technology as opposed to a non-working (or unverified) theory would lead to more credibility. Inventors had to worry about losing credibility for making outlandish claims. Edison himself overstated claims concerning his "discovery" of wireless transmissions in 1875, and "[h]e labeled the phenomenon the 'etheric force'” (Bazerman 27). Bazerman notes that Edison went to the press too quickly, causing the scientific community to claim his findings were "misguided and overblown," damaging his credibility (27-8).

In order to secure the scientific community's approval or acknowledgement of his ownership, Marconi impresses upon the audience the fact that others incorrectly understand his system. Of course, this idea relates to the previous example I mentioned where Marconi claimed that only the unknowledgeable do not understand the "proper" workings of the wireless. Marconi's presentations were a mixture of scientific and technical knowledge: scientific in that he commented on the science of radio waves (passing around the horizon, unhindered by iron, signaling distance related to height of tower); and technical in that he described the apparatus (coherers, wires, balloons, transistors, etc.) that created those waves. The wireless was not yet a large-scale commodity in the early twentieth century. Marconi’s audience may have been potential users, but most would not have been current users. 
Also, many readers/listeners would have been familiar with the work of other inventors. Marconi refers to Dr. Ambrose Fleming's lecture in his 1901 presentation "delivered before this society in November and December last year" ("Syntonic Wireless Telegraphy” 755). His immediate goal is to explain that "electrical oscillations set up by the ordinary spark discharge method cease" because of "electrical radiation removing the energy in the form of electric waves” (“Syntonic Wireless Telegraphy” 755).

Apparently, Fleming, a prominent scientist at the time, observed "that in the case of conductors of a certain form the electric oscillations die away with great rapidity" (qtd. in “Syntonic Wireless Telegraphy” 755). Marconi further builds a scientific ethos by equating himself with Fleming. He, again, shows that he is "standing on the shoulders of greatness" when he claims that he tried to "carr[y] out a great number of experiments by adding to the radiating and receiving wires inductance coils” similar to a patent held by Oliver Lodge (“Syntonic Wireless Telegraphy” 781). Although Marconi was unsuccessful, he continued to forge ahead and was eventually able to improve his system and patent this improvement "by myself on March 21, 1900, No. 5,387” (“Syntonic Wireless Telegraphy” 781-2). Therefore, his improvement nullifies the benefit of Lodge's patent.

Just as Lodge’s patent was incomplete and untested, so was W. G. Brown's patent on the "use of two conductors of equal length joined to each side of the spark-gap" (“Syntonic Wireless Telegraphy” 782). Marconi mentions Brown’s work only to undermine its importance: "[Brown] did not describe the inductance in series between them and the spark-gap, which, according to my experience, is absolutely essential for long distance work” (“Syntonic Wireless Telegraphy” 782). Marconi implies that long- 
distance communication is favorable, the way of the future. Of course, he also points out how he used certain techniques before others did. For instance, Marconi mentions that "[t]he idea of using a Tesla coil to produce the oscillations is not new" in order to set up the fact that he had been using the Tesla coil in his commercial system since 1898 (“Syntonic Wireless Telegraphy” 783). Although he mentions that others such as Lodge and Braun used such a technique, he points out that "[his] idea was to associate with this compound radiator a receiver tuned to the frequency of the oscillations set up in the vertical wire by the condenser circuit” (“Syntonic Wireless Telegraphy” 783). Thus, he separates his work from the others and further explains the technical details for using transformers and conductors to create these coveted oscillations.

Marconi shrewdly notes "that Professor Braun has recognized the necessity of tuning the circuits of the transmitter and receiver when using a Tesla coil in order to obtain syntonic effects, but I am not aware that such a proposal was published prior to the description given in [Marconi’s famous patent No. 7,777]” (“Syntonic Wireless Telegraphy" 783). The only reason to mention the fact that his system is the first to tune circuits when transmitting and receiving is to show his property, his patent. Although we can figure out the public experiment from his patent numbers, he describes his patents as lab events, showing ownership and demonstrating his technical knowledge. The explanations are mostly devoid of real-world examples; for instance, instead of saying where he accomplished or discovered that "it will not be difficult to transmit to any one of [the several stations], without danger of the message being picked up by the other stations for which it is not intended," he introduces this idea as a hypothetical possibility: "It is easy to understand that if we have several different receiving stations” "“Syntonic 
Wireless Telegraphy” 784 emphasis mine). Although he tested the induction in a lab setting, Marconi's system in 1901 was not strained by simultaneous transmissions. In the future, simultaneous transmissions would be an issue, but they were not at the time of this presentation. Presenting the wireless in this way rhetorically constructs it as a technology that performs a certain way, but it is not quite a viable commercial system.

Marconi brings up another patent in his “concluding” section of the 1901 presentation to return to more criticism of Slaby's work. He cites Slaby's use of a “multiplicator” by claiming Slaby refers to "an especially wound induction coil ('induction-spule'), the function of which is to increase the electro-motive force of the oscillations at the end of the coherer" (qtd. in "Syntonic Wireless Telegraphy" 785). Marconi tells his audience that "[he] assume[d] that the multiplicator was an oscillation transformer performing the function of those described in my patent, dated June 1, 1898” (“Syntonic Wireless Telegraphy” 785). Mentioning his patent here does reinforce his property and accomplishment, but it also sets up a dismissal of Slaby’s experiment; apparently, Slaby claims to have not used "a transformer, as [this multiplicator] has no secondary winding” (qtd. in "Syntonic Wireless Telegraphy” 785). Marconi continues to dissect Slaby’s supposed experiments by mentioning how he improved upon Slaby’s work; at one point he even discredits Slaby’s system by saying “[t]he reasons which demonstrate that a closed circuit, such as is employed by Slaby, must be a poor radiator, are obvious to those who have studied and read the classical works published since the time of Hertz’s experiments” (“Syntonic Wireless Telegraphy” 786). Basically, Marconi is saying that Slaby is out of touch with the fundamentals of the wireless, a claim he later repeats in his 1905 presentation that a certain wireless operation perceived to be a 
problem "appears to be much more serious to that section of the public which knows little or nothing of telegraphy in general than to telegraph engineers" ("Recent Advances in Wireless Telegraphy” 132). As I stated before, Marconi is convincing the audience that "most people know these facts; the unknowledgeable do not.” Marconi finishes discrediting Slaby by telling the audience that he has a better working system that has overcome the "big" difficulties (at least as far as May 1901 is concerned; he is still seven months away from crossing the Atlantic):

Slaby has not yet described how to obtain different messages from transmitters situated at equal distances from receivers, which is much more difficult in my experience, nor does it appear possible with the method he describes to transmit various messages at the same time from one sending wire, as can be done with the system I have just explained. (“Syntonic Wireless Telegraphy” 786, italics mine)

Marconi’s patents secured the legal ownership of his wireless system, but his presentations convey his ownership and knowledge about wireless technology. Although a patent is a form of discourse that represents the wireless's physical nature, Marconi’s presentations reify the idea of the wireless, bringing the physical (via patents and other diagrammatic representations), scientific, and economic aspects of the technology together.

Marconi's presentations show even in the most technical forum, he still speaks to the attitudes and values of the audience and emphasizes the practical potential of his system and not simply the physical make up of the wireless. The presentations are examples of how technology is infused in the workings of a society. The government, with its seemingly endless coffers of tax revenue, needs to support large technological systems in order for these technologies to become realized. Marconi needed the British and Canadian governments to support (and allow) the construction of wireless stations 
and, eventually, hire him to install the wireless onboard naval vessels. Also, he needed important figures (such as the Queen, kings, dukes, the President, and others) to use the wireless to garner the public's attention and the support of policy makers. Again, technology cannot be created in a vacuum. Marconi needed governments to grant him not only the right to perform experiments on their soil, but also to finance part of his system and, eventually, a national infrastructure. In fact, even the Italian government “placed a 7,000-ton cruiser, the Carlo Alberto, at the author’s disposal” to help Marconi carry out some experiments ("Recent Advances in Wireless Telegraphy” 139). This assistance shows that governments are also relevant social groups, to borrow Bijker's phrase, in creating technology.

Although Marconi occasionally and softly criticizes the British government for being behind the times, he immediately says "[I] considered it [my] duty to send the first messages [from Canada] to their Majesties the Kings of England and Italy, both of whom had previously given [me] much encouragement and assistance in [my] work" ("Recent Advances in Wireless Telegraphy” 141). Besides publicly thanking these two important figures, Marconi brings up the possibility of connecting different countries immediately through wireless communication by showing that "[m]essages were sent to His Majesty from Lord Minto, the Governor-General of Canada” and that "a message from President [Theodore] Roosevelt was successfully transmitted from this station [on Cape Cod] to His Majesty the King” ("Recent Advances in Wireless Telegraphy” 140). Having national leaders use new technology does more than legitimize the product; it causes the population, or at least a large portion of it, to recognize the technology as a force in their lives. Many presidents and state leaders have "opened" new technologies through 
ceremonies. David Nye claims that celebrating technology through ceremonies where politicians and other cultural elites gather creates a feeling within the population that the new technology, especially technology that shows off landmarks, “demonstrates how technological spectacle can produce bonds of solidarity” (172). That ceremony helps manufacture a positive attitude for the new technology, which has been constructed in accordance with the culture's values.

Marconi’s descriptions about implementing his system for satisfied customers are major instances where he creates a wireless consciousness. By discussing patents and commercial ventures, Marconi makes the wireless a reality for the audience; knowing that the system is in operation somewhere or that "the admiralty are taking steps to introduce the system into general use in the navy" ("Wireless Telegraphy” 292) reifies at least the belief in the technology because someone is using it. The wireless exists before it becomes commercially viable: Marconi may have been building stations and equipping ships with wireless systems in 1900, but they were mainly for test purposes. After the wireless became a viable technology, it contributed to mass communication. Marconi's scientific and technical descriptions show the benefits not just of a device, but of an international system of communication. Similarly, Edison was not just interested in inventing a light bulb; he wanted an entire electrical system that would guarantee households would be able to utilize the technology (Bazerman 159). Having a system as opposed to a simple tool makes the technology inevitable but only after the technology fits with current technology or practices. Unlike Aramis, which did not fit with Parisian commuter practices, Marconi's system was easily installed on ships that were already crossing the Atlantic. 
Additionally, the new technology begins to take shape within the culture as a representation of the culture's values. Marconi represented the wireless as an efficient, instant communication device. Efficiency and speed—two modernist tropes—speak to the values of Western industrialized nations, and they are values echoed in Marconi's presentation. Having royalty, governors, and presidents embrace these technologies implies that the culture embraces the technologies, which were already positioned according to the goals of the society. Fortunately, for Marconi and other inventors' progress is a value of industrial societies, so positioning a technology as an improvement over "the old way" fits the culture's ideology. The wireless was not yet a realized technology; instead, it was being negotiated by relevant social groups. Marconi created an abstract concept of the wireless through rhetoric, therefore, creating an image of a working, viable technology. Although I don't argue whether the audiences at the presentations accepted the wireless as real, I assume that Marconi's rhetoric was well received because his invention is recorded favorably by history. To continue examining favorably representations of the wireless in the early twentieth century, the next chapter examines how journalists enmeshed in modernist values and practices represented Marconi's wireless in the popular press. 
Notes

1. This presentation is published in two parts in The Electrical Review. Part I is published in the 15 June 1901 issue, and part II is published in the 22 June 1901 issue. Because both are the same presentation, I cite them as one source-_ "Syntonic Wireless Telegraphy”_-but they are listed separately in the Works Cited section.

2. The wireless invention is an engineering product, but sending "hertzian waves" was a science issue for nearly 100 years. However, both scientists and engineers would have been interested in Marconi’s presentations.

3. A coherer is a vacuum tube filled with pieces of iron and used to detect radio waves. Marconi used Edouard Branley's coherer in his early experiments, which was a great improvement over the older coherer invented by Heinrich Hertz. This is one reason I often call Marconi the "assembler" of the radio because he did not invent each component. Instead, he put the components together and envisioned that wireless signals could travel to and from transmitters and receivers.

4. Here I must pause to emphasize that this is a step toward decreasing human involvement in technical systems. Automation eventually removes human inefficiency (and error) by literally removing humans from tasks, but, before total human removal occurs, operational tasks are increasingly reduced to repetitive, simple commands or movements that cause the operator to work in a mechanical fashion.

5. Marconi established this law in a presentation to the Institution of Electrical Engineers-which is now know as the Institute of Electrical and Electronic Engineers (IEEE) - in March 1899 and restates the old law in this presentation. The law states "that the distance over which it is possible to signal with a given amount of energy varies approximately with the square of the height of the vertical wire, and with the square root of the capacity of a plate, drum, or other form of capacity area" ("Wireless Telegraphy" 289).

6. "The daylight effect" is the phenomenon whereby radio signals travel farther at night than during the day. Marconi and others knew about this, but did not understand why. In his Nobel Prize lecture, Marconi believes this effect has something to do with clear skies (“Wireless Telegraphic Communication” 211). However, long-range radio signals travel farther and stronger due to the fact that radio waves bounce off the Earth's ionosphere better at night. This does not work, however, for later FM transmissions.

7. This is similar to the phrases we often use: "eventually they'll produce computers that can perform miracles." I remember in the early 1990s while in high school taking a computer programming class that a math teacher of mine said, “all of you won't have to worry about spelling because in the future word processors will automatically correct your misspelled words as you type.” Of course, the autocorrect function is not perfect because it often "corrects" what we do not want changed. 


\section{CHAPTER III}

\section{POPULAR PRESS REPRESENTATIONS OF MARCONI'S WIRELESS}

The development of some varieties of municipal engineering is absolutely dependent upon the development of public opinion and must proceed with it. The matter of street cleaning is largely a question of an improved public taste in the matter of street paving. Unless streets are well paved they cannot be well cleaned except at a prohibitive cost. To jump from one degree of cleanliness in this respect, to another, without a supporting public opinion, may be enough to wreck an administration and to set the tide of civic improvement running in the opposite direction. The newspaper is a great educator in these matters today. Morris Llewellyn Cooke, "Paving Propaganda” (61)

In the early twentieth century, Marconi's wireless excited journalists on both sides of the Atlantic. Although his invention was not yet commercially viable or universally accepted, many relevant social groups affixed positive meanings to it. After Marconi demonstrated the wireless's potential in his technical presentations and physical demonstrations, journalists reconstructed the wireless for larger audiences. Many set out to promote Marconi’s “triumphs” in their periodicals. Even advertisers used “the wireless” to promote products: In the March 1903 issue of World's Work, an advertisement for Pears’ soap boasts of “A Wireless Message Across the Atlantic ... Sent 20 Years Ago” (Fig. 1). Positive representations of the wireless allowed readers “a glimpse into the future,” just as David Nye argued World’s Fairs did (205). Marconi’s invention and presentations appeared in periodicals as news events with much of the technical information removed or described differently for a lay audience; however, the popular press articles share several qualities of Marconi’s presentations. 


\section{AWIRELESS MESSAGE ACR0SS the ATLANTIC}

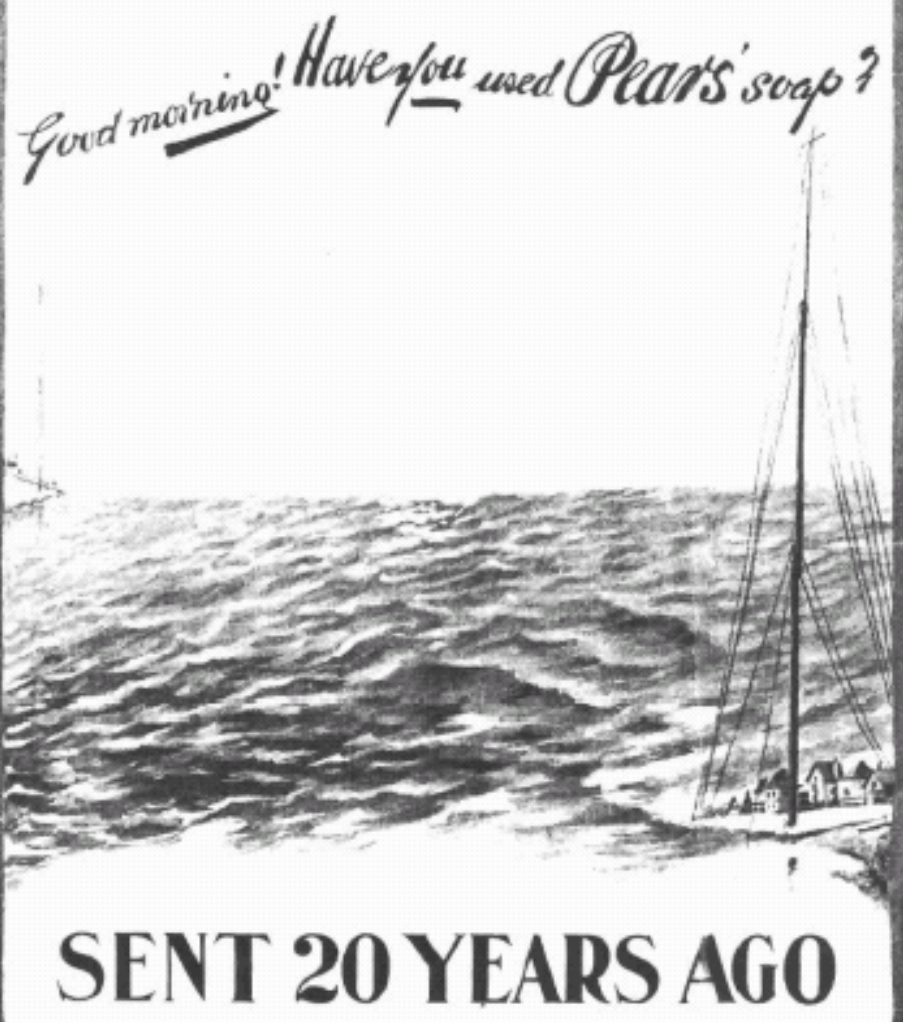

Fig. 1. Pears’ Soap advertisement (World's Work Mar. 1903: 3047).

This chapter demonstrates how pro-Marconi popular press articles used tropes of progress to reconstruct the wireless in 13 articles from the following American periodicals dated from 1899-1905: McClure's, World's Work, Current Literature, Frank Leslie's Popular Monthly, Living Age, North American Review, and The New York Times. Although Marconi was not an American, these American popular press articles show how Marconi’s experiments and potential thrilled journalists. This response is important because, though a British company in competition with other American and European 
inventors, Marconi and the Marconi Signal and Wireless Company emerge as the individual and company most responsible for bringing wireless technology to the world. History records Marconi as the "father of the radio," and American periodicals are one place where this status materializes. Their articles discuss similar international events and help trace the process by which the wireless and Marconi’s status become instantiated in the culture: These representations suggest his wireless fit with prevailing cultural values, attitudes, and practices of the early twentieth century. The articles mainly focus on Marconi, the man, his wireless feats and records, and his invention's future potential. While the wireless was not Marconi’s invention alone, the popular press represented it as his invention, helping solidify his future title of "father of the radio." These reconstructions also show the wireless as a progressive technology more efficient than contemporary alternatives. The wireless, consequently, reflects the social attitudes and values of the Industrial Revolution—specifically, the early twentieth century's technophilia. According to many journalists, the wireless would usher in a new communication standard and free humanity from physical wires or cables.

The following sections of this chapter discuss the importance of the popular press as a relevant social group, the instances where Marconi's persona is positively ascribed, the ways the popular press described the wireless as monumental, and the visions/prophecies of wireless benefits. First, the popular press is an important relevant social group because its texts represent the wireless's image and, therefore, its reality prior to becoming a black box. Second, the popular press constructed Marconi's trustworthiness just as how he himself built a scientific ethos in his presentations: Both construct Marconi as an important cultural figure. Finally, just as Marconi envisioned 
future practical applications for the wireless, journalists also reconstructed the wireless's value by discussing its potential. Interestingly, the popular press proclaims that the wireless’s potential is “beyond expectation” much more boldly than even Marconi.

\section{The Relevance of Journalists and Their Descriptions of the Wireless}

Before discussing the "relevance" of journalists, I need to explain what I mean by “popular press,” which distributed journalists’ contributions. Journalists fulfilled an important role as a relevant social group because they constructed the news. According to Bazerman, “[n]ewspapers are the daily world gathered into words and pictures” (2). Bazerman discusses the importance of the “emerging world of news” for Edison’s inventions: As technology allowed greater contact via telegraph communication, “journalism turned from small circulation partisan commentary to mass-circulation retelling of the happenings of the world” (23). Journalists captured “[e]vents that happened anywhere ... everywhere ... or nowhere (like the promise of a new invention)” (Bazerman 23). I refer to the journalists' texts on Marconi’s wireless as the "popular press" because I want to stress the popular nature of this particular venue. As Bazerman points out, the press "became a new kind of stage” for representing “technological advance[s],” one that popularized inventions and inventors (23).

Although I do not argue specifically how audiences received the wireless's popular representations, from journalist's descriptions of Marconi’s wireless, I have found descriptions that adhere to prevailing cultural values. These accounts do not represent all wireless-based journalism; instead, they reflect how pro-Marconi descriptions conveyed the wireless's image as a new, efficient marker of progress. 
While no discourse holds a technology's total value, texts from different genres reflect some of the cultural work a technology does. For instance, contemporary media report work on the supercollider, virtual reality systems, spacecraft for civilian travel, and even “wireless” Internet access. Also, commonly reported, not-yet-available scientific products are abundant in popular press reports on potential medicines/treatments. One need only recall that often repeated phrase about a medical breakthrough reported on the nightly news that is "pending FDA approval" to understand the parallel between the wireless prior to becoming a black box and a forthcoming medication or vaccine. ${ }^{1}$ Although audiences did not need a consistently working wireless model as proof, they needed to be told the wireless was coming or in use somewhere in order to accept the technology. Fortunately, the public "loved" the wireless because the press promoted it, at least in part, in accordance with their values and expectations. This dissertation does not argue that the public wholeheartedly believed Marconi’s truthfulness or that the wireless was a physical reality but that popular press accounts act as a cultural repository where the wireless "existed."

All texts about technologies are sites for negotiation. Even though I do not argue specifically how or to what extent audiences believed in the popular representations, the articles I examine fit the early twentieth century's progressive industrialized ideology. These articles convey that cultural work; therefore, the journalists are an important “relevant social group.” They described an exciting new scientific breakthrough-a "human” advancement. As David Nye argues, technological achievements are important cultural markers that transcend nationality and excite or electrify the cultures in which they are invented (xiii). Although Marconi was an Italian subject doing most of his work 
for his British company, American journalists capture or report the sublime effect the wireless had on them to the public. The wireless bridged the Atlantic and made the world "smaller"; it was not contained within a single society but spread from Britain to Italy to the United States to Hawaii to Japan and even to Africa. The international reach seems to be a marker of progress for the industrialized Western World, causing American periodicals to celebrate a foreign invention. ${ }^{2}$ Even Henry Adams "would have hugged Marconi” out of reverence for his invention as he stood awe-struck in front of the great dynamos at the 1899 World's Fair (380).

The emerging interest in science and technology in the early twentieth century is apparent from popular press descriptions, suggesting that scientific and technical subjects were of interest to wider audiences. In the previous chapter, Marconi’s presentations were meant for highly technical audiences—-people judging the physical viability of the wireless. Although non-scientists and non-technologists attended the Royal Institution and the Society of Arts lectures, they were not peer reviewers. The popular press coverage suggests what a culture (in general) found worthy to follow, and the wireless was important news. The articles were not for science and engineering discourse communities, but the journalists validated the wireless by reifying it in a popular forum. To popular audiences in the early twentieth century, machines were wonderful (even liberating) inventions—although, many high modernist artists would later lament the dehumanizing mechanization of consciousness and human labor. The popular press articles I examine contain no hint of mechanical dehumanization, environmental degradation, or human alienation. Quite the contrary. Journalists provide glowing 
accounts and possibilities for the wireless; the only negativity is towards "outdated" technologies about which they create "dissatisfaction.”3

Although anti-Marconi articles exist, their attempt to dissuade the public from holding Marconi in high regard ultimately failed. In fact, one quasi-critical article about the wireless praises Marconi's "wonderful achievement of transmitting a message across the Atlantic," but claims that tests "in the Mediterranean proved a 'total failure”" (“Wireless Telegraphy,” Current Literature 3). Nevertheless, the article does not conclude negatively. Instead, it connects optimistically about the new wireless technology because "[m]odern ingenuity is not daunted by the failure of experiments, but takes new courage from defeat, and triumphs in the end" ("Wireless Telegraphy," Current Literature 3). And many popular press articles connect Marconi to this "triumph."4

Journalists constructed Marconi as the main inventor in a group of important world-renowned figures: "Lodge, Fleming, Muirhead, Fessenden, de Forest, Tesla, Ducretet, Rochefort, Guarini, Popoff, $\left[{ }^{5}\right]$ Arco, Brann, Slaby” (Waterbury 656). This portrayal creates an image of the soon-to-be "father of the radio." One journalist commented that "in many cases [wireless] patents show that there have been independent discoveries of exactly the same thing in different countries at practically the same time" (Waterbury 656). However, Marconi’s importance as the main inventor is apparent when one article notes that "a dozen or more people have sprung up to share or to attempt to obtain the glory of originality," but "Marconi stands unquestionably at the head of the list” (“Recent Wireless Telegraphy Development” 419). I avoid patent-battle articles and focus on descriptions of Marconi's wireless's events and uses because the legal 
construction is not valuable for my study of rhetoric aimed at a popular audience. While rivals had their own national and international attention, these other systems did not receive the same "buzz" contemporarily or historically. The journalists helped construct Marconi’s system as a benchmark even though he “compiled” his apparatus from his own work and the inventions of others. Other systems and apparatus existed, but they existed as just that—other — or other-than-the-benchmark standard according to the popular press. $^{6}$ The articles describe Marconi’s invention's profitability, usefulness, scientific importance, and improvement over cable — the existing "inefficient" technology of the time period. They also construct Marconi’s image.

\section{The Popular Press's Apotheosis of Marconi}

The popular press constructed Marconi as an almost royalty-like celebrity. The King of Italy bestowed in 1897 the title chevalier, which "correspond[s] to an English knighthood” (A Friend 529). Much later in his career he was reported as having received the Italian nobleman title of Marchese in 1929, and "King George V conferred upon him the Honorary Knighthood of the Grand Cross of the Victorian Order” (Hancock 163), which establishes his historical significance. His royal status began almost immediately after his first public experiments. Marconi’s apparatus, even though not commercially viable in the early twentieth century, had famous users, adding to its status as an exciting, important invention. The popular press made many reports about wireless transmissions between the Queen of England and her son (the future King Edward VII), and later the press reported messages between Theodore Roosevelt and King Edward VII. One article reports that transmissions between the Queen and Prince "were the memorable tests ... 
between Osborne House, on the Isle of Wight, and the royal yacht, with the Prince of Wales aboard" (Moffett 4). Such descriptions invoke the wireless as an invention for royalty.

After crossing the Atlantic Ocean, as one article claims, "[t]he people of the 'ancient colony' of Newfoundland . . . crowned [Marconi] with every honor in their power," and that "it seemed as if every fisher and farmer in that wild country had heard of him ... at twenty-three he was famous the world over” (Baker 4, italics mine), despite the fact that his fame was probably concentrated in Europe, America, and the colonies. Henry Herbert McClure portrays Marconi’s elevated status by noticing that "Marconi’s party occupied four staterooms on the upper deck" during wireless experiments aboard the Philadelphia (526). Marconi and his "party" carried out the experiments in one of the rooms, but occupied the other "upper-deck staterooms" as would any high-class celebrity.

This attempt to promote Marconi as "royalty” helps lend importance to his system. The wireless was a newsworthy event, which meant Marconi, the man who brought the wireless to the world, had celebrity-like attributes. Furthermore, these reports on Marconi’s status reinforce his magical character. After all, sending invisible waves would have been magical for this early twentieth-century audience. ${ }^{7}$ Other inventors also had magician-like qualities in the popular press. Leo Henricus Arthur Baekland, who invented "the first truly synthetic plastic” (Bijker 101), was described by the popular press as a “'grand duke, wizard, and bohemian’” (Bijker 197). Although Bijker argues that the "wizard" attribute distorts the social construction of a technology by possibly portraying the invention as "the development of ... the genius of" an inventor (197), the magical aura described recurs in popular press accounts, especially 
those accounts that identify a single inventor of a new technology. Edison was popularly known as the "wizard of Menlo Park," and Marconi similarly was often attributed with magician-like qualities. ${ }^{8}$ For instance, one article specifically describes Marconi’s wireless's ability to transmit invisible waves through the "ether": "Electric waves cannot be seen, but electricians have learned how to incite them, to a certain extent how to control them, and have devised cunning instruments which register their presence” (Baker 6). Therefore, Marconi, the electrician whose system was being described, can manipulate nature.

Marconi makes the invisible a reality through his "cunning” apparatus and magical quality. Another popular press article describes Marconi as a "wonder-worker" and "an audacious experimenter," which, combined with the idea that he is "a man who has largely complemented whatever promises he has made” (A Friend 530), suggests his limitless potential as an inventor. Andrew Carnegie establishes that Marconi’s persona and power are beyond the audience's imagination: “"No one can tell or even dream of what tremendous things he will be able to do in a few years"' (qtd. in Wallace 1). While commenting on Marconi's transatlantic feat, one article establishes that even though the world "accepted that [Marconi] was now preparing for bolder ventures ... none imagined a project so amazing as he entertained" (A Friend 530).

These popular press accounts, therefore, help establish the wireless—or, more appropriately for 1899-1905, the science of radio waves—as a reality; Marconi created or discovered knowledge, and "to the world, what was hardly a probability three months ago is now an undisputed fact" (McClure 526, italics mine). McClure's comment comes from an article reporting on a new advancement circa April 1902 and is explicitly stating 
a "truth" for the audience: Marconi has discovered, created, and established a "fact." Another article underscores the perceived need to show an inventor's trustworthiness because "at present one certainly takes the public into one’s confidence when one sends a wireless telegraphic message” (Waterbury 658). Wireless signals are invisible—-they cannot be seen or heard. In contrast, the public can see or hear "the construction of ships, the transmission of sound, the detonation of explosives, etc.” (Waterbury 658). Because wireless signals are intangible, discourse must construct their existence, so Marconi’s celebrity and pseudo-royalty status help create his image, which, in turn, helps establish the wireless's potential for the audience.

The popular press reporting a transmission as "fact" further adds to the excitement surrounding the wireless. Because industrial nations had a growing scientifically and technically aware population, journalists create almost fantastic stories about new technologies to excite readers. The fact that so many popular press accounts about Marconi's experiments exist is one testament to the excitement he created. One journalist remarks that "the world throbbed with the surprise of his [crossing the Atlantic], and the cables were loaded with congratulatory messages to him” (A Friend 532). Additionally, periodicals would preview up-coming experiments or interviews with inventors alongside advertisements for adventure novels and other sensational bestsellers to be printed: McClure's Magazine advertised between a review of Robert Louis Stevenson's St. Ives and Anthony Hope’s sequel to "The Prisoner of Zenda" that a future issue would have an interview with Marconi and J. Chandra Bose. ${ }^{9}$ The fascination and awareness of important new technologies was not new in the early twentieth century. World's Fairs had been exciting people for decades. But machines had a superhuman quality to them, 
and many popular press accounts insisted the audience ought to trust a technology over a human. In fact, journalists portrayed Marconi himself as a machine, a characteristic that allows him to succeed: “[T]he keynote to [Marconi’s] success is his unfailing industry and energy. He is a human dynamo" (A Friend 532). Dynamos were the computers of the time period.

But accolades would not have had the same force in print had Marconi not been seen as trustworthy. Years of reports and even contact with wireless apparatus might have reified Marconi’s “miracle,” but journalists help construct the wireless by filtering Marconi’s credibility. The popular press builds Marconi's scientific ethos by praising his great scientific/technical mind and builds trust by pointing to his careful nature when revealing success to the public. Edison also developed public credibility, allowing him to claim he had a working light bulb nearly a year prior to a completed prototype "and an additional year before a full system was ready” (Bazerman 13). Bazerman argues that "the meanings people attributed to [Edison] were embedded in specific and welldeveloped systems of communication that made his work seem credible” (13). Therefore, Edison had to have an aura of credibility to help establish his invention as extant or possible. As was often the case for Marconi, his credibility establishes that the invention is "just around the corner." Belief is enough for a technology to exist rhetorically. Marconi's wireless's rhetoric necessarily establishes his invention, for the popular press argues his truthfulness and dependability, suggesting that he will continue to improve his invention.

Many popular press articles tout Marconi’s record for not making bombastic claims about experiments and his potential for future development. One article claims 
Marconi and the wireless share the following "confidence” for future progress: “[W]ith an assured achievement and practical daily working of 200 miles, and an experimental success of 2,000, it is beyond dispute that Marconi's work warrants the confidence which enthusiasts have in its future" (A Friend 533, italics mine). Another article claims that Marconi’s truthfulness “unquestionably carried great weight in convincing Mr. Edison, Mr. Graham Bell, and others of equal note of the literal truth of his” experiments (Baker 4). Major S. Flood Page (Marconi’s assistant) reaffirms Marconi’s credibility in the popular press by stating that Marconi "has never made any statement in public until he has been absolutely certain of the fact: he has never had to withdraw any statement that he has made as to his progress in the past” (qtd. in Baker 4). While reporting Marconi’s claim that it would be possible to "establish wireless communication between San Francisco and Manila without an intermediary station at Honolulu or Wake Island,” the journalist points out that "Mr. Marconi has never been known to say that he could do a thing which he either had not already done or very shortly did do” (Wallace 4).

Marconi's trustworthiness is constructed as "business success." The popular press made the wireless seem to be destined to work out its flaws, with a final product beyond the readers' imaginations. Similarly, one article assures readers that Marconi will fulfill his promise of creating a wireless station in Nantucket that will allow for consistent, reliable transatlantic transmissions: "It is the first prophecy that Marconi has made since he began his work in wireless telegraphy seven years ago. He has not failed before. Few believe that he will fail now" (McClure 527). In effect, the article attempts to recruit the audience to believe in Marconi's invention. In April 1902, when that article was published, Marconi's work was mainly experimental, but it existed as a viable idea 
with the article's reassurance that Marconi spoke the truth and could not fail. This and other reports help establish Marconi’s trustworthiness and help establish the wireless as a “real” technology, partially by using Marconi’s personality and celebrity status to build the wireless's image as an actual technology progressing to better levels.

\section{Popular Press Representations of the Wireless as an Important Historical Development and Progression of Past Science}

Much like Marconi builds a scientific ethos by showing himself as continuing the important work of past scientists, the popular press often shows Marconi's work as a continuation—a progression—of past science. In one article, the author ${ }^{10}$ recognizes a simple version of "wireless telegraphy" existed before Marconi, "for a score of inventors had preceded him ... and Heinrich Hertz, the famous German savant, had proven that” wireless signals could be sent (A Friend 531-32). But the article goes on to claim Marconi kept persevering “and spent five years before he solved the [early wireless] difficulties” (A Friend 532). In other words, Marconi continued from the point where others, according to the article, had stopped. Such an account contributes to the "lone inventor myth” because it never names other inventors from whom Marconi compiled various components to use in his wireless apparatus. ${ }^{11}$ This omission adds to the ahistoricity of technology (an important component of F.T. Marinetti's "The Founding and Manifesto of Futurism”): Although journalists may discuss past science, they do not usually write about the many other specific contributors to an invention. Marconi is often given credit for the entire wireless in popular articles; he is perceived as being the most important inventor because he created a commercial enterprise for the wireless. 
Therefore, the popular press accounts are as much about Marconi, the man, as they are about the wireless.

Several authors of this time period-literary, popular, and artistic_-portray machines as all powerful. While describing the power required to send wireless signals, one journalist shows his awe of the telegraphic spark by claiming it to be "as thick as a man’s wrist . . . the most powerful electric flash yet devised” (McClure 526). The journalist goes on to claim "the very ground near by [the spark] quivered and cracked with the energy," and “[n]o human being could stand near the huge coil which produced this tremendous flash of lightning” (McClure 526). These texts show the "power” and “energy” needed to transmit signals across vast distances. Therefore, the image the popular press creates is one that positions the wireless as real and monumental. These larger-than-life accounts of the wireless praise Marconi and his invention, a machine.

Machines also add validity to Marconi’s experiments. After observing Marconi’s transmissions from land stations to the Philadelphia, which were captured by a recording tape, H. H. McClure argues for the transmission’s authenticity because “[w]hen a machine does a thing, we humans believe; so long as a man stands between, we doubt” (525). That is, humans distrust what they perceive as human inefficiency; a machine, in contrast, is trustworthy and accurate because “there [is] no human agency to 'think' or ‘imagine,' and perhaps err” (McClure 525). Another writer also argues that machines are better "from the fact that a record on a tape is quite independent of what any man with a telephone thinks he hears” (Waterbury 660). Even Marconi’s system, which “was successfully established among the Sandwich Islands . . . failed through unreliability caused [solely] by lack of skill among the native operators” (Waterbury 661). The 
machine, the wireless, was not to blame-the human operators were. While Henry

Adams' account of the awesome power he felt from the dynamos shows how many in the late-nineteenth century worshipped machines, these popular press accounts tell us that some saw technology as superior to human interpretation. Machines are seen as more accurate and, therefore, more useful. Such a view reaffirms dominant progress tropes of modernism such as speed and efficiency. The wireless was a new marker of human progress. The popular press uses exciting language to describe the wireless and attempts to "prove” the wireless’s importance by discussing its current usage and “obvious” future potential.

The biographical literature describes Marconi as a genius for being the "first" to create a viable technology. After envisioning the wireless's potential, which came to him after he read an article by his former professor Augosto Righi, Marconi set out to make a practical, commercially viable invention (Hancock; Tarrant). However, though many popular press accounts describe past scientists who developed theories about radio waves, they begin with Marconi as the inventor of the first practical apparatus; and it is this practicality that privileges Marconi’s status as the inventor of the wireless. In fact, even more technical journalists overlooked Marconi’s contemporaries: In a 14 October 1898 article from The Electrician, the author solidifies Marconi's preeminent status as the wireless inventor:

For some considerable time the scientific aspect of this development (Hertz and Clerk Maxwell) completely obscured its more practical applications. Scientists were so charmed with the experimental evidence it afforded as to the validity of Maxwell's electromagnetic theory, that for many years the fact that these experiments possessed any practical value as a means of signalling between two pieces of physically, mechanically disconnected apparatus almost escaped their notice ... All honour is due to Marconi for having been the first to bring prominently forward before 
official bodies and the public the possibility, and, indeed, the eminent practicability of using Hertzian waves for telegraphing between two places not connected by an electrical conductor. (Reprinted in Hancock 67 , italics mine) $)^{12}$

The science may be the work of others, but the practical invention is Marconi’s.

Although Marconi appears as the sole inventor, articles also suggest Marconi’s modesty. Many articles establish that Marconi "makes no claim to being the first to experiment along the lines which led to wireless telegraphy ... . it remained for Marconi to perfect a [wireless] system and put it into practical working order” (Baker 5, italics mine). One journalist notes that many other inventors helped contribute to the wireless's invention but argues that "Marconi's discovery gave the clue to practical and useful ranges; he was the first to see the commercial value of Wireless Telegraphy, and the Marconi Company was the first company in the field to exploit the new discovery” (Waterbury 656). Several pro-Marconi popular press articles agree with the above ones but make it clear to the readers that "[Marconi] deserves all the credit the world can give him for making the idea of such great practical value” (Wallace 2).

Occasionally, eminent scientists who would write about Marconi’s status in popular periodicals would not ignore other contributors as journalists often did. Professor John Ambrose Fleming, Marconi’s friend and mentor, minimizes the contributions of Marconi's contemporaries and portrays Marconi as the inventor who had the vision for commerce. Professor Fleming (later Sir John Ambrose Fleming) traces the “world's" knowledge of ether as a conductor ${ }^{13}$ from "Prof. J. C. Maxwell," who "left as his most splendid intellectual legacy to the world his remarkable Electro-magnetic Theory of Light" (632). He notes that this electromagnetic science is "research of the present century” (631), a point Marconi borrows in his 1900 presentation discussed in the 
previous chapter. Fleming covers Clerk-Maxwell, Faraday, and Hertz-the past electromagnetic scientists—in detail, but he simply lists Marconi’s contemporaries: “Lodge, Fitzgerald, Trouton, Savasin, de la Reve, Bose and many other physicists extend[ing]" Hertz's research (636). Fleming portrays Marconi as the major wireless technologist “[s]tarting from [the scientists'] known facts” (636). Marconi’s experiments mark the beginning of what Fleming calls "the Ether Age" (640): This new age marks human progress, and Fleming, writing in May 1899, foresees the twentieth century as a period of time history will judge according to the wireless's ability to produce practical applications associated with "the ether waves we are learning to employ" (640). Interestingly, Marconi's crossing of the Atlantic appears to be the end of historical discussions of past scientists in the popular press. This situation may be due to the fact that the wireless's Atlantic crossing solved an important question: Could wireless signals make it around the Earth's horizon? The only exception to this omission is in a June 1902 article in McClure's Magazine that briefly discusses Clerk-Maxwell and the fact that Hertz stumbled upon his own theory while "trying to disprove ClerkMaxwell's theory” (Wallace 1). The article even lists contemporary inventors who tinkered with Hertz’s experiments, but argues “it remained for the young Italian (Marconi) to jump across the gap of years of scientific study and make practical the most important discovery since Faraday invented the induction coil” (Wallace 2, italics mine). Other inventors such as Varley, Calzecchi-Onesti, and Branly created imperfect coherers based on Faraday's coil, but Marconi perfected those gadgets and "began then a series of experiments which would have discouraged any less determined man” (Wallace 2). Although Hertz, Faraday, and other non-contemporary “electromagnetic” scientists are 
mentioned in glowing accounts of Marconi, their inclusion still does not diminish Marconi's status. Other articles attempt to "shed light" on contemporary inventors, but rarely do they try to supplant Marconi as the main wireless inventor. ${ }^{14}$

Being seen as the sole inventor is part of Marconi's charisma, and charisma is important for inventors being perceived as trustworthy and capable. Charles Bazerman argues that "Edison was the charismatic center of the organizations that formed around him” (259). Bazerman goes on to argue that Edison’s "first institutions to develop, manufacture, and disseminate his system of delivering light and power were built on the force of his authority and the trust he granted his close associates"; his charisma, therefore, built the foundation of his corporate legacy (259). Bazerman uses Max Weber's theory of charisma as an aspect of authority: Followers place their “'personal trust in the leader's revelation, his heroism or his exemplary character'” (260). The authority in the relationship of chief inventor to assistant inventors mirrors Marconi's authority in the popular press. The articles promote Marconi as trustworthy, which acts as proof of the wireless's future applications and current existence. Marconi most likely had charismatic power over his close associates, but the popular press uses his wordsjournalists often quote Marconi in their articles—-to construct the wireless's potentiality for their audiences. Marconi, the inventor, is as important in the popular press accounts as his invention.

The popular press helped rhetorically construct the wireless's potential black box status (the future radio) by presenting its monumental nature. Long before DC Comics' Superman excited audiences with his super powers, Marconi "leaped the ocean at one single bound" (A Friend 529). His crossing of the Atlantic inspired writers to portray 
him as a "latter-day Columbus, with the same splendid daring, [who] faced the broad expanse of waters to demonstrate another mighty scientific fact" (A Friend 529, italics mine). Fleming comments that "[p]ublic attention, on both sides of the Atlantic, has recently been strongly directed to the possibilities of telegraphy through space, by remarkable experiments of Sig. G. Marconi” (630, italics mine). Fleming writes just after Marconi crossed the English Channel, but he prophesizes the potential of Marconi’s work as "the crowning achievement in a long series of scientific labors" (631). Another journalist believes the wireless has yet to reach its full potential, but even a limited invention would still be good: "Let his system be limited to but one hundred miles, and within that radius it will develop inestimable services" (Iles 1785, italics mine). The image constructed is that of an inventor and invention unbounded by any constraints. The journalists wrote about Marconi's wireless as if it were a black box, but it was not even viable for transmitting across the Atlantic at the time on a regular basis.

Marconi mainly conducted scientific experiments during this early period; he was still “tinkering” with his apparatus—boosting its transmission capacity. Even his crossing of the Atlantic was a kind of tinkering but on a scale much larger than when he conducted his first experiments "transmitting messages over distances of a few miles" back in Villa Grifone, the enormous estate near Bologna, Italy where Marconi grew up (Tarrant 22). With the Atlantic experiment, though, his international tinkering made news, and journalists rhetorically constructed the wireless through their accolades. One article praises the wireless (specifically, the crossing of the Atlantic) as unimaginable and "of a nature to balk human credulity" (Baker 4) ${ }^{15}$ The article's introduction claims 12 December 1901 is “a day destined to be important in the annals of invention” (Baker 5). 
The praises continue by noting Marconi’s work is “[o]ne of the great wonders of science ever wrought” and that Marconi has delivered "a new scientific wonder” to the world (Baker 6). Another article proclaims “[t]here can scarcely be a reader of McClure’s Magazine who has not known of the great work which Marconi has accomplished in wireless telegraphy” (Wallace 1$).{ }^{16}$ The journalist tells readers that skeptics should not doubt Marconi's triumph: If skeptics were present at the wireless demonstrations, "Marconi would be hailed by them, as he has been hailed by many great scientists who have seen his system in operation, as one of the greatest inventors of all time” (Wallace 1). The New York Times also hailed Marconi and his Atlantic crossing as monumental: One article claims Marconi is a giant, and "his name will stand through the ages among the very first of the world's great inventors” ("The Epoch-Making Marconi” 8); and months later after a land-to sea experiment, The New York Times claims the occasion "marks the beginning of an epoch in international intercommunication" ("Wireless Telegraphy" 6). Another article addresses the lay audience by noting that "[t]o those of us unfamiliar with electrical apparatus there is something incomprehensible in the feat of Marconi” (Iles 1784, italics mine). These praises rhetorically construct both Marconi and the wireless as groundbreaking.

\section{Popular Press Constructions of Military and Commercial Uses of the Wireless}

Much like Marconi's rhetorical representations to the scientific and technical community, the popular press focused on more than the technical descriptions of the wireless. On face, the lack of journalists' expertise in wireless science may appear to be the obvious reason for non-technical descriptions. However, many popular press 
accounts also include technical descriptions along with current successes, future potential, profitability, and other non-technical descriptions common to Marconi’s own presentations. One possible reason for this is that technical descriptions mean nothing to a popular audience without the knowledge of the wireless's commercial use (or potential). The wireless could not simply exist as a physical product; it had to mean something to the audience to which it was described; it had to be constructed as useful. The popular press descriptions suggest the audience's imaginations would be excited by new breakthroughs and future potentials. Consumers could not yet buy radios, but they learned about wireless transmissions on the high seas and "Marconigrams"—wireless telegrams_-being sent by important people.

The articles I consider describe the “countless” uses of the wireless, projecting its importance and potential. For instance, one article lists the possible uses of the wireless when commenting on its future profitability:

[T]here will be considerable profit from leases of the service to great lake steamers, to pleasure yachts, and to a number of ships in our merchant marine. In addition, there is to be considered the possibility of Government use; the operation of the system overland, along our coast, in the lighthouse stations; by the Weather Bureau in foretelling approach of storms; in time of war by our armies; and on the ships of our navy. (Wallace 4)

The popular press discussed wartime applications as much as other potential commercial applications. The growing militarization of the West, foreshadowing WWI, appears on the pages of the popular press accounts, and the wireless becomes an important technology for future wars.

Marconi spent some time on the wireless's wartime potential in his presentations, but these popular press articles discussed such applications (maneuvers and surveillance) 
much more. The growing agitation of European nations and their warlike past may have unconsciously influenced journalists covering new technologies. Eventually, Marinetti will figuratively describe the wireless as a weapon assisting Italy's campaign in Tripoli in 1911. The wireless's war potential described by journalists acts as a rhetorical appeal in these accounts. One such article warns that “[w]ithout secrecy no system of wireless telegraphy could ever reach great commercial importance” (Baker 7). The article summarizes Marconi’s response to the wireless’s secretive capabilities by discussing a "reflector” that “could be faced in any desired direction” and, therefore, would not allow an unintended ship to pick up the signal (Baker 7). That description is not enough for the author who points out that "an enemy [ship] might still creep in between the sending a receiving stations” (Baker 7). Such conjecture at an early stage of the wireless shows at the very least a popular suspicion of other nations or acceptance of war and the new technologies that may be used in future wars.

Concern with wartime use appears in other popular press accounts. Cleveland Moffett interviewed Marconi and asked about message secrecy and if during wartime “communications between battleships or armies [would] be at the mercy of any one including enemies” (12). Moffett also reports Marconi’s position that the wireless would allow the U. S. "to keep close guard over Havana harbor without sending” in the navy; instead, the U. S. would need only "a single fast cruiser” if "[the] Americans were at war with Spain” (16). Moffett's article from June 1899 comes less than six months after the Treaty of Paris ended the Spanish-American War. Many popular press accounts cover the potential for war, and, because Moffett uses Marconi’s words, he creates the wireless as a potential device for "[t]he warfare of the future," which "will have startling things in 
it; perhaps the steering of torpedo craft from a distance will be” possible (17). Such advancements would have been considered fantastic to a world without automobiles; in fact, bicycles were the most "hi-tech" mode of personal transportation in 1899 even though internal combustion engines were being developed.

Other popular press accounts construct the wireless's versatility for wartime uses: The wireless "can be moved as easily as a machine gun ... and keeps in communication bodies of troops within four days’ march of one another” (Lyle 5845). To emphasize the war-like nature or, at least, potential of the time period, one writer even asks how "the nations—-huge belligerent individuals that they are—” will use the wireless (Lyle 5847), suggesting the audience expected or was receptive to descriptions of a technology's wartime application. The journalists also construct the wireless as an important tool for colonization. The U. S. had just “won” its first Pacific territory during the SpanishAmerican War-Guam. Because cable would have been outrageously expensive, one article claims America's interests in the Pacific would be improved by "the installation of [Marconi's] system between California and Honolulu and Manila, thus joining together by invisible links, as it were, the widely scattered possessions of the United States in the Orient” (Wallace 1, italics mine). The journalist suggests that these American "possessions" have to be in contact with the U. S. mainland in order for America to prosper in its new imperialistic endeavors in the Pacific. Demonstrating that the wireless supports imperialism implies that the wireless will assist in military expansion. Furthermore, the journalist tells his audience that America’s “enormous telegraph business with Europe; our trade with Cuba, Porto Rico, the Philippines, and Alaska makes us more and more of a world power," and Marconi’s wireless will become "the 
daily means of communication from our shores to our various possessions and other countries over seas” (3, italics mine).

The popular press not only describes the wireless's current applications but also predicts the wide range of future possibilities. Just as Marconi describes his system's current usage during his presentations, the popular press focuses on the wireless's current commercial applications and often uses exact figures for costs. Articles on the wireless dispel the notion that "wireless telegraphy is still largely in the uncertain experimental stage" by noting "it has long since passed from the laboratory to a wide commercial use" (Baker 8). The press emphasizes the speed at which Marconi advanced: Wireless “development ... has been astonishingly rapid," and "[m]ost of the ships of the great navies of Europe and all important ocean liners are now fitted with the 'wireless'” (Baker 8, italics mine). One article tells the audience that they "may communicate with a friend on almost any transatlantic liner ... send ... money, or give notice of legal action”; also, according to the article, one could even play a game of chess with” people on different ships or in different countries (Lyle 5843). The wireless supports industrialization and keeps the "businessman” efficient: “A passenger on an ocean grayhound no longer loses a week" because "[the passenger] learns that the Russians are retreating in good order," and "he notes the wheat crop reports from Argentina, and straightaway orders his New York broker to sell or buy” (Lyle 5843).

Other articles report the wireless's profitability by noting that “[e]ach installation on a transatlantic passenger ship now nets about $\$ 5,000$ a year," and “more than 8,000 words were transmitted in a few hours from an ocean liner, and on another ship the receipts for two days' operation amounted to $\$ 300$ ” (Wallace 3). The article goes further 
by claiming "this business is increasing in volume" and the future profit estimate "from one installation ... would amount to over a million dollars a year" (Wallace 3). Another article specifies that wireless telegrams (marconigrams) cost "twelve cents a word for transmission to [seagoing] vessels" and that the "[Marconi] company was now actually doing a profitable business on a commercial basis” (Baker 8). In other words, profits make an invention real because that means "useful" and, therefore, "in demand." The legitimacy or accuracy of these profit estimates are irrelevant to the image they construct. Rhetorically, the wireless is profitable, and people appeared to be using it at an increasing rate.

Showing Marconi as the origination of commercial applications establishes his credibility for the claims he and the popular press articles make about the wireless's future potential. Marconi made the "impossible ... later come to pass” (Lyle 5848). Because Marconi made this wireless “miracle” possible, his claims about future possibilities are more believable than those of a non-celebrity inventor. One "fantastic" potential the popular press reported was the Internet-like qualities possible (ones not recognized for over 90 years): "the news might be ticked off tapes every hour right into the houses of all subscribers" with Marconi apparatus (Moffett 16); and "the time will even come when the great banking and business houses, or even families and friends, will each have its own wireless system" (Baker 8). ${ }^{17}$ Marconi’s credibility helps construct an image of the wireless's future potential, and his business sense also seems important for journalists: One journalist shows Marconi as a man in league with Edison and Bell, and "[b]ecause of these facts of character, and the thoroughly business-like manner in which the plans have gone ahead for the various utilities of his system, it is difficult to know just 
where to limit Marconi’s possibilities” (Wallace 4). Such articles claim Marconi’s system has arrived, furthering the image of the wireless as a permanent technology. Also, the fact that Marconi’s English and American companies have capital backing and his stock has been rapidly acquired "is sufficient evidence of the confidence in which the investing public holds Marconi and his work” (Wallace 4, italics mine). This “investing public" is confident that Marconi will continue to be profitable; otherwise, as the popular press implies, he would not have excited the business-oriented groups.

These faceless investors and the general audience might have been fascinated by the thought of what was to come next in wireless technology when the popular press claims improvements seem always to be "on the way." Articles often quote Marconi or speak through his persona, explaining that he will overcome current obstacles. Marconi made a bold statement shortly after crossing the Atlantic to one journalist: "Give me a week at Nantucket and I will guarantee to receive signals from England . . . and all kinds of messages across the Atlantic” once he has built a reliable station (qtd. in McClure 527). He also claimed his experiments in syntony_tuning transmissions for specific frequencies - are not perfect because "the electric tuning of a particular transmitter to a particular receiver” still permits some interference, but this "is a possibility in the future," which "bids fair soon to be realized" (qtd. in Moffett 16). Another journalist claims being able accurately to warn "vessels entering a dangerous harbor in thick weather . . . is one of the developments of the near future” (Baker 7). The popular press, especially those favorable to Marconi, help construct the idea of a working technology. And the Marconi system, specifically, will help usher in "the time when messages [will] be 
regularly flashing between Europe and America,” a time “much nearer than most people [think]” (Baker 8).

An interesting contrast to the above rhetorical claims that the wireless is sure to accomplish its goals appears in John I. Waterbury’s November 1903 article from The North American Review. Waterbury supports many of Marconi’s claims and maintains that the wireless is an extremely important invention, but he also claims that the "importance lies more in the future than in the present[,] for Wireless Telegraphy is still in that nebulous state which prevents one from fairly judging whether or not it is of such real value as its present condition would indicate” (655). His article differs from the other positive Marconi articles in its discussion of the merits of many other wireless systems; for instance, he briefly talks about the de Forest system - the biggest American rival $^{18}$ —as well as the various "national” systems that tried to emerge in France, Germany, Austria, Russia, and Spain (661-62). Waterbury merely reviews which systems the different European countries happen to use. Unlike the other popular press articles I have analyzed, which are obviously pro-Marconi, Waterbury’s does not argue for future potential of one system over another. He even promotes the polygenesis theory of the wireless's invention: "It is the old story over again that is found in the history of so many inventions: the world being ripe for the idea, the minds of many men in many countries were turned to it at the same instant” (656). Waterbury, therefore, minimizes Marconi’s role by being somewhat skeptical of the wireless's future and by not focusing as much (or solely as other accounts do) on Marconi’s system. However, Waterbury points to Marconi as the first to see the commercial potential. He just does not emphasize Marconi’s system as the system; instead, he argues that the future of the wireless (not a 
particular inventor's version) looks promising. The more pro-Marconi articles argue specifically for Marconi’s future potential and current success; also those articles show that Marconi’s system will replace the current inefficient cable technology.

The popular press created dissatisfaction with cables by pointing out their shortcomings—unreliability and outrageous expense. Cables were the established technology for long-distance communication: Telegraph wires had been in place for nearly 60 years and the transatlantic cable had been operating for nearly 40 years before Marconi sent wireless signals across the Atlantic. Just as Marconi created dissatisfaction with cable technology, the popular press constructed "wired" communication as unsatisfactory. One article notes that "Professor [Michael I.] Pupin”-a Serbian emigrant and physicist who created an important induction coil for telegraph wires—-"has pointed out that ... any one cable cannot work faster than a single Marconi installation," and "it is evident that the Marconi system has all the elements of competing successfully with the cables now in greater operation” (Wallace 3). Other popular press accounts go into greater detail on why cables are not as good; for instance, one article suggests "that [Marconi] would be able to build and equip stations on both sides of the Atlantic for less than $\$ 150,000$ ” (Baker 8). In contrast, “[a] cable across the Atlantic costs between $\$ 3,000,000$ and $\$ 4,000,000$, and it is a constant source of expenditure for repairs” (Baker 8). Furthermore, "messages which now go by cable at twenty-five cents a word might be sent profitably at a cent a word or less" (Baker 9) ${ }^{19}$ Consumers "win" by being able to send cheap marconigrams, and investors or other interested business parties (i.e., the government) can establish a Marconi wireless station for a fraction of the cost of laying cable. 
Many popular press accounts prophesized the wireless's replacement of cable. One article creates dissatisfaction with cable by claiming offshore lightships provide "the Marconi system admirable opportunity of replacing cables, which are very expensive and in constant danger of breaking” (13-14). Speaking in an interview about savings with the wireless, Marconi claims that “deep-sea cable costs $\$ 750$ ” and landed cables cost about $\$ 1,000$ per mile (qtd. in Moffett 16). Marconi also mentions "the great expense of keeping a cable steamer constantly in commission making repairs and laying new lengths” (qtd. in Moffett 16). On the other hand, Marconi claims “[a]ll we need is a couple of masts and a little wire," and "[t]he wear and tear is practically nothing” (qtd. in Moffett 16). The expensive, unreliable cables cannot withstand the inexpensiveness and versatility of the wireless. The popular press creates dissatisfaction with cable technology, which, in turn, constructs more than the wireless's potential; dissatisfaction makes the wireless a real alternative.

And alternatives were important for the hyper-industrialized nations of the early twentieth century. The time favored new technologies and judging by how much emphasis Marconi and the popular press placed on progress, the wireless had to fit that ideal before it would become realized. Of course, the professional relevant social groups, such as engineers, scientists, and businesspeople certainly played a beginning role in physically constructing the wireless and other technologies. However, the public were potential users who also had to be convinced of the wireless's worth. The image the popular press constructs is that of an important new technology. For instance, the wireless can be used during war "over stretches where it might be impossible for the telegraph corps to string wires or for couriers to pass on account of the presence of the 
enemy” (Baker 9). The popular press even claims “it is beyond dispute that Marconi’s work warrants the confidence which enthusiasts have in its future” (A Friend 533). Because of Marconi’s “miracle," in the near future “[t]he Pacific cable will be unnecessary[,] [t]he Atlantic cables will be abandoned[, and] [1]and lines eventually may be forced out of business" (A Friend 533). Because the popular press engages in such dissatisfaction rhetoric, the wireless's image—at least in the popular press articlesbecomes a real alternative. The popular press probably would not have written so many articles had they not thought the public would be engulfed or moved by them. Using tropes of progress, the articles boast that Marconi's invention would bring the "future" to the present. Often the "beyond belief" or "around the corner" descriptions reified the technology.

And the wireless, which was ultimately successful, adheres to the same strategies as the other two discourses I consider: Marconi’s work stands for progress. Rhetoric constructs the wireless as a progressive, efficient, and profitable technology and constructs Marconi himself as a genius inventor who could be trusted to bring the future to the world. One could certainly examine the accounts of other wireless inventors' systems to understand how they, too, were rhetorically constructed. What is important in this chapter is that Marconi's work was being closely followed by the popular press and (re)presented according to particularly important themes: The wireless was a monumental new invention based on nearly 100 years of research, important for war, commercially viable, and more efficient, therefore, better than cable. Such themes as those above suggest the audience would be receptive to the wireless because it fit the “modern” lifestyle socially, economically, and even personally. The popular press 
creates the simultaneous images of a technology that's "right around the corner" and also "here and now." Those seemingly contradictory images have a rhetorical basis: The popular press accounts portray both the current uses for the wireless and prophesize its future. Therefore, the wireless is "the technology of the day"; older technologies, then, become outdated. Creating dissatisfaction with cable and other "outdated" technologies seems to be a key component of the values associated with wireless technology; in contrast to cables and wires, the wireless is cheaper, more versatile, more efficient, and more modern.

In the next chapter, I analyze how an artistic movement re-presented the wireless along with other early twentieth-century technologies in order to give a more robust analysis of the wireless's rhetorical representations alongside other progressive technologies. I do not argue that the wireless caused artists to glorify technology; instead, technologies were already being fetishized or invoking awe (c.f. Adams; Nye). As an industrial product of modernity, the wireless speaks to the theories of modernism. F. T. Marinetti, the founder of the first avant-garde (Futurism), reinscribed the wireless into his aesthetics. Instead of being a scientist, engineer, journalist, or consumer, Marinetti was a lover of the wireless—a modernist technophile—who shared a passion for efficiency with the likes of Frederick W. Taylor and Henry Ford. 
Notes

1. Mifeprestone (or RU-486) is a good (albeit controversial) example because its introduction in the United States had to overcome social, political, and scientific pressure that thwarted its approval for many years.

2. Although the US Navy appears to have awarded a contract to an American over a foreign company for certain experiments circa 1910 (c.f. Yeang), Marconi’s status as an inventor was quite high in the American popular press.

3. Although this dissertation's methodology has limitations because I have almost exclusively chosen positive representations of Marconi's wireless, the patterns that appear in the articles are at least suggestive of audience values and expectations. If anything, we can observe that Marconi's contemporaries in the mass media articulated certain positive images of his wireless.

4. The Marconi Signal and Wireless Co, founded in the late nineteenth century, continued to have "Marconi" in its name- there were minor changes — until the company was sold off in January 2006. Rogue polemicists online do rail against Marconi as the "father of the radio"; one particular site claims Nikola Tesla was the true inventor and Marconi was a thief (“Why I Hate Marconi.” http://www.loneinventor.com/).

5. Alexander Stepanovitch Popoff, a Russian electromagnetic scientist in the late nineteenth and early twentieth century, has his name spelled "Popoff" and "Popov." When I quote an author's mentioning of him, I use the same spelling as the author.

6. A current example of how a specific name secures itself as a benchmark long after other companies' products have reached the market is the adjective/verb/noun XEROX: Many of us have created xerox copies, xeroxed originals, or asked "Where's the Xerox?" in order to photocopy originals using an HP, Panasonic, Samsung, or other photocopier brands.

7. Arthur C. Clarke, the famous science fiction writer, claims that any new technological discovery should not be very far removed from magic.

8. I attended T. A. Edison High School in Franconia, VA. Students had to do reports on Edison and were often told that he was a "wizard." In fact, my lacrosse team had shirts made with "The Wizards of Menlo Field" printed on the back as a pun on Edison's lab at Menlo Park. Unfortunately, we lost all but one game the entire season.

9. J. Chandra Bose has recently been accepted as the inventor of the coherer Marconi used in his 1901 transatlantic experiments (Bondyopadhyay 259).

10. The article's author is simply credited as "A Friend," and the article is a glowing account of Marconi's accomplishments as well as a brief history of the wireless up to March 1902. 
11. Bijan Jabbari, a senior IEEE member, notes that "Marconi put to work the concepts already developed by Hertz, Branly, Lodge, Popov, and a few others” (1523).

12. H. E. Hancock's history of Marconi's wireless, written in the late 1940s as a celebration of Marconi's work, also overlooks Marconi’s contemporary contributors.

13. "Ether" was believed to be the unseen matter in the universe, a substance that could conduct electricity and, subsequently, radio waves.

14. While it may seem as if I am glorifying Marconi and contributing to his lone inventor legend, my emphasis on him reflects my argument that the popular press rhetorically constructed the Marconi wireless apparatus as the most important and dominant system. His celebrity status and (eventual) Nobel Prize — which he shared with a lesser-known German inventor, Karl Ferdinand Braun — does not prove historically that he was the sole inventor of the wireless technology, but his popularity does suggest his wireless was known as one of the first and most important inventions.

15. Baker's introduction to this article also appears in the March 1902 issue of Current Literature, and another large section is quoted in Herbert Wallace's June 1902 McClure's Magazine article.

16. McClure's Magazine was extremely positive about Marconi's work. Robert McClure was actually present in Dover, England for Marconi's crossing of the English Channel and was "allowed to hold cross-channel conversation" with Cleveland Moffett in order to, "in the interests of [McClure's] readers, satisfy ourselves that this wireless telegraphy marvel had really been accomplished" (Moffett 15).

17. Although the Internet in the form of the World Wide Web was recognized by consumers in the early 1990s, its creation dates back to the 1960s. Beaming nightly news into the homes of families seems more an invention for satellite television, but Baker believes the news would be written down for the occupants to read at their leisure. Interestingly, the idea of people gathering around a radio set or television set to listen or watch "news" was not part of the popular consciousness as evidenced in these popular press articles.

18. Nicola Tesla also had a wireless idea and worked extensively in America, but his outlandish claims eventually made him seem too far out to be a serious rival.

19. The popular press varied in its price-per-word estimates. Authors claimed the system would be profitable at less than a cent a word to around five cents a word. Of course, all claimed the wireless rate was significantly cheaper to telegram rates. Also, there were differences in the exact price of building stations and outfitting ships. 


\section{CHAPTER IV}

\section{TROPES OF PROGRESS IN F. T. MARINETTI'S EARLY FUTURIST TEXTS}

History is more or less bunk. It's tradition. We don't want tradition. We want to live in the present and the only history that is worth a tinker's dam is the history we make today. Henry Ford, "Making History" (61)

Western industrialized societies of the early twentieth century were entrenched in ideologies favoring progress: From human advancements to management science, the early twentieth century believed "efficiency” was one of the highest goals of progressive life. Frederick Taylor’s efficiency manifesto The Principles of Scientific Management, for example, articulated efficiency principles that were put into practical use by one of the leading industrialists of the time, Henry Ford. Fordism/Taylorism exemplifies the early twentieth century's fascination with efficiency and progress, and modernist artists captured similar images, attitudes, and situations related to these values in their works. After all, art reflects the artist's world and world view. European and American avantgardes contributed to new artistic movements that incorporated and promoted new technological advances. A machine gun, an automobile, and a wireless telegraphy station replaced (somewhat) “traditional” muses such as an ocean, a mountain range, and a flower. Even artists who did not glorify technological progress were affected by the new tools of science that excited the minds of artists and audiences. ${ }^{1}$ To live in industrialized countries meant one could experience the progress around him or her. New advancements were integral elements of avant-gardes such as Futurism. 
This chapter demonstrates how F. T. Marinetti incorporated values and attitudes of progress associated with the wireless and other early twentieth-century technologies into his early Futurist manifestos. His manifestos are products of a period consumed by new scientific, technological, and industrial discoveries and, therefore, reflect the culture's overall belief that "progress" is an important social goal. For Marinetti, the wireless and other contemporary technologies signified humanity's progress(ion) away from an irrelevant past. Other artists were not so sure new technological advancements deserved such praise; for instance, D. H. Lawrence, Virginia Woolf, H. G. Wells, and Aldus Huxley presented technology in less panacean and more skeptical ways. In contrast, Marinetti fetishizes technology and promotes new advancements as beneficial products and markers of civilization. Marinetti describes these technologies similarly to how Marconi and the popular press describe the wireless but in exaggerated ways. Using tropes of progress in his early Futurist texts, Marinetti shows how technologies exemplify the values of speed, efficiency, evolution, and ahistoricity.

Those values continue to manifest themselves into rhetorical constructions of technologies as I show in previous chapters. In this chapter, I will demonstrate how an adamant technophile such as Marinetti rhetorically reconstructs the wireless using tropes of progress that he also affixes to other inventions (i.e., the machine gun, airplane, ocean vessel). His texts portray early twentieth-century inventions as saviors of humanity, the pride of industrialization, and a model for humans to emulate. Marinetti wanted his audiences to embrace the values of progress as represented through speed, efficiency, evolution, and ahistoricity. According to Marinetti’s Futurist agenda, technology helps humans "escape" from passéisme, which is a love for the sentimental past and not for the 
industrial future. Also, as an avant-garde artist, Marinetti’s texts display an experimental aspect through telegraphic lyricism or mimicking telegraphic discourse.

My analysis is meant to be not an exhaustive study on Marinetti or Futurism but a suggestion that Marinetti's fascination with technology indicates that he is a product of modernity. Futurism is often used interchangeably with Italian Futurism, which mistakenly implies Marinetti’s aesthetics were universally accepted by the various Futurist groups—Russian Futurism, Cubo-Futurism, Ego-Futurism—and that his aesthetics were representative of avant-garde aesthetics. Many scholars even note that as the first avant-garde, Marinetti influenced all of the avant-gardes that followed (Bondenella; Butler; Kirby; Perloff; Poggioli; Rainey). One scholar observes that “[Marinetti's] ideas were received enthusiastically by most of the principal writers of the times,” but later many withdrew their support or denied Futurism's influence (Bondanella 316). Also, the avant-garde was not the only crowd receptive to Marinettii. ${ }^{2}$

To demonstrate how Marinetti’s aesthetics relate to industrial or technological tropes of progress, I analyzed the following texts from his early phase of Futurism: ${ }^{3}$

1. "The Founding and Manifesto of Futurism,"

2. "The Birth of a Futurist Aesthetic,"

3. "Electrical War (A Futurist Vision-Hypothesis),"

4. Destruction of Syntax-[Wireless Imagination]-Words in Freedom, 5. and Zang Tumb Tumb.

I cover the last text Zang Tumb Tumb briefly in order to give some examples of Marinetti's parole in libertá poetry. ${ }^{4}$ Much of Marinetti’s aesthetic license is obvious in the first four texts, but Zang Tumb Tumb's onomatopoeic style and avant-garde nature are 
best seen and not described. The reader should examine Richard Pioli's translation of Futurist texts Stung by Salt and War and Elizabeth R. Napier and Barbara Studholme’s translation of Marinetti's texts Selected Poems and Related Prose (compiled by Luce Marinetti, Marinetti’s daughter) in order to observe the multiple typefaces, font sizes, and styles that make Marinetti's parole in libertá unchained. These foundational texts of Italian Futurism and, therefore, the historical avant-garde were published shortly after Marconi's wireless became a black box. Marinetti's reliance on the machine in his art is more than an allegory of speed, efficiency, evolution, and the future; he also pushes Italian modernization.

To demonstrate Marinetti's avant-garde penchant for glorifying technologies in his manifestos, I discuss how Marinetti’s texts position him as a product of modernity: His nationalism, accompanied by a desire for militarism and further industrialization fits the cultural values and practices of early twentieth-century industrial nations. Furthermore, technologies are muses for Marinetti, and his texts show science fiction fascination with machines. Whether he is describing a futuristic monoplane or "twentyfirst-century" wireless warfare, Marinetti constructs another type of favorable rhetoric in order to explain the (potential) usefulness of an invention—-he echoes the other discourses that described the wireless as "beyond expectations."

\section{Marinetti's Response to the "Cult of Efficiency" Surrounding New Technologies}

The wireless was one of these important technologies that performs "beyond expectations” in Marinetti's work. Marinetti often groups the wireless together with telephones, automobiles, machine guns, and even airplanes when he claims "inventions" 
will bring Italy to greatness. Such nationalist sentiment emerges when he advocates war and attacks what he sees as weakness in a past-loving culture. His polemics rarely focus on concrete possibilities for new machines; instead, he makes bombastic claims about an unrealistic future, a utopia brought about through technology. Marinetti's art often has a science fiction appeal; he represents technologies by describing them as exciting or fantastic tools that are also economic and industrial "saviors."

Marinetti believed techno-salvation is possible and issued the first avant-garde manifesto in 1909 (“The Founding and Manifesto of Futurism”) to show the explicit importance of technology. For Marinetti, technologies do not just advance progress; they are the muses which humans and his new Futurist movement must emulate. The word "Futurism" implies that Marinetti’s goal was for the future: He wanted Italy to advance technologically away from the past, which was dead to him, and move into a new industrial age, one that favored the machine. By advancing mechanistic "virtues," Marinetti proposes that life—not just art—ought to follow technological values: Humans should be fast like cars, explosive like bombs, super productive like factories, and as free as wireless signals. The technologies Marinetti favors also act as aesthetic "models" for his art; for example, in “The Electrical War (A Futurist Vision-Hypothesis),” Marinetti pays homage directly to the wireless and offers it as a model for his poetry.

The speed with which the wireless communicates (instantaneously) and the form an author's words take in telegraphic communication define Marinetti's "telegraphic lyricism” style. Such a style is “a swift, brutal, and immediate lyricism” (DWW 104). Marinetti aimed to reduce words to the simplest, most efficient form possible. Various 
Futurist groups experimented with telegraphic styles (J. White 147), so Marinetti was not the sole originator. As John White points out,

Even granting Futurism an instrumental role in disseminating and popularizing telegraphic writing among the Orphists, the Expressionists, and the Vorticists, in the case of such a widespread modernist phenomenon one has to allow for the eventuality of polygenesis. Indeed, the possibility that the attractions of such a style had occurred almost simultaneously to various avant-garde writers in different countries is a strong one. (147)

These European Futurist artists lived in industrial(izing) nations, so they and their aesthetics are products of their social context. The spirit of progress and modernization influenced this European "cult of the 'telegraphic,"” and “[i]ts mushrooming popularity owed much to two things: the discoveries of Guglielmo Marconi, and contemporary mythification of the Eiffel Tower” (J. White 147).

Although Marconi’s invention is an important object for Marinetti, the promotion of progress underlies the goals set forth in his manifestos and poems. Besides his typographical long poem Zang Tumb Tumb, his early manifestos show this terse, telegraphic writing as an artist's duty and embracing industrialization perpetuates human evolution. Marinetti can be used synonymously with Italian Futurist beginnings because Marinetti was the movement's leader, ${ }^{5}$ he is considered the most important (Blum; Bondanella; Hewitt; Perloff; Poggioli; J. White). From his first Futurist texts, readers are bombarded with industrial images. For instance, the first Futurist manifesto shows the movement's love of speed and violence in the prologue, where Marinetti and his friends become re-energized after their car crashes into a river full of factory effluents (FMF 401). Such markers of industrialization pinpoint the correlation between art and the industrialized world’s pro-technological values. "Growth,” "progress,” and "evolution” 
existed prior to Marinetti; after all, World's Fairs had been exciting the public with their technical, scientific, and industrial marvels for over half a century before Futurism. Marinetti, Marconi, and others were influenced by an age that celebrated humanity's techno-evolution. Machines were prostheses to humans, allowing them to accomplish "higher" forms of work. Increased production through mechanization meant humans could become superhuman workers. Marinetti also portrays the machine as a model for human biology. To transform into a machine meant being able to cast off human "frailties" and become the most efficient specimen possible.

According to Marinetti, the Futurists, as super-efficient beings, "have already scattered treasures, a thousand treasures of force, love, courage, astuteness, and raw will power," yet, “[o]ur hearts know no weariness because they are fed with fire, hatred, and speed!” (FMF 43-4). The image most appropriate for this transformation is to imagine a "radio-bomb." The radio signifies his increased communication speed through telegraphic lyricism, and bombs reflect his incendiary rhetoric, which permeates Marinetti’s poetry and prose. ${ }^{6}$ An important aspect of his parole in libertá is “[l]ove of speed, abbreviation, and the summary. 'Quick, give me the whole thing in two words!'” (DWW 98). As a "radio-bomb," Marinetti, who did not use this particular expression, ${ }^{7}$ becomes a weapon launched from a radio tower to incite chaos. Although we often have to consider the figurative nature of poetry and prose, Marinetti's texts imply that he would have literally wanted to become a radio transmission and explode his invectives for millions within the reach of this new international communication technology. The wireless was a tool for the future, and "Marinetti singles out the invention of wireless telegraphy as one of the great milestones in civilization's progress towards the Futurist 
electric millennium of the twenty-first century” (J. White 148). As John White points out, the wireless excited the mass audience:

News could be transmitted and received virtually instantaneously thousands of miles away. The telegraphic dissemination of the new word of science became the technological equivalent of the spreading of the Gospel, and writers treated the subject with an appropriate religiosity, often using the imagery of the biblical word. (148)

From White's argument, the wireless's reception, fetishization, and subsequent reinscription can be said to have happened because the invention embodies the power of a divine miracle. Divinity had been replaced by technology (c.f. Adams).

Specifically, Futurism captures the culture's reliance and devotion to progress in works that range from manifestos and poems to sculpture and architecture. Each art genre—painting, literature, architecture, sculpture, etc.—had its own manifesto.

Although Marinetti's movement was Italian, the value of mechanization, of progress through technological advancements, was international. Such sentiments ran through the European avant-garde circles and reflected the growing dependence on new sciences and technologies. In order to compete effectively in this hyper-industrial situation in which Marinetti and others found themselves, each nation had to acquire the proper technologies.

Marinetti's techno-dogma suggests that he attempted to help Italy see the need for a social push for modernization. During a visit to Venice, Marinetti and a few of his followers passed around leaflets chastising the "romantic" passéisme of the city. He wanted Italy to become a major industrial power, and he despised those who wished to reminisce about the past. The image is best captured by the comic strip artist André Warnod in Comedia from 1910: 
[T] he cartoonist provided comic 'before' and 'after' pictures ... Before: grotesque and flabby lovers smooching in the Piazza San Marco; after: a city of bridges dirigibles, smoke stacks, and electric lamps, their rays replacing those of the sun. To the left of center, we see a replica of the Eiffel Tower, as if to say Venice has now become Paris. (Perloff 104)

Paris, which had radio broadcasts beaming from the Eiffel Tower, was the pinnacle of modernization for Marinetti, a state Italy should mimic. Modernization aroused strong nationalist sentiments in Italy, and Marinetti himself conflates patriotism with a lust for mechanization. Because technology marked progress for Marinetti, anyone not consenting to the mechanical present (or future) "affirmed once again the ridiculous nullity of nostalgic memory, of myopic history and the dead past” (BFA 83). New technologies offered direction "from a new sun, which is certainly not the sun that caressed the placid backs of our grandfathers - those slow steps sagely measured to the lazy hours of provincial cities with their grassy cobblestones of silence” (BFA 83). Progress and progress reified through technological advancements were objects behind which pro-modernization forces rallied. ${ }^{8}$

\section{The Effect of the Wireless and Other Technologies on Futurist Aesthetics}

The Futurists, the wireless, and Marconi were products of the early twentieth century—an era consumed with progress. Just as Marconi and the popular press presented the wireless as another possible incarnation of modern progress, Marinetti unleashed his Futurist polemics urging further industrialization and, of course, mechanization. New technologies encouraged progress because they extended the work a human could do: The automobile, assembly line, and wireless were all prostheses allowing humans faster movement, more efficient production, and wider communication 
possibilities. Prostheses like these helped create the aesthetic of dynamism: "The world the Futurists knew could be traversed ... using such new means of transportation as the automobile, the high-speed train, and, for short runs, even the airplane” (Perloff xxxvii). In his texts, Marinetti imagines the human-machine possibilities of these new technologies. Although one cannot deny the comfort of some technologies of leisure (cars, TVs, airplanes, etc), the assembly line and factory itself are technologies of mechanization. Fordist/Taylorist management science sought to reduce the human (error) element in production by creating a situation (i.e., the assembly line) where workers' tasks could be reduced to simple repetition and little, if any, thought. ${ }^{9}$ Such streamlining reflects dominant tropes of speed, efficiency, evolution, and ahistoricity.

Marinetti glorifies technology by linking machine advancement to human progress — evolution. Current scholarship claims that Marinetti's aesthetics embody advancement through machinery. Although most scholars make the connection between technology and Marinetti’s poetic style (Blum; Butler; Campbell; Hewitt; Perloff; C. Taylor), John J. White specifically claims that Marconi’s wireless was a key influence on artistic telegraphy or, as he puts it, "the cult of the 'telegraphic'” (147). White also argues that Marinetti was not the only artist experimenting with such a style because “'telegraphic' writing was generally 'in the air' in European avant-garde circles” in the early twentieth century (160). White credits Marconi’s popularity and discoveries for inspiring "the public imagination and ... hav[ing] a tangible influence on the quality of everyday modern life" (148). In fact, Marinetti claims that the wireless influenced his style after his time as a war correspondent during Italy's bombing of Tripoli (J. White 161); however, White believes that account to be Marinetti’s revisionist history (162). 
Christine Poggi argues that Marinetti’s telegraphic parole in libertá writings "violate all the rules of proper telegram writing” (qtd. in J. White 165). White notes that Poggi's argument for "the violation of the conventional rules for telegrams lies in Marinetti's use of diagrammatical pictures instead of any words" (165). Focusing on Marinetti's violation of "proper" telegraphic form reduces his artistic contribution to telegraphic lyricism because "violation" assumes his style is somehow a miscommunication. Such a style was not meant to be of practical use in wireless or “wired” telegraphy. For example, Marinetti’s famous bombardment poem Zang Tumb Tumb uses "tataluuuntlin" to describe the sound of a train going over an iron bridge and "sssssssiii ssiissii ssiisssssiiii" to describe the sound or whistle of a train's smoke stack (56 and 57). Furthermore, the bolded text denotes loudness. Although a radio operator or telegrapher could easily record or decipher the letters above, Marinetti’s onomatopoeic "words" were not meant to be communicated via Morse code. This style was meant to be read or heard (as it was in Marinetti's public performances). Marinetti's texts included such constructions as

\section{POESIA NASCERE}

in order to signify a crescendo and to reinforce the idea that his poetry is born in this new age of bombs. ${ }^{10}$ The crescendo, the gradual increasing of sound, mimics the gradual increasing loudness of a bomb falling to the ground, and the finale is an explosion.

The wireless influenced Marinetti's concept of parole in libertá, which offers readers a sense that contemporary communication technologies played a significant role 
in Futurist aesthetics. That style reinscribes tropes of progress. Marinetti's aesthetics derive cultural and artistic value from “progress” based on Industrialization’s larger culture influences. Marinetti valued technology in a way that Latour's fictional sociologist would recognize as “love.” Although Marinetti’s response was more of an obsession than a practical technological design project, he reflects a larger cultural "love" of technology that allowed early twentieth-century inventions to become realized. Industrial cultures embraced new technologies and even felt in awe of their massive power, as Henry Adams did at the 1899 World's Fair. Marinetti felt humans should embrace technology in order to leap into the future. His devotion to ahistoricity is simultaneously his rejection of the past, a time, according to Marinetti, that is worthless.

But not all modernists subscribed to technological utopian dreams. For instance, D. H. Lawrence had an interest in Futurism, but considered the movement immature, and his works do not promote technology as any savior. Whether Lawrence has coal mines cut into the English landscape or creates characters dehumanized by "modern" technology and industrialization, Women in Love critiques the modernist reconstruction of technology as progressive-in the sense that progressive connotes beneficence or necessity. Although different modernist artists did not share the same views on technology, technology still had a role in modernist texts. ${ }^{11}$ While Lawrence and Woolf were critical of technology because of its destructive, alienating qualities, Marinetti celebrated it.

Marinetti’s war imagery is enhanced by using onomatopoeic and experimental typography. Besides a steadily increasing font size, Marinetti often "render[s] dynamism typographically by using shaped writing to indicate lines of movement” (J. White 18). 
The cover of his 1919 novel 8 Souls in a Bomb (Fig. 2) portrays the sound of a bomb firing out of a cannon (TUM), going up into an arc (rrrrrr ... ), coming down onto a hillside (ua ua ua ... ), and exploding (Braaang Bragraa). This format was not supposed to be used as sound telegraphic style; instead, the typographical "image" conveys Marinetti's poetry as explosive. The eight souls of the title may represent eight Futurist artists-F.T. Marinetti, Giacoma Balla, Antonio Sant’Elia, Gino Severini, Carlo Carrá, Umberto Boccioni, Luigi Russolo, and Andengo Soffici ${ }^{12}$ — with the image evoked by the text's artistic representation of the Futurist polemical assault from the air and, possibly, the air waves. Although Boccioni, Russolo, and Sant'Elia died during (or from injuries sustained in) WWI, they were integral members pushing the boundaries of avantgarde art prior to WWI.

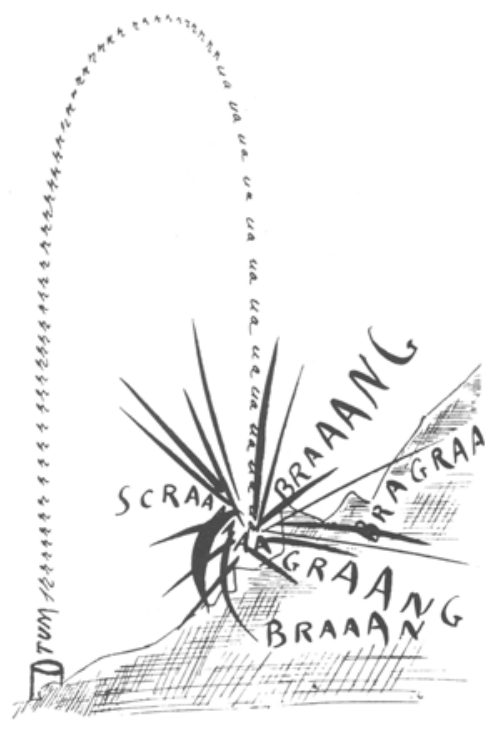

Fig. 2. Cover to 8 Souls in a Bomb by F. T. Marinetti. Rpt. in John J. White, Literary Futurism: Aspects of the First Avant Garde. Oxford: Clarendon P, 1990.

Those artists also celebrated movement, speed, and efficiency in their work, so the novel's cover represents the Futurist Movement's overall goal of exciting the imagination of the Italian masses through incendiary art. During a 1910 performance in 
Venice, Marinetti and his cohorts scolded the Venetian crowd because they were not embracing modernization enough: "Shame on you! Shame on you!” he shouted. He wanted the Venetians to get out of the way "while we prepare a great strong, industrial, commercial, and military Venice on the Adriatic Sea, that great Italian Lake!” (qtd. in Perloff 106). In the 1920s and 1930s, Marinetti would douse his audience with his polemical Variety Theatre and radio broadcasts, but the pre-WWI violent rhetoric exists on the page in Marinetti's earlier works, much of which glorify bombardment and communication as ways to attack. Other technologies contribute to Marinetti's violent poetry, but his "wireless imagination” concept creates an ideal freedom inextricably linked to mechanical values and tropes of progress. After all, the mechanical wireless produces signals that "fly" back and forth between stations.

One of Marinetti's most celebratory works specifically about the wireless is his poem-manifesto ${ }^{13}$ “Electrical War (A Futurist Vision-Hypothesis)," which shows how the wireless is reconceived through bombardment imagery to become both a muse of sorts and a means to promote Italian nationalism. This pre-WWI piece heralds a new panitalianismo, which will be carried out in large part by new technologies. "Electrical War” opens with the following introduction: “Oh! how I envy the men who will be born into the next century on my beautiful peninsula when it is wholly vivified, shaken and bridled by the new electric forces!” (104). ${ }^{14}$ The wireless acts as an important controlling mechanism for Marinetti’s imagined, future Italy “transformed by man’s genius into many millions of Kilowatts” (EW 104). In the vision, Marinetti denounces the romanticist poets of the past for their love of the sea and claims humans have found a way to make the sea labor for Italy "with all its diligent, raging storms to set in ceaseless 
motion numberless iron pontoons that energize two million dynamos scattered along the beaches and in a thousand working gulfs" (EW 104). This energy "needing no wires" in Marinetti’s vision is "controlled from keyboards with a fertilizing abundance that throbs beneath the fingers of the engineers” (EW 104). Instead of having a world created by natural forces, Marinetti's vision promotes a hyper-industrial science fiction reality where radio-type engineers "sit before switchboards, with dials to right and left, keyboards, regulators, and commutators, and everywhere the splendid flash of polished levers" (EW 104-5). While this “control room” reflects a science fiction spaceship, Marinetti’s description comes from a radio room. The vision's engineers "have finally won the joy of living between iron walls," and, because "[t]hey are finally free of wood and its lesson of weakness," mechanization forges a new reality based on the strength of new materials (EW 105). Marinetti privileged machines for their power and denigrated the natural, which he saw as weakness needing to be conquered. Not surprisingly, this vision comes from his novel War, the World's only Hygiene where he glorifies the cleansing aspects of destruction—-destruction of the past carried out by new technologies.

Airplanes and the wireless assist the vision's engineers who "regulate the lightning speed of the seed-scattering trains that two or three times a year cross the lowlands for basic sowing” (EW 105, italics mine). Airplanes had yet to have wireless capabilities in 1911, but popular press articles had already prophesized remote control possibilities—-mechanical manipulation via radio signals—so a radio in an airplane would not have seemed too far fetched. One article even speculated that remote control torpedoes would eventually be used during naval battles (Moffett 17). While popular press reports speculated on non-organic wireless and general electrical possibilities, 
Marinetti has a more fanciful, organic vision where electricity not only plants seeds but helps them grow. Marinetti envisions crops and orchards with "numberless lightning rods” placed in the ground to "tickle the turgid bellies of storm clouds" in order to excite "the roots of the plants" (EW 105). This electro-fertilization helps grow bigger, stronger crops faster, a system far more efficient than simply organic means. Electricity, which appears to follow the idea that ether is a conductor, is no longer wasted: "All the atmospheric electricity hanging over us, all the incalculable electricity of the earth, is finally harnessed” (EW 105). Plants also grow "with lightning speed” when stimulated by "artificial electricity at high tension" (EW 105). The wireless makes this electroagricultural vision possible because invisible electric signals—with no physical connection—have no limits for Marinetti. ${ }^{15}$ Wireless signals penetrate walls, hills, and other barriers, so electricity "will penetrate every muscle, artery, and nerve of the [Italian] peninsula” (EW 104).

The Futurist(ic) vision assumes that "the discovery of the wireless telegraph far in the past” helped bring about this techno-utopian Italy (EW 106). Marinetti's glimpse of the future reflects Marconi and the popular press's topos that the wireless's potential is beyond expectations, and that the future will fully recognize the wireless and other technologies' capabilities. The wireless and the fact that "the use of dielectrics increases every day” (EW 106) builds Marinettis's vision of a hyper-industrial and hyper-efficient new world. Just as Marconi and supportive popular press writers rhetorically constructed the wireless as a commercial success, Marinetti infuses his poem-manifesto with labor images, which show both the popular press and Marinetti promote industry. In Marinetti’s utopian world, physical occupations are done by machines: "Ended now the 
need for wearisome and debasing labors. Intelligence finally reigns everywhere. Muscular work ceases to be servile” (EW 106). Marinetti also promotes a Libertarian or proto-Objectivist theory ${ }^{16}$ because laissez faire economic principles appear to give humans massive surpluses. No hunger or poverty exist in this vision because "[t]he financial question [has been] reduced to a simple matter of accounting” and society allows “[f]reedom for all to make money” (EW 106).

Because of these new commercial successes, Marinetti creates a new ideal for human intellect and prosperity. Basically, he wants machines to (do the) labor, so that these new humans "can perfect their lives in numberless antagonistic exertions" (EW 106). The new humans no longer walk on earth—too inefficient; instead, they fly in personal monoplanes. Physical exertion "now [has] only three goals: hygiene, pleasure, and struggle” (EW 106). Even today pro-industrialists promote technology as saving human time. Machines are seen as more efficient, which is why athletes and coaches often describe a person's body through machine metaphors. A machine rarely gets sick or performs inconsistently in such comparisons. If athletes have automatic, mechanical physical responses at game time, they will win. Marinetti envisions such cyborg-like creatures who can now be more efficient because "[e]yes and other human organs are no longer simple sensory receptors, but true accumulators of electric energy” (EW 106). ${ }^{17}$ In other words, Marinetti celebrates as human evolution the mechanical and human worlds becoming entwined after technological efficiency has replaced human labor.

For Marinetti, advancement breaks from the "old ways," so techno-celebrations fit Futurist art well. Because technology is valued for commercial reasons, its promoters (as I have shown in the previous two chapters) emphasize commercial potentials. Marinetti 
is no exception. The world he envisions includes "[t]wenty five great powers ... fighting over markets of a superabundant industrial production” (EW 107). Marinetti envisions that "the first electric war" will not use "more of those old explosives" but will harness the energy of the atmosphere and attack using wireless means—signals as bombs (EW 107). In this poem-manifesto, the wireless is a central technology that helps usher in this new utopian (albeit violent) hyper-industrial world. The world powers fight over resources in cleansing wars. Marinetti felt war was the world's only hygiene, for it removes the past and the inefficient elements that stand in the way of progress. To indicate progress and a break from the past, Marinetti’s vision offers a horrific image: "The sick and weak, crushed, crumbled, pulverized by the vehement wheels of intense civilization. The green beards of provincial back alleys will be shaved clean by the cruel razors of speed” (EW 108).

Before this new world can begin, Marinetti claims Italians must "kill” the past. In “The Founding and Manifesto of Futurism,” which establishes Marinetti’s movement, he rejects the past and is born anew. He advances his attack further in "The Electrical War" by denouncing passéisme. Marinetti ridicules lovers of the past and those who love Italy specifically for its past. To "correct" this seemingly misguided love he offers the following plan: "After having insulted every stranger who adores our Italian past and despises us as singers or serenades, as ciceroni or beggars, we have asked them to admire us as the most gifted race on earth. Thanks to us, Italy will cease to be the love-room of the cosmopolitan world” (EW 108). Marinetti wants Italy to evolve into this utopian vision through technology. 


\section{A Love of Technology}

Marinetti's vision captures a love of technology and dismisses any remotely nostalgic aesthetic. While telegraphic lyricism is a common component of the European avant-garde circa 1910 (Perloff; J. White), the techno-fetishization apparent in Marinetti's art is predominantly Futurist. J. White argues that Marinetti's parole in libertá style can be "interpreted as a part of a process of liberation from the hold of the past which is an inevitable feature of the modern world" (164). White also claims that the Futurists' love of brevity "is more than just a virtuous economy reflecting the pace of modern life"; instead, "it is in some way the key to greater truths and thus renders most passéist writing not only anachronistic but also superficial” (164). Marinetti’s style reflects the industrial world's cult of efficiency more than any link to actual telegraphic writing practices. He envisions a smaller world "brought about by the great discoveries of science” (qtd. in Perloff 57), and he promotes these new discoveries in his poetry and prose. His manifestos and telegraphic writing point to the technological and scientific undercurrent of his time period.

Marinetti positions the wireless as the new, efficient communication technology helping to make the world smaller. He also portrays other technologies—often in the image of a generic machine—as indicative of modern progress. "The Founding and Manifesto of Futurism," "The Birth of a Futurist Aesthetic," and Destruction of Syntax[Wireless Imagination]-Words in Freedom demonstrate Marinetti's connection or simply his mirroring of progress tropes. These texts serve as sites where Marinetti's early Futurist stance can be read as propaganda for a future that will glorify technological advancement as reified progress: "Marinetti's argument [for speed and efficiency] is 
reductive enough to make for compelling propaganda” (Perloff 57). Although such a discussion could highlight Marinetti’s proto-fascist leanings, I want to avoid reading fascism into Marinetti's early works because that would risk being reductive as Perloff warns (xxix). ${ }^{18}$ Marinetti's glorification of violence, war, and industrialization is not uniquely fascist. After all, quite a few parallels exist between the Futurist Manifestos, Marconi’s presentations, and the popular press's re-presentations. To read his works as fascistic ignores the richer discussion that argues fascist principles are inherent in hyperindustrial, hyper-fetishistic technological societies. Even “democracies” such as the United States or Britain had more of an oligarchy controlling resources and production. In order for industries to profit, they needed highly efficient and dependent labor.

The new materials (and material conditions) of the early twentieth century require new ways of organizing resources. Frederick Taylor advocates his management science theories to help make factories more efficient. Marinetti, on the other hand, raises “efficiency” as a virtue. Instead of promoting efficiency as a practical element for the modern industry as Taylor does, Marinetti promotes efficiency as human virtue—one developed by privileging mechanical qualities over human frailty. To label such an aesthetic quality or industrial practicality as fascist, ignores the ideological link to all industrial economies_-fascist, communist, capitalist, or “mixed” systems. The wireless and Futurism are both products of modernity, and two important events in 1909 help point to the significance of science and technology in popular and literary consciousness: Marconi won the Nobel Prize for Physics, and Marinetti published his first Futurist manifesto. Marconi’s Nobel Prize did not introduce him to the world but helped certify his status among the scientific community. In contrast, Marinetti, who "was a mediocre 
late Symbolist" until his seminal manifesto (Perloff 84), exploded onto the new avantgarde literary scene.

Marinetti’s manifesto and Marconi’s Nobel Prize both reflect the industrialized world's positive attitude toward progress. Just as Marconi and the popular press present the wireless as a marker of "good" civilization, Marinetti uses the same tropes of progress to praise technologies: speed, efficiency, evolution, and ahistoricity. Marinetti's works show technology as a new way to liberation—freeing humans from their servile manual labor. Such a situation distinctly marks human progression away from the past. Industrialization will usher in a new Italy, so past attributes or history itself is irrelevant.

\section{Ahistoricity in Marinetti’s Aesthetics}

Marinetti's most obvious trope of progress extends from his disdain for the past and promotion of ahistoricity. Futurism is born in an allegorical "escape" from a backward, non-industrial countryside: After an evening contemplating where art should go, Marinetti and his friends "trampled our atavistic ennui" and roared away in an automobile (FM 39). Marinetti signals their departure from the past by shouting "Mythology and the Mystic Ideal are defeated at last ... We must shake the gates of life, test the bolts and hinges” (FM 40). After a series of quick twists and turns while roaring down the highway, Marinetti crashes into a ditch of "[f]air factory drain" (FM 40). The polluted river appears to revitalize Marinetti: “And so, faces smeared with good factory muck—plastered with metallic waste, with senseless sweat, with celestial soot—we, bruised, our arms in slings, but unafraid, declared our high intentions to all the living of the earth” (FM 41). Thus begins the first avant-garde manifesto. 
As the name implies, Futurism wishes to look forward, and Marinetti clearly shows his loathing for passéisme in his early works. The eighth point of the first manifesto claims "[w]e stand on the last promontory of the centuries! ... Why should we look back, when what we want is to break down the mysterious doors of the Impossible? Time and Space died yesterday" (FM 41). Marinetti also claims to want to "destroy the museums, libraries, academies of every kind" and "fight moralism, feminism, every opportunistic or utilitarian cowardice” (FM 42). Only the new is to be admired in both art and technology. Marinetti attacks passéisme by "establish[ing] Futurism, because we want to free this land from its smelly gangrene of professors, archaeologists, ciceroni and antiquarians. For too long has Italy been a dealer in second-hand clothes. We mean to free her from the numberless museums that cover her like so many graveyards” (FM 42). He rails against museums, claiming they are cemeteries, and "[a]dmiring an old picture is the same as pouring our sensibility into a funerary urn instead of hurtling it far off, in violent spasms of action and creation” (FM 42). Being linked to the past stops "action and creation,” signifying death or halting progress.

Although denying the past and stressing progress(ion) are avant-garde characteristics, these are also the tropes of business. Frederick Taylor asserts that "great gain, both to employers and employés," will come "from the substitution of scientific rule-of-thumb methods in even the smallest details of the work of every trade” (24, italics mine). Taylor's text is also a manifesto of sorts. He, as does Marinetti, places the onus on the individual to eliminate sloth and inefficiency. Inefficient workers were guilty of dereliction of duty. Taylor argues that "[t]he enormous saving of time and therefore increase in output ... can be fully realized only after one has personally seen the 
improvement” of Taylor’s scientific application (24). One major goal of Taylorism was efficiency from "[t]he general adoption of scientific management" to achieve "the increase, both in the necessities and luxuries of life, which becomes available for the whole country" (142). Also, another goal would be "the elimination of almost all causes for dispute and disagreement between [management and workmen]" (142). According to Taylor, applying scientific principles to the factory leads to efficiency and benefits allscience touches all workers and helps produce goods efficiently. Likewise, Marinetti finds a similar attitudinal change because "Futurism is grounded in the great discoveries of science" (DWW 96, italics mine). For both men, science is a good organizational strategy for either factories or art.

Although Taylor directly addresses managers and workers, the results of his system portend benefit to all industrialized nations: "Is it not the duty of those who are acquainted with these facts, to exert themselves to make the whole community realize this [study of scientific management's] importance” (144). Taylor’s text has a certain avant-garde quality inherent in its hyper-industrial fervor, but it is hardly the polemic of Marinetti’s art. In fact, Taylorism (and its famous put-in-practice system, Fordism) adheres to early twentieth-century ideology—speed, efficiency, evolution, and ahistoricity. Besides promoting progress, Taylor chastises his inefficient audience as morally defunct, thus satisfying Renato Poggioli's definition of the avant-garde: "Ideology, therefore, is always a social phenomenon. In the case of the avant-garde, it is an argument of self-assertion or self-defense used by a society in the strict sense against society in the larger sense" (4). Taylor's manifesto is a product of the time, and a rubric for adhering to the value of efficiency. Factories need only follow the principles Taylor 
puts forth, and they will assert their productive dominance in the market. Taylor advocates his "primer's" value for the larger society would be modernization, the same argument Marinetti made when he advocated "killing” any connection to the past would help Italian modernization.

I am not arguing, however, that Taylor shared Marinetti’s ahistorical stance against cultural markers and artifacts. While Marinetti’s work is prone to violence, exaggeration, and performance, Taylor appears more practical, systematic, and industrious. Taylor privileges the worker and management's role in maintaining a wellorganized firm. Ultimately, he does not fit Poggioli’s definition of an avant-garde artist because his work is not absorbed into "the demagogic moment," which Poggioli argues fuels the “[avant-garde’s] tendency toward self-advertisement, propaganda, and proselytizing” (34). Although Taylor's lack of gross exaggeration and ferocious polemical stances mitigate his avant-garde status, his importance for gauging industrial practice is without question: His text exists as a heuristic for industrial progress. Simply put, progression toward increased production and profits mirrors part of Marconi and the popular press's rhetoric of technology. The wireless, besides often being "praised" for its potential, reflected human advancement and commercial/industrial success. In this historical moment, when, as Taylor claims, "our larger wastes of human effort, which go on every day through such of our acts as are blundering, ill-directed, or inefficient, and which Mr. [Theodore] Roosevelt refers to as a lack of 'national efficiency,' are less visible, less tangible, and are vaguely appreciated” (5), Marinetti provides a symbolic transition. Instead of looking to the past's supposed "summit" or "fullness of time" as a 
goal for avoiding “a fatal infelicitous fall back to barbarism” (Poggioli 72-3), Futurism experiments with the new.

These new experiments, although brash and violent, glorify new technologies that are unconsciously accepted by industrial cultures. Although I cannot possibly pinpoint the mass culture or even the media's ideology, technologies exist because a group accepts them. Because we have the benefit (or burden) of historical hindsight, we know that the wireless extended the reach of communication — it was heralded as a genius product of modernity. Likewise, automobiles became accepted as beneficial technologies, "liberating" individuals in industrialized nations because of their potential for allowing greater mobility. Today, wireless transmissions, automobiles, and other technical objects are more than just tools; these technologies are prostheses for human activity in industrial, hyper-technological societies.

Technologies do not have to be accepted universally in order to become realized. We cannot claim every member of a society uses such technologies only that they are popularly seen as efficient, necessary products we cannot live without. ${ }^{19}$ As long as large enough groups accept a certain technology, these tools will be seen as useful and, therefore, be realized. In fact, these technologies (and "universal” technologies like computers, PDAs, or mobile phones) can really only be said to be prostheses for middle, working, and wealthy classes. Claiming "everyone has a mobile phone” marks the chauvinistic impulse in dominant society to ignore the material conditions of poorer groups. ${ }^{20}$ Such chauvinism appears in Futurism specifically and avant-gardism generally, which "is by nature solitary and aristocratic" (Bontempelli qtd. in Poggioli 39). Marinetti claims "I do not care for the comprehension of the multitude," and that poetry, avant- 
garde or "traditional" also "requires a special speaker if it is to be understood" (DWW 106). Likewise, because new technologies provide markers for civilization, a citizen must acquire the appropriate artifacts to be in accord with the well-to-do members. Consumerism allows individuals of any background to "buy into" the aristocratic image. An aristocratic technology such as the wireless held a certain regal aura because of how favorable relevant social groups rhetorically constructed it. Marconi and the popular press documented when royalty and national leaders used the wireless, constructing it as an aristocratic or "elevated" technology. However, for a small fee, any individual could send a wireless telegram (Baker 9), allowing him or her access to an aspect of an aristocratic lifestyle.

Marinetti addresses these aristocratic desires through tropes of efficiency and the new efficient, machine-like aristocrat. But, because of Marinetti's disdain for tradition, the old aristocrat (the noble or royal) cannot serve as a model. Although Marinetti came from a wealthy family (Bondanella 315) and, as Bontempelli points out, "[the avantgarde] loves the initiated and the ivory tower” (qtd. in Poggioli 39), the new aristocrat must embrace modernization. Marinetti praises the industrial(ized) aristocracy over the royal by promoting aesthetic goals against ornamentation: "A modern aesthetic most responsive to utility has no need of royal palaces with domineering lines and granite foundations that loom massively out of the past over the little medieval towns, confused welters of wretched dog kennels" (BFA 80-1, italics mine). Instead, the "definitive Futurist aesthetic" included "great locomotives, twisting tunnels, armored cars, torpedo boats, monoplanes, and racing cars” (BFA 81). The new "modern phenomena”technologies forged from modern ideals—succeed in "hav[ing] reduced to uselessness the 
great, decorative, imperishable buildings that once expressed kingly authority, theocracy, and mysticism" (BFA 80). In order to progress and fully enjoy modern life, such as "the speed of international communications,” modern comforts from "well-ventilated apartment blocks" to "perfect chambers de toilette" are required (BFA 80). These technologies, these phenomena, signal progress to Marinetti.

\section{Progress Tropes in Marinetti’s Art}

Marinetti does not stop by listing the important new technologies of the time period; he also celebrates "progress" as an abstract goal useful for his new aesthetic and ideal for life. Humans should strive for progress and hold dearly to the concept as a defining goal. Marinetti’s rhetoric of technology favoring progress matches Marconi and the popular press's rhetoric because all three discourses advocate technological advancement as inherently progressive. Progress is the code by which society should live: "Put your trust in Progress, which is always right even when it is wrong, because it is movement, life, struggle, hope” (BFA 82). Marinetti’s own capitalization of the word "Progress" reinforces the concept’s importance for the new modern world. Progress and constant motion (dynamism) are both elements of Marinetti's aesthetics reinscribed into Futurist art. Marinetti's art—pushing dynamism as one goal—privileges the struggle or act of creation over a finished product: “The frame of a house in construction symbolizes our burning passion for the coming-into-being of things. Things already built and finished, bivouacs of cowardice and sleep, disgust us!” (BFA 82). Futurist sculpture, painting, and even architecture have widely been analyzed for their adherence to dynamism (Butler; Kirby; Perloff; Poggioli; Rainey; Rye). Only through dynamism in 
art and life can one find beauty: "Except in struggle, there is no more beauty. No work without aggressive character can be a masterpiece” (FM 41). Marinetti sees progress reified through construction "according to the ever-changing moods of the winds" (BFA 82).

This change supports Marinetti’s view that “the world's magnificence has been enriched by a new beauty, the beauty of speed” (FM 41). According to Marinetti, speed is limited when humans cling to the past. Italy's past is a "heavy burden ... that weighs down our swift and warlike vessel” (BFA 83). That burden of the past works against modernization, and Marinetti's claim that "we Italian Futurists have no desire to see Italy left in an inferior state” (BFA 83) reflects the rhetoric behind promoting technology as a way out of "barbarism." Although barbarism is an exaggerated term, the concept is what the time period read as evolution's antithesis (c.f. Childs). Just as today's educational push for more math and science skills is argued as crucial to a country's economic prosperity, lack of industry marked then a nation’s backwardness. A January 1902 article from The North American Review claims that “America's position in the world of science is inferior," and that Americans_-even with "the stimulating examples of Edison, Tesla, [and] Elihu Thomson"- -have been slow to pursue scientific enterprise (Snyder 59). ${ }^{21}$ In order to remedy this “dire” situation, Snyder claims Americans should create an equivalent of England's Royal Institution; however, for this situation to yield results "would require ... those who are broadly interested in scientific progress, and [those] who have a desire to keep abreast of the swiftly advancing knowledge of the day” (59). Science and technology advance rapidly, and both Marinetti and Snyder promote a rhetoric that identifies speed and advancement as a cultural value. 
In Marinetti’s words, Futurism “create[d] the new aesthetic of speed,” which "notably diminished the concept of time"; before long "[w]e will arrive at the abolition of the year, the day, and the hour” (BFA 81). All that remains is the quickness of a moment. But Marinetti does not argue for "speed" in his art just by presenting images of racing cars and fast-moving ocean liners; he links the reader's imagination to the speed of telegraphy by claiming "the analogical foundation of life" requires quick communication "with the same economical speed that the telegraph imposes on reporters and war correspondents in their swift reportings" (DWW 98). This new aesthetic reaffirms what Marinetti argues is the relationship between poet, audience, and industrialization: "This urgent laconism answers not only to the laws of speed that govern us but also to the rapport of centuries between poet and audience” (DWW 98). ${ }^{22}$ Within this new aesthetic, Marinetti describes certain tenets or textual properties that favor speed, such as Futurism's “[d]read of slowness, pettiness, analysis, and detailed explanations” (DWW 97-98).

Speed and efficiency are major modernist tropes and topoi for Marconi and the popular press, and Marinetti's reinscription of efficiency into his aesthetic and his glorification of it signal another rhetorical reconstruction of industrial values. For Marinetti, technologies did not just mark progress, they helped humans achieve progress. New technological discoveries “have a decisive influence on [users'] psyches” (DWW 96) because a human becomes intertwined with the machine's efficiency; after all, Marinetti feels technologies act as prostheses, creating "[m]an multiplied by the machine” (DWW 97). This “[n]ew mechanical sense” Marinetti attributes to humans creates a better worker through "a fusion of instinct with the efficiency of motors and 
conquered forces” (DWW 97). The height of efficiency for Marinetti’s new human would come from what we today know as cyborgs—cybernetic organisms that are part human and part machine. While "preparing the ubiquity of multiplied man” (BFA 81), Marinetti sets forth a concept that violently dehumanizes "regular" humans. In order to be efficient, one must use the new technologies simultaneously; one must multi-task. Others have pointed out that Futurism has Nietzschean roots (Bondanella; Childs; Perloff; J. White), and Marinetti's concept of the "multiplied man" is nothing more than an übermensch made "super” through technological prostheses. Workers extend their productive capacity by replicating mechanical responses, and these "most gifted people" are also "the most elastic [and] quick" (BFA 83). Such malleability—and speed from having a worker mimic a machine—-show dehumanization: An individual has been reduced to a machine part. This individual is multiplied throughout a factory when the workers cling to (or are made to embrace) scientific labor.

Scientifically or technologically reproduced "humans" appear in popular visions of cyborgs today, ${ }^{23}$ but an unfavorable contemporary portrayal of scientifically managed workers appears in D. H. Lawrence's Women in Love. The novel mainly follows the relationships of two sisters, Gudrun and Ursula, who fall in (and out) of love. Ursula and Rupert are the novel's eventual happy couple who stand by one another. In contrast, Gerald and Gudrun have difficulties connecting to each other, and their relationship disintegrates. But before the demise, Lawrence describes Gerald's new management techniques for his mines as techniques scientifically "formulated" to produce efficient results. Gerald believes, as the boss "above" the workers, he is "giving them what they wanted" because his firm is part of the "great and perfect system that subjected life to 
pure mathematical principles” (Lawrence, Women in Love 231), which is the Futurist credo. Gerald’s miners did not like his new management practices at first, but they eventually "submitted to it all” (Lawrence, Women in Love 230) because this was the future-human evolution through mechanized frameworks:

There was a new world order, a new order, strict, terrible, inhuman, but satisfying in its very destructiveness. The men were satisfied to belong to the great and wonderful machine, even whilst it destroyed them. It was what they wanted, it was the highest that man had produced, the most wonderful and superhuman. (Lawrence, Women in Love 231, italics mine)

Gerald runs the company "on the most accurate and delicate scientific method”; thus, "the miners were reduced to mere mechanical instruments" (Lawrence, Women in Love 230). Of course, this Taylorist/Fordist impulse for ultra-efficiency was part of the rise of industrial America. Lawrence appears to be aware of America’s dominance (or coming dominance in industrialization) because he says that the "[n]ew machinery was brought from America, such as the miners had never seen before, great iron men, as the cutting machines were called, and unusual appliances” (Women in Love 230, italics mine). Even the machines had nicknames to reinforce their "human” qualities.

Gerald became the workers’ god: "He was the God of the machine. [The miners] made way for his motor-car automatically, slowly” (Lawrence, Women in Love 223). Gerald, literally, kept the gears turning; he would dispose of non-critical, inefficient parts (workers) as he needed. An apotheosis of mechanization is apparent in Gerald's "incarnation of his power, a great and perfect machine, a system, an activity of pure order, pure mechanical repetition, repetition ad infinitum, hence eternal and infinite” (Lawrence, Women in Love 228). Besides reinforcing the repetitive nature of the industrial gear, Lawrence exposes science or, in this case, mechanization begetting 
mechanization over and over again. This circular framework of Gerald's mind—and heart—foreshadows the dead end where he arrives at the novel's conclusion. The mechanization loop is not a loop an industrialist can escape. It is a self-contained view of production and progress that does not allow for new phenomena to develop. Humans will only "evolve" by going round and round on the merry-go-round of circular technological advancement, ad infinitum. Gerald is the god in his own mind because he adheres so vehemently to the cult of efficiency that permeates industrialization. By putting humans into this framework, their value is seen only by their "instrumentality," as Gerald puts it. The worth they can have directly relates to the work they produce.

Unfortunately, this system sets humans up for failure because the loop continually pushes them to work faster and faster, which is "terrible and heartbreaking in its mechanicalness” (Lawrence 230). Therefore, Gerald is not inherently corrupt and destined to breakdown as a machine would, but he is a victim of his own dogma, an ideology the industrialized world embraces along with the cult of efficiency. Gerald must keep moving to be worth anything, and he is overcome with fear when he succeeds at his "exalted activity" of running the company down to a science: "And once or twice lately, when he was alone in the evening and had nothing to do, he suddenly stood up in terror" and went to the mirror to look at himself and saw "the darkness in [his eyes]" (Lawrence, Women in Love 232). For Gerald was "afraid that one day he would break down and be a purely meaningless babble lapping round a darkness" (Lawrence, Women in Love 232). That darkness can be seen as the Nietzschean void that one fills to hold onto meaning in a meaningless world. This terror Gerald feels relates to his inability to connect to women other than for surface affection, and it foreshadows his breakdown on the mountain after 
he realizes Gudrun will never be his wife and that he became a monster by almost killing her.

Such mechanical (in)humanity is ridiculous to Lawrence, who, in a letter to Arthur McLeod, claimed that the Futurists were rather sophomoric in their art. Although he is attracted to the Futurists' attempts "of the purging of the old forms and sentimentalities," which he appreciates "for its saying—enough of this sickly cant, let us be honest and stick by what is in us" ("To Arthur McLeod" 180), he rejects them as "very young, infantile, college student[s] and medical-student[s] at [their] most blatant” ("To Arthur McLeod” 180). Lawrence views Futurism as a young movement, but he does not see it maturing; instead, "[t]hey will progress down the purely male or intellectual or scientific line. They will even use their intuition for intellectual and scientific purpose. The one thing about their art is that it isn't art, but ultra scientific attempts to make diagrams of certain physic or mental states” (“To Arthur McLeod” 181). The Futurists' "revolt against beastly sentiment and slavish adherence to tradition and the dead mind" are aspects Lawrence praises in the Futurists, but he “[doesn't] agree with them as to the cure and the escape"-the obvious militaristic, mechanistic nature of the movement ("To Arthur McLeod” 181). From this letter, Lawrence shows he is clearly distrustful of scientific laws being applied to human consciousness, for this is the downfall of Gerald in Women in Love and a critique of the over-mechanization of thought: inhuman desire to act like a machine.

Such action leads to Marinetti's most dehumanizing vision of a worker dying for the "noble" cause of construction. Marinetti values efficient human production to such an extent that job sites will hear "from time to time-yes, let it happen —-the harrowing 
cry and heavy thud of a fallen construction worker," causing Marinetti to exclaim "great drop of blood on the pavement!” (BFA 81-2, italics mine). Workers are valued for efficiency: Their humanity has been reduced to what their labor produces, and they are expected to give even the ultimate sacrifice if need be. This sacrifice contributes to Marinetti's rhetoric of technology because he values struggles to create new machines. Of course, his manifestos are exaggerations of hyper-industrialization, but they mirror Marconi and the popular press's topoi of presenting technologies (and modernization in general) related to tropes of progress.

Progress permeates the technological and scientific literature I have examined from the early twentieth century. Marinetti’s early Futurist texts demonstrate how one important historical avant-garde managed to reinscribe dominant tropes of progress into the movement's aesthetics. Marinetti captures the essence of progress in his texts by advocating the same values and practices of the larger culture; specifically, he reflects industrial society’s push for modernization by glorifying contemporary technologies and arguing for their future potential. Because technologies marked an advanced civilization, the Futurists saw new technologies as a way to bring Italy further progress and become a world industrial leader. Although such advocacy was an exaggeration of societal values and goals, Futurism embodies the ideologies favoring science and technology and portrays new advancements as expanding human capacity.

New tools and techniques excited some individuals (i.e., Marinetti, Taylor, and the popular press writers I examined) as did the World's Fairs or other major cultural events celebrating technology. These tools can be thought of as extensions or prostheses for human labor and evolution. Marinetti’s “man multiplied by the machine” (DWW 97) 
reflects the cultural condition of modernity that views scientific and technological progress as human evolution: Humans evolve by "plugging into" the new electric forces technology harnesses. For example, the wireless advanced human capabilities of speech by allowing an individual to communicate with others around the world instantaneously. Of course, at the time, communications were sent through Morse code, which constrained one’s prose. Marinetti saw such constraints as liberating words from syntactical "strings" by allowing one word to communicate an idea that took several words before. Such telegraphic minimalism was not unique to Marinetti; many artists and artistic movements experimented with a style that reflected industrial culture's drive for greater efficiency. And artists were not the only group experimenting with “efficiency.” Marinetti's texts share Frederick Taylor's efficiency manifesto's goal for promoting increased production. Besides increased output, efficient technologies allowed life to speed up. Marinetti wanted speech streamlined as much as possible, and he saw the wireless as a practical tool for such a goal. Whereas Marconi and the popular press promote the wireless specifically as an important efficient technology, and Taylor promotes scientific management more broadly, Marinetti violently advocates efficiency as an artistic and even spiritual goal. The wireless and all technologies were tools for business, and industry, but Marinetti also believed they were tools for progressing away from a useless past. His work shows that technologies of the early twentieth century represented attitudes and values of a society, an industrial society. Because Marinetti is a product of modernity, as is the wireless, his work resides in the context of industrialization and mass culture. Within such a context, Marinetti’s art conforms to other contemporary protechnological discourses with tropes of progress like Marconi and the popular press 
employed. In short, his work reflects the culture's positive (albeit exaggerated) fascination that helps technologies become realized. The rhetoric of technology or, specifically, the rhetoric of the wireless presents this new technology as a tool for today and tomorrow. Technology thrusts humans toward the future, and, according to Marinetti, “[a]ll ... hope should be in the Future” (BFA 82). 
Notes

1. Andreas Huyssen notes that "[m]odernists such as T. S. Eliot and Ortega y Gasset emphasized time and again that it was their mission to salvage the purity of high art from the encroachments of urbanization, massification, technological modernization, in short, of modern mass culture"; however, the avant-garde wished to overthrow such highminded pretension related to "forms of bourgeois society" (163).

2. Even D. H. Lawrence was familiar with the Futurists and claimed he had an interest in their works: "I have been interested in the futurists . . . I read Marinetti's and Paolo Buzzi’s manifestations and essays and Soffici's essays on cubism and futurism. It interests me very much” (“To Arthur McLeod” 180).

3. I refer to the beginning phase-or "the truly revolutionary phase" as Bondenella calls it (229) — as the work done from 1909 to the beginning of WWI. Marinetti's later work experiments more with performance than manifestos. Also, the movement was co-opted by the fascists following WWI and, therefore, ceased to be "edgy" or avant-garde because the movement was now part of the establishment.

4. The concept parole in libertá is commonly translated as "words in freedom” or "words in liberty." Either is acceptable, but readers should not confuse parole in libertá with "free verse" - a composition Marinetti despised as reminiscent of the past. Marinetti's goal was to free words from their syntactic “oppression” and let them communicate their essence. According to Christopher Butler, "Marinetti's aim, through the disruption of syntax, metre, and punctuation, is to produce a 'lyrical intoxication', which will abolish the reassuring musical continuities of vers libre, in favour of an abrupt, instantaneous, telegraphic form of communication” (173).

5. Although Marinetti was the first Futurist and Futurism was the first avant-garde movement, other futurisms flourished in Europe in the early twentieth century-Russian Futurism, Ego-Futurism, and Cubo-Futurism. Even Vorticism, an English avant-garde led by Wyndam Lewis, resembled Italian Futurist aesthetics. Futurism's appeal could be found in places like Italy, France, Poland, Germany, and Russia (Calinescu; Childs; Nicholls; Perloff; J. White). But, as Perloff argues, the avant-garde's short-lived internationalism ended with the onset of nationalist fervor leading up to WWI (xxxvi).

6. Marinetti's incendiary work was a major component of his public performances, such as his "attack" on Venice (Perloff 201-2) and the packed theater houses that stunned Ezra Pound (Rainey 29). This violence and discordant noise-as the Futurists often brought loud speakers in order to play awful sounds for the audience-continued into the 1920s with the Variety Theater.

7. “Radio-bomb” is a phrase I use to demonstrate Marinetti's desire to assault audiences with his manifestos and his love of destruction. His texts reveal a strange desire to be beamed into the physical minds of audiences. The ultimate "evolution" for him would be to actually become a radio wave to be broadcasted to the world. 
8. Technology was not the only movement organized around nationalism. A political rally for Italy's intervention into WWI actually started the acquaintanceship between Marinetti and Benito Mussolini. Their relationship began around 1915 when the two were arrested for an interventionist rally (Bondanella 318). The two men banded together possibly because of Marinetti's anti-communism and his acceptance of Mussolini's nationalist sentiments for a strong, united Italy. Today, the fascist party in Italy (led by Mussolini's grand-daughter) still believes in a strong free market expansionism for the modern Italian state, but they differ from their close right-wing allies in parliament, $\mathrm{La}$ Lega Nord, on one very fundamental issue-Italian unification. The LN wants to divide Italy into separate northern and southern nations because the industrialized north feels the "backward" south is a blight to economic prosperity. The fascists, on the other hand, do not want a divided Italy.

9. Sociologist George Ritzer's book The McDonaldization of America describes how these rational ultra-efficient practices have crept into contemporary service-economy jobs.

\section{Translated as poETRY BEINGBOR (Marinetti, Zang Tumb}

Tumb 57).

11. Robert Frost's 1916 poem “The Line-Gang” responds to the encroachment of telephone wires from the city on the New Hampshire countryside (Rhodes 62).

12. Carlo Carrá left the Futurists in 1916 after WWI (Rye 153). Although Giovanni Papini was a lesser-known Futurist-who joined the movement with Soffici in 1913 (Rye 13)_the eighth soul could have very well been Benito Mussolini's because the novel was written before Marinetti's disillusionment with the fascist dictator. Also, the soul could have been Armando Mazza, another lesser known Futurist poet.

13. I call this work a "poem-manifesto" because it has polemic manifesto qualities much like "The Founding and Manifesto of Futurism," and it also has poetic wireless imagery - energy, kilowatts, dials. However, unlike other manifestos, Marinetti does not set down specific goals for his movement, and, unlike his heavily onomatopoeic poems, this text describes energy, bombardment, and movement using common descriptive adjectives and not made-up words or extravagant typefaces and font sizes.

14. This quotation encapsulates John White's argument that the Futurists glorified the science fiction of electrical forces of the imagined twenty-first century.

15. In fifth grade I attempted to stimulate plant growth for a science project by running an electrical current through soil. It did not work. I do not even remember why I assumed electricity could be conducted through soil.

16. By Objectivist, I mean Ayn Rand's ultra-capitalist philosophy advocating "the virtue of selfishness." 
17. Another science fiction example of "reading" or perceiving electrical forces occurs in The Matrix. To observers outside the Matrix, the binary code flashing on monitors represents action inside the Matrix, which is a "fake" world created by machines.

18. Andrew Hewitt covers Marinetti's and other modernists' fascistic ideologies in his book Fascist Modernism.

19. I have often heard my students (and others) claim that they could not live without their mobile phones. I am often asked "how can you live without a cell phone or cable TV?” I just do somehow.

20. However, many can point to the generic individual in poverty who happens to own a cell phone or subscribes to cable/satellite TV.

21. Interestingly, Snyder's comment follows a list of prominent Europeans who "made wireless telegraphy possible” (59). Also, Snyder points to "Marconi’s admirable triumphs” as an extension of past scientists' work in electromagnetism (59).

22. Apparently, "the rapport of centuries between poet and audience" is an element or relationship of the past that Marinetti wishes to keep.

23. Seven of Nine, a popular cyborg from Star Trek Voyager, was rescued from the efficient Borg collective. And John Flynn from Tron is digitized in order to enter the computer; thus, in order to be replicated, humanity must become machine-like before reproduction. 


\section{CONCLUSION}

\section{STS AND TECHNICAL COMMUNICATION: EXPANSIVE POSSIBILITIES}

The treatment of scientific knowledge as a social construction implies that there is nothing epistemologically special about the nature of scientific knowledge: It is merely one in a whole series of knowledge cultures (including, for instance, the knowledge systems pertaining to "primitive" tribes). Of course, the success and failures of certain knowledge cultures still need to be explained, but this is to be seen as a sociological task, not an epistemological one. Trevor Pinch and Wiebe E. Bijker (qtd. in Pool 13)

Science, Technology, and Society studies has had a growing impact on technical writing scholarship/pedagogy over the last three decades. I believe my analysis of Marconi's wireless is an example of a project that is essentially about scientific and technical communication but influenced heavily by cultural studies approaches of STS. No longer is technical writing simply "nuts and bolts"; instead, technical writing pedagogy approaches research from historical, philosophical, and social perspectives. This approach is best shown through William E. Rivers' call for a more robust technical writing discipline: He believes “[technical writing scholars] need a better understanding of the interactions between technical, scientific, and business writing done in different languages and cultures” (45). He also supports using approaches to technical writing scholarship that lie outside the field; in fact, he specifically mentions the disciplines of literature and literary criticism as two areas to “incorporate into our bag of analytical tools” for studying technical writing (45). My impetus for pursuing this dissertation initially came from Rivers’ article. ${ }^{1}$ 
My dissertation’s case study on Marconi’s wireless addresses Rivers’ call because the invention was a product not just of a lab but of a culture. The wireless existed because rhetoric shaped its value and viability in relation to cultural attitudes, values, and practices. The wireless was popular and successful because it was made to fit into the time period's desires. However, lay audiences, believing in the neutrality of language, do not always notice that discourse "constructs" technologies and sciences. One popular notion of technical and scientific communication is that those discourses communicate facts with singular interpretations derived effortlessly from experiments; unfortunately, such an idea ignores the social and community construction of science and technology. Just as famous scientists such as Einstein, Watson, Crick, Curie, and Salk had to communicate their findings to receptive audiences through rhetoric, Marconi and pro-Marconi writers had to employ rhetoric to construct the wireless as a viable technology that fit within industrial cultures. Popular representations aided the rhetorical construction of Marconi's wireless thus creating interest in the invention. The wireless was progress, evolution, efficiency; it had an image of prosperity and viability before it became a black box. As a cultural artifact, the wireless, or rather, the success of the wireless, suggests that the discourse surrounding it and the culture's overall fascination with technology helped audiences believe in the wireless and, therefore, realize it. Furthermore, Marinetti's fetishization of the wireless demonstrates a cultural fascination but through an exaggerated medium—avant-garde art. Without positive discourse, the wireless would not have become a realized technology, and, without its reinscription into Futurist aesthetics, it would not have been able to represent the early twentieth 
century's value for hyper-industrialization. After all, Marinetti’s love of efficiency through art is not very different from Taylor's blueprint for industrial efficiency.

Further analysis of other texts would enrich this study. Patent documents or other technical specifications would offer revelations on technical writing conventions. Business communication such as marketing texts, business proposals, and shareholder reports could be examined to analyze the rhetorical strategies employed in that particular discourse convention. However, the wireless was a product that was more than a "sound," profitable technical application; it was an invention that held many early twentieth century values. Therefore, I could expand the modernist literature I examine to include more descriptions of the wireless from the perspectives of other artists.

The wireless did permeate Western culture in the early twentieth century, and I believe I could locate more tropes of progress associated with wireless descriptions. Being labeled as a progressive technology suggests the wireless "spoke" to the cultural desire to advance through machines. The wireless was promoted as an evolutionary feat, a marker of industrial progress, just as Edison's electrical works projects were seen in places like San Francisco and Louisville (Bazerman 219). Analyzing such cultural values is the STS influence of my dissertation, reflecting a growing interest in broader technical writing scholarship. Therefore, the pedagogical base of technical writing scholarship has expanded to incorporate the theories and methodologies of STS, especially the case study approach to analyzing the rhetorics of technologies and sciences. Technical writing students can benefit from work outside of "nuts and bolts" discussions of layout and design. If technology is a 
semiotic system as I suggest in the Introduction, bringing broader cultural concerns into the classroom ought to enable discussions and further inquiry into technical communication history.

I believe this dissertation's investigative approach to Marconi's wireless can be expanded or redirected in several ways. First, more emphasis should be placed on pedagogical implications of analyzing the discourse of an historical phenomenon/apparatus. Students should learn that science and technology do not exist without rhetoric: Physical inventions and impressive theories are not realizable without community acceptance. Second, tracing the discourse surrounding radio innovations after Marconi’s “black box” would allow for an important historical analysis of the trends of rhetoric surrounding the radio. Such a direction would help demonstrate the way(s) in which progress continued to be associated with this invention or even mass communication in general. Third, contrasting pro-Marconi rhetoric with anti-Marconi rhetoric and the rhetoric surrounding other wireless pursuits of the early twentieth century would help identify instances where Marconi's wireless's rhetoric was similar or dissimilar to that of contemporary inventions. I believe this research would help readers better understand why Marconi is historically seen as the inventor of the radio even though he mainly assembled the apparatus. I briefly indicate that a major reason for Marconi’s title of "father of the radio" comes from his celebrity status as being the first to excite the world with his invention. Finally, each chapter could be expanded to analyze more instances where the wireless's rhetoric and literary value demonstrate why the invention was a 
monumental early twentieth-century technology that embodied particular tropes of progress—speed, efficiency, evolution, ahistoricity, and profitability.

We can always "grab more actors” as Bruno Latour says. These new actors will tell us new stories and support former positions. Technologies become realized because potential users perceive or are made to perceive their usefulness. We accept technologies because they become familiar to our values and practices. Likewise, we reject technologies when they disrupt our way of life. Even though individuals may reject certain technologies, society may collectively accept technologies perceived as "necessary.” As Charles Bazerman argues, "products of the built environment” reflect cultural values. 
Note

1. Of course, my initial interest of wanting to examine technical writing in a larger social context was too broad and unorganized until the guidance I got in English 620 on how to approach a manageable dissertation project. 


\section{REFERENCES}

Adams, Henry. "The Dynamo and the Virgin.” The Education of Henry Adams. Ed. Ernest Samuels. Boston: Houghton, 1974.

Advertisement 634. McClure’s Magazine 1 Jan. 1897: 204. APS Online. ProQuest Company. University of Louisville Libraries, Louisville, KY. 27 June 2006 $<$ http://proquest.umi.com/>.

A Friend. "Marconi, the Man.” Frank Leslie’s Popular Monthly 53.5 (Mar. 1902): 529-

33. APS Online. ProQuest Company. University of Louisville Libraries, Louisville, KY. 27 February $2005<$ http://proquest.umi.com/>.

Åkesson, Lynn. “Trick or Treatment: Brokers in Biotech.” Löfgren and Willim 37-45.

Aristotle. On Rhetoric: A Theory of Civic Discourse. Trans. George A. Kennedy. New York: Oxford UP, 1991.

Arthur, W. Brian. “Competing Technologies and Economic Prediction.” MacKenzie and Wajcman 106-12.

Attwood, David and Guy Ryecart. The Radio: An Appreciation. San Diego: Laurel Glen, 1997.

Badiou, Alain. Metapolitics. London: Verso-New Left Books, 2005.

Baker, Ray Stannard. “Marconi’s Achievement.” McClure’s Magazine 18.4 (Feb. 1902): 4-12. APS Online. ProQuest Company. University of Louisville Libraries, Louisville, KY. 27 February 2005 <http://proquest.umi.com/>. 
Bazerman, Charles. The Languages of Edison's Light. Cambridge: MIT P, 1999.

---. "The Production of Technology and the Production of Human Meaning.” Journal of Business and Technical Communication, 12 (1998): 381-87.

Beard, Charles A. “The Inevitability of the Machine.” 1928. Rhodes 97.

Beatty, Jack, ed. Colossus: How the Corporation Changed America. New York: Broadway Books, 2001.

Berman, Marshall. All That Is Solid Melts into Air: The Experience of Modernity. New York: Simon \& Schuster, 1982. New York: Penguin, 1988.

Bijker, Wiebe E. Of Bicycles, Bakelites, and Bulbs: Toward a Theory of Sociotechnical Change. Cambridge: MIT P, 1995.

Blum, Cinzia Sartini. The Other Modernism: F. T. Marinetti's Futurist Fiction of Power. Berkeley: U of California P, 1996.

Bondenella, Peter, and Julia Conaway Bondenella. Dictionary of Italian Literature. Westport: Greenwood P, 1979.

Bondyopadhyay, Probir K. Sir J. C. Bose’s Diode Detector Received Marconi’s First Transatlantic Wireless Signal of December 1901 (The 'Italian Navy Coherer’ Scandal Revisited).” Proceedings of the IEEE 86.1 (Jan. 1998): 259-85.

Bradshaw, David. A Concise Companion to Modernism. Malden, MA: Blackwell, 2003.

Brandt, Deborah. Literacy in American Lives. Cambridge: Cambridge UP, 2001.

Bucci, O. M., G. Pelosi, and S. Selleri. "The Work of Marconi in Microwave Communications.” IEEE Antennas and Propagation Magazine 45.5 (Oct. 2003): 46-53. 
Bunch, Bryan. The History of Science and Technology: A Browser's Guide to the Great Discoveries, Inventions, and the People who Made them, from the Dawn of Time to Today. Boston: Houghton Mifflin, 2004.

Burns, William E. Science and Technology in Colonial America. Westport: Greenwood P, 2005.

Butler, Christopher. Early Modernism: Literature, Music and Painting in Europe, 19001916. New York: Clarendon P, 1994.

Campbell, Timothy. Wireless Writing in the Age of Marconi (Electronic Mediations). Minneapolis: U of Minnesota P, 2006.

Calinescu, Matei. Five Faces of Modernity. $2^{\text {nd }}$ ed. Durham: Duke UP, 1987. Cardwell, Donald. The Norton History of Technology. New York: Norton, 1995. Carlson, W. Bernard. Innovation as a Social Process: Elihu Thomson and the Rise of General Electric, 1870-1900. New York: Cambridge UP, 1991.

Ceruzzi, Paul. “Inventing Personal Computing.” MacKenzie and Wajcman 64-86.

Childs, Peter. Modernism. London: Routledge, 2000.

Cooke, Morris Llewellyn. “Paving Propaganda.” 1915. Rhodes 60-61.

Corazza, G. C. “Guglielmo Marconi-Marconi’s History.” Proceedings of the IEEE 86.7 (Jul. 1998): 1307-11.

Cowan, Ruth Scwartz. “The Industrial Revolution in the Home: Household Technology and Social Change in the $20^{\text {th }}$ Century.” Reynolds and Cutcliffe 291-313.

Cross, Gary and Rick Szostak. Technology and American Society: A History. Englewood Cliffs: Prentice Hall, 1995.

Crowther, James Gerald. Six Great Inventors: Watt, Stephenson, Edison, Marconi, 
Wright, Brothers, Whittle. London: Hamilton P, 1954.

Das, Mitra and Shirley Kolack. Technology, Values and Society: Social Forces in Technological Change. New York: Peter Lang, 1990.

DeLaet, Marianne. Research in Science and Technology Studies: Knowledge and Technology Transfer. Greenwich: JAI P, 2002.

Dobres, Marcia-Anne and Christopher R. Hoffman. The Social Dynamics of Technology: Practice, Politics, and World Views. Washington: Smithsonian, 1999.

Dosi, G. “Technological Paradigms and Technological Trajectories: A Suggested Interpretation of the Determinants of Technical Change.” Research Policy (1982) 11: $147-67$.

Downey, Gregory J. Telegraph Messenger Boys: Labor, Communication, and Technology, London: Routledge, 2002.

“The Epoch Making Marconi.” New York Times 17 Dec. 1901: 8.

Esper, Thomas. "The Replacement of the Longbow in the English Army.” Reynolds and Cutcliffe 107-18.

Everdell, William R. The First Moderns. Chicago: U of Chicago P, 1997.

Fallows, James. "The American Army and the M-16 Rifle.” MacKenzie and Wajcman 382-93.

Feenburg, Andrew. Questioning Technology. London: Routledge, 1999.

Flannery, Gerald V. Mass Media: Marconi to MTV: A Select Bibliography of New York Times Sunday Magazine Articles on Communication 1900-1988. Rowman \& Littlefield, 1989.

Fleming, J[ohn] A[mbrose], [Sir]. “Scientific History and Future Uses of Wireless 
Telegraphy.” The North American Review 168.510 (May 1899): 630-40. APS Online. ProQuest Company. University of Louisville Libraries, Louisville, KY. 1 February $2005<$ http://proquest.umi.com/>.

Flint, R. W., ed. R Marinetti: Selected Writings. Trans R. W. Flint and Arthur A. Coppotelli. New York: Farrar, 1971.

Ford, Henry. "Making History.” 1916. Rhodes 61.

Fuller, Steve and James H. Collier. Philosophy, Rhetoric, and the End of Knowledge: A New Beginning for Science and Technology Studies. $2^{\text {nd }}$ ed. Mahwah: Lawrence Erlbaum, 2004.

Garratt, G. R. M. The Early History of Radio: From Faraday to Marconi (IEE History of Technology, No 20). IEE Publishing, 1994.

Gates, Henry Louis, Jr. “One Internet, Two Nations.” New York Times 31 Oct. 1999: 15.

Giddens, Anthony. The Constitution of Society: Outline of a Theory of Structuration. Berkeley: U of California P, 1984.

Gilbert, G. Nigel and Michael Mulkay. Opening Pandora's Box: A Sociological Analysis of Scientists' Discourse. Cambridge: Cambridge UP, 1984.

Glick, Thomas F., Steven J. Livesey, and Faith Wallis, eds. Medieval Science, Technology, and Medicine: An Encyclopedia. New York: Routledge, 2005.

Hancock, Harry E. Wireless at Sea. New York: Arno, 1974.

Heath, Christian and Paul Luff. Technology in Action. Cambridge, Cambridge UP, 2000.

Hewitt, Andrew. Fascist Modernism: Aesthetics, Politics, and the Avant-Garde. 
Stanford: Stanford UP, 1993.

Hiskes, Anne L. and Richard P. Hiskes. Science, Technology, and Policy Decisions. Boulder: Westview P, 1986.

Hoddeson, Lillian. "The Emergence of Basic Research in the Bell Telephone System, 1875-1915.” Reynolds and Cutcliffe 331-63.

Hong, Sungook. Wireless: From Marconi's Black Box to the Audion. Cambridge: MIT P, 2001.

Huxley, Aldous. Brave New World. 1932. New York: Harper, 1960.

Huyssen, Andreas. After the Great Divide: Modernism, Mass Culture, Postmodernism. Bloomington: Indiana UP, 1986.

Iles, George. “Marconi’s Triumph.” World’s Work Feb. 1902: 1784-85.

Jabbari, Bijan. "Introduction to the Classic Paper by Marconi.” Proceedings of the IEEE 85.10 (Oct. 1997): 1523-25.

Jaffe, Aaron. "Inventing the Radio Cosmopolitan: Vernacular Modernism at a Standstill.” Broadcasting Modernism. Eds. Michael Coyle, Debra Rae Cohen, and Jane Lewty. Tallahassee: U of Florida P, forthcoming.

Jensen, Peter. From the Wireless to the Web: The Evolution of Telecommunications, 1901-2001. Sydney: U of New South Wales P, 2000.

Johnsom, Jim [a.k.a. Bruno Latour]. "Mixing Humans and Nonhumans Together: The Sociology of a Door-Closer.” Ecologies of Knowledge: Work and Politics in Science and Technology. Ed. Susan Leigh Star. New York: State U of New York P, 1995: 257-77.

Journet, Debra. "Biological Explanation, Political Ideology, and 'Blurred Genres’: A 
Bakhtinian Reading of the Science Essays of J. B. S. Haldane.” Technical

Communication Quarterly 2.2 (Spring 1993): 185-204.

Kirby, Michael. Futurist Performance. New York: PAJ Publications, 1971.

Kline, Ronald and Trevor Pinch. “The Social Construction of Technology.” MacKenzie and Wajcman 113-15.

Kranakis, Eda. “Constructing a Bridge.” MacKenzie and Wajcman 87-105.

Kraeuter, David W. “The U.S. Patents of Armstrong, Conrad, De Forest, Du Mont, Farnsworth, Fessenden, Fleming, Kent, Marconi, and Zworykin.” A. W. A. Review 5 (1990): 143-91.

Latour, Bruno. Aramis, or the Love of Technology. Trans. Catherine Porter. Cambridge: Harvard UP, 1996.

---. The Pasteurization of France. Trans. Alan Sheridan and John Law. Cambridge: Harvard UP, 1988.

---. Science in Action. Cambridge: Harvard UP, 1987.

Latour, Bruno and Steve Woolgar. Laboratory Life: The Social Construction of Scientific Facts. Beverly Hills: Sage Publications, 1979.

Lawrence, D. H. “To Arthur McLeod.” 2 June 1914. Letter 731 of The Letters of D. H. Lawrence. Ed. George J. Zytaruk and James T. Boulton. Vol. 2. Cambridge: Cambridge UP, 1979. 180-82.

Lawrence, D. H. Women in Love. London: Penguin, 1995.

Lewis, Elmer E. Masterworks of Technology: The Story of Creative Engineering, Architecture, and Design. Amherst, NY: Prometheus, 2004.

Löfgren, Ovar, and Robert Willim eds. Magic, Culture, and the New Economy. Oxford: 
Berg, 2005.

Lomask, Milton. Invention and Technology. New York: Scribner’s, 1991.

Lyle, Eugene P., Jr. “The Advance of ‘Wireless.”” World’s Work Feb. 1905: 5842-48.

MacKenzie, Donald, and Judy Wajcman eds. The Social Shaping of Technology. $2^{\text {nd }}$ ed. Philadelphia: Open UP, 1999.

Marconi, Degna. My Father, Marconi. $2^{\text {nd }}$ ed. Ottawa: Balmuir, 1982.

Marconi, Guglielmo. "Messages without Wires.” 1901. Rhodes 32.

---. "Recent Advances in Wireless Telegraphy.” 3 March 1905. Smithsonian Annual Report, 1906. 131-45.

---. “Syntonic Wireless Telegraphy.” 15 May 1901. Electrical Review 38.24 (15 June 1901): $754-756$.

---. “Syntonic Wireless Telegraphy_II.” 15 May 1901. Electrical Review 38.25 (22 June 1901): 781-86.

---. “Wireless Telegraphy.” 2 February 1900. Smithsonian Annual Report, 1901. 287-

96. Rpt. of Proceedings of the Royal Institution of Great Britain 16.2 (n.d.): 24756.

---. “Wireless Telegraphic Communication.” Nobel Lecture. 11 December 1909: 198222. 2 February $2006<$ http://nobelprize.org/nobel_prizes/physics/laureates/1909/ marconi-lecture.html>

Marconi, Maria Christina. Marconi, My Beloved. $2^{\text {nd }}$ ed. Ed. Elettra Marconi. Boston: Dante U of America P, 2001.

Marinetti, F. T. "Destruction of Syntax—[Wireless Imagination]—Words-in-Freedom.” 
1913. Trans. Robert Brain et. al. Futurist Manifestos. Comp. and ed. Umbro Apollonio. New York: Viking P, 1973. 95-106.

---. "The Birth of a Futurist Aesthetic.” 1911. Trans. R. W. Flint and Arthur A.

Coppotelli. Flint 80-83.

---. “Electrical War (A Futurist Vision-Hypothesis).” 1911. Trans. R. W. Flint and Arthur A. Coppotelli. Flint 104-08.

---. “The Founding and Manifesto of Futurism.” 1909. Trans. R. W. Flint and Arthur A. Coppotelli. Flint 39-44.

---. Selected Poems and Related Prose. Trans. Elizabeth R. Napier and Barbara Studholme. Comp. Luce Marinetti. New Haven: Yale UP, 2002.

---. Zang Tumb Tuum. 1914. Stung by Salt and War: Creative Texts of the Italian Avant-Gardist F.T. Marinetti. Comp. and trans. Richard J. Pioli. New York: Lang, 1987.

McClure, Henry Herbert. “Messages to Mid-Ocean: Marconi’s Own Story of His Latest Triumph.” McClures’s Magazine 18.6 (Apr. 1902): 525-27. APS Online. ProQuest Company. University of Louisville Libraries, Louisville, KY. 27 February $2005<$ http://proquest.umi.com/>.

McGrath, P. T. “A Very Loud Electromagnetic Voice.” 1902. Rhodes 32.

Melzer, Arthur M. “The Problem with 'The Problem of Technology.” Globalization, Technology, and Philosophy. Eds. David Tabachnick and Toivo Koivukoski. Albany, State U of New York P, 2004. 107-41.

Misa, Thomas J. Leonardo to the Internet: Technology and Culture from the Renaissance to the Present. Baltimore: Johns Hopkins UP, 2004. 
Mitcham, Carl. Thinking through Technology: The Path between Engineering and Philosophy. Chicago: U of Chicago P, 1994.

Moffett, Cleveland. “Marconi’s Wireless Telegraph.” McClure’s Magazine 13.2 (Jun. 1899): 4-17. APS Online. ProQuest Company. University of Louisville Libraries, Louisville, KY. 27 February $2005<$ http://proquest.umi.com/>. Montagu, Ashley and Floyd Matson. The Dehumanization of Man. New York: McGraw, 1983.

Myers, Greg. Writing Biology: Texts on the Social Construction of Scientific Knowledge. Madison: U of Wisconsin P, 1990.

Nelson, Anna K. "Theodore Roosevelt, the Navy, and the War with Spain.” Theodore Roosevelt, the U.S. Navy, and the Spanish-American War. Ed. Edward J. Marolda. New York: Palgrave, 2001.

Nelson, Richard and Sidney Winter. An Evolutionary Theory of Economic Change. Cambridge: Harvard UP, 1982.

Nicholls, Peter. Modernisms: A Literary Guide. Berkeley: U of California P, 1995. Noble, David F. The Religion of Technology: The Divinity of Man and the Spirit of Invention. New York: Penguin, 1997.

Nye, David E. American Technological Sublime. Cambridge: MIT P, 1994.

Oudshorn, Nelly. “The Decline of the One-Size-Fits-All Paradigm, or, How Reproductive Scientists Try to Cope with Postmodernity.” MacKenzie and Wajcman 325-40.

Pacey, Arnold. Meaning in Technology. Cambridge: MIT P, 1999.

Patnode, Randall. “What These People Need Is Radio: New Technology, the Press, and 
Otherness in 1920s America.” Technology and Culture 44.2 (2003): 285-305.

Pears’ Soap. Advertisement. World's Work Mar. 1903: 3047.

Perloff, Marjorie. The Futurist Moment: Avant-Garde, Avant Guerre, and the Language of Rupture. 1986. Chicago: U of Chicago P, 2003.

Poggi, Christine. "Dreams of Metallized Flesh: Futurism and the Masculine Body.” Modernism/Modernity 4.3 (1997): 19-43.

Poggioli, Reanato. The Theory of the Avant- Garde. Tran. Gerald Fitzgerald. Cambridge: Belknap P of Harvard UP, 1968.

Pool, Robert. Beyond Engineering: How Society Shapes Technology. Oxford: Oxford UP, 1997.

Radetsky, Ari Tye. “The Perfect Piece of Toast.” Science \& Spirit (Jan/Feb 2003): 1415.

Rainey, Lawrence S. Institutions of Modernism: Literary Elites and Public Culture. New Haven: Yale UP, 1998.

“Recent Wireless Telegraphy Development.” Current Literature 34.4 (Apr. 1903): 419. APS Online. ProQuest Company. University of Louisville Libraries, Louisville, KY. 27 February $2005<$ http://proquest.umi.com/>.

Rescher, Nicholas. The Limits of Science. Berkley: U of California P, 1984. Pittsburgh: U of Pittsburgh P, 1999.

Restivo, Sal, ed. Science, Technology, and Society: An Encyclopedia. Oxford: Oxford UP, 2005.

Reynolds, Terry S., and Stephen H. Cutcliffe eds. Technology and the West: A 
Historical Anthology from Technology and Culture. Chicago: U of Chicago P, 1997.

Rhodes, Richard, ed. Visions of Technology: A Century of Vital Debate about Machines, Systems and the Human World. New York: Touchstone, 1999.

Rip, Arie and R. Kemp. “Towards a Theory of Socio-Technical Change.” Human Choice and Climate Change. Ed. S. Rayner and E. L. Malone. Vol. 2. Columbus: Battelle P, 1998. 329-401.

Ritzer, George. The McDonaldization of Society. Thousand Oaks, CA: Pine Forge P, 1996.

Rivers, William E. "Studies in the History of Business and Technical Writing: A Bibliographic Essay.” Journal of Business and Technical Communication 8.1 (Jan. 1994): 6-57.

Rouse, Joseph. Knowledge and Power: Toward a Political Philosophy of Science. Ithaca: Cornell UP, 1987.

Rutland, David. Behind the Front Panel: The Design and Development of 1920s Radios. Philomath: Wren Publishers, 1994.

Rye, Jane. Futurism. London: Studio Vista, 1972.

Salk, Jonas. Introduction. Laboratory Life: The Social Construction of Scientific Facts. By Bruno Latour and Steve Woolgar. Beverly Hills: Sage Publications, 1979. $11-14$.

Selfe, Cynthia. Technology and Literacy in the Twenty-First Century: The Importance of Paying Attention. Carbondale: Southern Illinois University Press, 1999.

Sikorski, Wade. Modernity and Technology: Harnessing the Earth to the Slavery of 
Man. Tuscaloosa: U of Alabama P, 1993.

Snyder, Carl. "America’s Inferior Position in the Scientific World.” The North American Review 174.542 (Jan. 1902): 59. APS Online. ProQuest Company. University of Louisville Libraries, Louisville, KY. 1 February 2005 $<$ http://proquest.umi.com/>.

Squier, Susan M. Communities of the Air. Durham: Duke UP, 2003.

Stent, Gunther S. Paradoxes of Progress. San Francisco: Freeman, 1978.

Strum, Shirley and Bruno Latour. "Redefining the Social Link: From Baboons to Humans.” MacKenzie and Wajcman 116-25.

Tarrant, D. R. Marconi’s Miracle: The Wireless Bridging of the Atlantic. St. John's, Newfoundland: Flanker P, 2001.

Taylor, Christiana J. Futurism: Politics, Painting, and Performance. Ann Arbor: UMI Research P, 1974.

Taylor, Frederick Winslow. The Principles of Scientific Management. 1911. New York: Norton, 1967.

Tedlow, Richard S. “Ford vs. GM.” Beatty 224-55.

Van Slyck, Abigail A. "Kitchen Technologies and Mealtime Rituals: Interpreting the Food Axis at American Summer Camps, 1890-1950.” Technology and Culture 43.4 (2002): 668-92.

Wallace, Herbert. “A Great American Enterprise: Development of Marconi’s Inventions in the United States and it Dependencies.” McClure’s Magazine 19.2 (Jun. 1902): 1-4. APS Online. ProQuest Company. University of Louisville Libraries, Louisville, KY. 1 February $2005<$ http://proquest.umi.com/>. 
Walker, Samuel J. "Nuclear Power and the Environment: The Atomic Commission and Thermal Pollution, 1965-1971.” Reynolds and Cutcliffe 425-53.

Watterbury, John I. “The International Preliminary Conference to Formulate Regulations Governing Wireless Telegraphy.” The North American Review 177.564 (Nov. 1903): 655-70. APS Online. ProQuest Company. University of Louisville Libraries, Louisville, KY. 27 February 2005 <http://proquest.umi.com/>.

Weaver, Richard M. The Ethics of Rhetoric. South Bend: Regnery, 1953.

Weber, Rachel N. “Manufacturing Gender in Military Cockpit Design.” MacKenzie and Wajcman 372-81.

Weightman, Gavin. Signor Marconi’s Magic Box. Cambridge: Da Capo P, 2003.

White, John J. Literary Futurism: Aspects of the First Avant Garde. Oxford: Clarendon P, 1990.

White, Lynn, Jr. Medieval Technology and Social Change. New York: Oxford UP, 1978.

Williams, Raymond. “The Technology and the Society.” Popular Fiction: Technology, Ideology, Production, Reading. Ed. Tony Bennett. London: Routledge, 1990. 922.

Williams, Rosalind. “All that is Solid Melts into Air: Historians of Technology in the Information Revolution.” Technology and Culture 41.4 (2000): 641-68.

Willmore, L. “Government Policies toward Information and Communication Technologies: A Historical Perspective.” Journal of Information Science (2002).

Winner, Langdon. “Do Artifacts have Politics?” The Whale and the Reactor: A Search 
for Limits in an Age of High Technology. Chicago: U of Chicago P, 1986: 19-

39.

“Wireless Signals across the Ocean.” New York Times 15 Dec. 1901: 1.

“Wireless Telegraphy.” New York Times 9 Mar. 1902: 6. APS Online. ProQuest

Company. University of Louisville Libraries, Louisville, KY. 27 February 2005 $<$ http://proquest.umi.com/>.

“Wireless Telegraphy.” Current Literature 34.1 (Jan. 1903): 3. APS Online. ProQuest Company. University of Louisville Libraries, Louisville, KY. 27 February 2005 $<$ http://proquest.umi.com/>.

Yeang, Chen-Pang. "Scientific Fact or Engineering Specification? The U.S. Navy's Experiments on Wireless Telegraphy circa 1910.” Technology and Culture 45.1 (2004): 1-29. 


\begin{abstract}
APPENDIX
List of Abbreviations

BFA "Birth of Futurist Aesthetics"

DWW Destruction of Syntax-[Wireless Imagination]-Words in Freedom

EW "Electrical War (A Futurist Vision-Hypothesis)”

FM “Founding and Manifesto of Futurism”
\end{abstract}




\section{CURRICULUM VITAE}

NAME: $\quad$ Aaron Antonio Toscano

ADDRESS: Bingham Humanities, Rm. 315

Department of English

University of Louisville

Louisville, KY 40292

DOB: $\quad$ Washington, DC - June 2, 1976

EDUCATION: $\quad$ Ph.D., Rhetoric and Composition

University of Louisville

2002-2006

M.S., Professional Writing

Towson University

1998-2000

B.A., Economics/English

Virginia Tech

1994-1998

TEACHING

EXPERIENCE: $\quad$ Assistant Professor, Department of English, University of North

Carolina at Charlotte, Charlotte, NC (starting 08/2006)

Graduate Teaching Assistant, Department of English, University of Louisville, Louisville, KY (08/2002-05/2006)

Assistant Director for Computer Assisted Instruction (CAI), Department of English, University of Louisville, Louisville, KY (08/2003-05/2005)

Visiting Instructor of English, Department of English, George Mason University, Fairfax, VA (08/2001-07/2002)

Adjunct Professor, Languages and Literature Department, Northern Virginia Community College, Annandale, VA (01/200107/2002) 
Adjunct Professor, Modern Languages and Literature Department, The College of Southern Maryland, La Plata, MD (05/2000-08/2000)

TECHNICAL

EXPERIENCE: Technical Writer, contracted by the U. S. State Department, Washington, DC (08/2000-05/2001)

Web Editor, National Center for Curriculum Transformation Resources on Women, Towson University, Towson, MD (09/199806/2000)

Document Analyst, Rust Federal Systems, Reston, VA (05/199608/1998)

PUBLICATIONS: "What One Gamer's Literacy Reveals about Reading the Semiotics of Video Games.” Studies in Popular Culture. 20 Ms. Pages, under submission.

"Experimenting with Multimodality.” Multimodal Composition for the 21st Century: A Resource Book for Teachers. Ed. Cynthia Selfe. Cresskill, NJ: Hampton Press: 45 Ms. Pages, forthcoming. (coauthored with John Branscum)

CONFERENCES: "Coalition of the Unwilling: Privileging False Communities in the Professional Writing Classroom.” Conference on College Composition and Communication. Chicago, Illinois, March 2006.

"Video Games and Cultural Reinscriptions: What One Gamer Reveals about Catharsis, Literacy, and Ideology.” Popular Culture Association in the South/American Culture Association in the South Conference. Jacksonville, Florida, October 2005.

"Systemic Inspiration: Futurist Literature and Marconi's Wireless.” Kentucky Philological Association Conference. Highland Heights, Kentucky, April 2005.

"Reading Postmodern and Modernist Architecture: A Video Essay.” Thomas R. Watson Conference on Rhetoric and Composition. Louisville, Kentucky, October 2004.

"Anecdotes and Office Space: One Instructor's Incorporation of Personal Workplace History into the Professional Writing Class." Conference on College Composition and Communication. San Antonio, Texas, March 2004. 
“D. H. Lawrence's Views on (or Hopes for) Human Development: Exploring the Futurist Influence in Women in Love.” TwentiethCentury Literature Conference. Louisville, Kentucky, February 2004.

"Mistaking Capitalist Allegory as Italian-American Stereotypes: A Critique of The Godfather's Representation of the American Utopian Fantasy.” Hawaii International Conference on Humanities. Honolulu, Hawaii, January 2004.

GRADUATE COURSEWORK UofL:

GRADUATE COURSEWORK TOWSON:

TECHNOLOGICAL LITERACIES: $\quad$ Extensive knowledge of web page development (Front Page, Dreamweaver, and HTML) Proficient in multimodal technology (digital audio/video recording and Pinnacle Studio)

MS Office software, Publisher, Visio, PageMaker, Photoshop, and Adobe software, Windows, Macintosh, SUSE Linux, and UNIX operating systems

FOREIGN

LANGUAGE: Reading knowledge of Italian
Composition Theory and Practice (B. Huot)

Classical Rhetoric (M. Rosner)

Teaching College Composition (B. Huot)

Teaching English as a Second Language (K. Mullen)

Literacy, Technology, and Education (C. Selfe)

Research Methods in Composition (D. Journet)

Special Topics in Rhetoric and Composition: Composing

Identities (B. Williams)

Rhetorical Studies: Intersections of Technologies in Composition

Studies (P. Takayoshi)

Genre Studies (S. Griffin)

Literature and Film (T. Byers)

$20^{\text {th }}$ Century Literature (S. Henke)

Contemporary Theories of Interpretation (T. Van)

Technical and Scientific Writing (S. Gibson-Groshon)

Modern Rhetoric (K. Dungey)

Rhetorical Grammar (E. Duncan)

Research Methods (C. Hill) 
PROFESSIONAL

ASSOCIATIONS: Association of Teachers of Technical Writing

National Council of Teachers of English

The Society for Literature and Science

ACTIVITIES: $\quad$ Member of the Informal Reading Group (IRG) — a critical theory discussion group (2003-2006)

Vice President (and Co-Founder) of Alter-EGO (2003-2006)

Majordomo for the IRG listserv (2004-2006)

Majordomo for the Alter-EGO listserv (2003-2006)

PROFESSIONAL

INTERESTS:

Technical/Business Writing

Rhetoric and Rhetorical Studies

Composition

Science, Technology, and Society Studies

Popular Culture Studies

Film Studies

Modernism

Computers and Composition 